University of Louisville

ThinkIR: The University of Louisville's Institutional Repository

Electronic Theses and Dissertations

$12-2014$

\title{
Graduate students who are part-time workers : how does occupational stress and gender role affect job satisfaction?
}

\author{
Megan Church-Nally \\ University of Louisville
}

Follow this and additional works at: https://ir.library.louisville.edu/etd

Part of the Student Counseling and Personnel Services Commons

\section{Recommended Citation}

Church-Nally, Megan, "Graduate students who are part-time workers : how does occupational stress and gender role affect job satisfaction?" (2014). Electronic Theses and Dissertations. Paper 1721.

https://doi.org/10.18297/etd/1721

This Doctoral Dissertation is brought to you for free and open access by ThinkIR: The University of Louisville's Institutional Repository. It has been accepted for inclusion in Electronic Theses and Dissertations by an authorized administrator of ThinkIR: The University of Louisville's Institutional Repository. This title appears here courtesy of the author, who has retained all other copyrights. For more information, please contact thinkir@louisville.edu. 
GRADUATE STUDENTS WHO ARE PART-TIME WORKERS: HOW DOES OCCUPATIONAL STRESS AND GENDER ROLE AFFECT JOB SATISFACTION?

\author{
By \\ Megan Church-Nally \\ B.A., Bellarmine University, 2005 \\ M.A., Xavier University, 2007
}

\begin{abstract}
A Dissertation
Submitted to the Faculty of the

College of Education and Human Development of the University of Louisville in Partial Fulfillment of the Requirements

for the Degree of

Doctor of Philosophy

Department of Leadership, Foundations, and Human Resource Education

University of Louisville

Louisville, KY
\end{abstract}

December 2014 
Copyright 2014 Megan Church-Nally

All Rights Reserved 

GRADUATE STUDENTS WHO ARE PART-TIME WORKERS: HOW DOES OCCUPATIONAL STRESS AND GENDER ROLE AFFECT JOB SATISFACTION?

\author{
By \\ Megan Church-Nally \\ B.A., Bellarmine University, 2005 \\ M.A., Xavier University, 2007
}

A Dissertation Defense Approved on

November 24, 2014

by the following Dissertation Committee:

Dr. Namok Choi (Chair)

Dr. Brad Shuck

Dr. Meera Alaganda

Dr. Diane Kyle 


\section{DEDICATION}

This dissertation is dedicated to my dad, Dr. Stephen H. Church. Your belief in my academic prowess and confidence in my abilities has been a shining light and guiding purpose throughout this dissertation and my life. Thank you for believing in me. 


\section{ACKNOWLEDGEMENTS}

"If I were dropped out of a plane into the ocean and told the nearest land was a thousand miles away, I'd still swim ..." Abraham Maslow

This quote perfectly expresses the last $2 \frac{1}{2}$ years of this exhilarating and strenuous process that is finally complete. This dissertation would not have been possible without my amazing committee of Dr. Diane Kyle, Dr. Brad Shuck, and Dr. Meera Alagaraja. Your academic insights have been invaluable throughout this process. Most of all, I would like to thank my chair, Dr. Namok Choi. Even though Chapter 2 took me longer than most, with many words added to my "do not use" list or my made up words list, you never stopped pushing me to make it better. Thank you for patience and guidance throughout this process. You have become not only a respected colleague, but a dear friend.

In addition to my committee, my family has stuck by me through the last few years and has given me endless support and guidance. Thanks Mom for always being just a phone call away. Dad, you saw the dissertation as being just as important as I did and always encouraged me on the roughest days. My brothers, Ryan and Matt, who edited my dissertation more times than I can even count. Of course, I could not forget my dearest sister, Emily, who always sent me encouraging songs, inserted cheerleader clip art in my drafts, and never failed to remind me that I was awesome. My awesome inlaws (Mark and Lisa Nally, Ashley Nally, Ethan Nally, John Malloy, Jeni Church, and 
Kelly Church) always supported me and understood my hermit-like status the past few years. I would also like to thank my pets (Harvey and James) for their support and company on those long nights of working on my dissertation. My nieces and nephews (Sam and Tony Church, Ethan and Eli Goodman, and Keely Huhn), who always reminded me to play and provided lots of laughter the last few years. Lastly, I would like to thank my awesome husband, Eric, who went above and beyond the marital vows. Not many would go through the first two and half years of marriage with a wife whose laptop was permanently attached to her, listen to editing sessions at 4 a.m., and never forget to have caffeine stocked for me. Thank you for your encouragement- I could not have done this without you.

Next, I would like to thank my wonderful colleagues. Thank you, Dr. Don Osborn, for encouraging me from my first day in my psychological endeavors and introducing me to my love of psychology. Thank you, Dr. Pam Cartor, for giving me my first chance to teach and always providing me with encouragement. Thank you, Dr. Courtney Keim, for always picking up the phone at 11 p.m., cheering with me when my data was collected, and believing in me. Thank you also to Dr. Hank Rothgerber, Dr. Ann Jirkovosky, Dr. Tom Wilson, Dr. Anne Buccalos, Dr. Christy Wolfe, Dr. Joy Jacobs-Lawson, Dr. Morrie Mullins, and Lora Roberts for your support. Thank you to Dr. Mark Nagy, my advisor at Xavier, who continues to advise me and be an awesome mentor years later.

Lastly, I would like to thank my friends, who have accepted my largely absent self for the past few years. Thank you, Kayla Huhn, for believing in me, the encouragement, and always providing me with desserts. Thank you to my dear friends 
(Jessica Holloman, Shannon Nash, Jackie Cecil, Alicia Smith, Allison Goodman, Hannah Huggins, Erin House, Jesse Isaacs, Katie and Doug O’Bryan, Krista Rummage, and Mike Huhn) for your encouragement and faith in me the last few years. Thank you to my doctoral cohort of Dr. Matt Bergman and Brittany Cox for calming my nerves and always supporting me. Thank you to my extraordinary friend-mentor-research partner, Dr. Denise Cumberland. Not only have we conquered comps, but we have also conquered the dissertation. I would also like to thank my amazing and exceedingly patient editors at the writing center who made this dissertation so much better. Lastly, I would like to thank my students, who make my life and work worthwhile.

Without all of your support, I would not have come this far. I promise to be worthy of your support and dedication the rest of my life. Thank you from the bottom of my heart. 


\section{ABSTRACT \\ INVESTIGATION INTO THE GRADUATE STUDENT PART-TIME WORKERS Megan Church-Nally}

November 24, 2014

Job satisfaction and occupational stress have consistently been examined in professionals for decades due to its link to turnover and reduced productivity. Similar concepts have been investigated in undergraduate students, but there is paucity of research of attrition in graduate students. This gap persists despite estimates that $50 \%$ of graduate students fail to graduate (Cassuto, 2013). Such attrition is not due to deficiency in academic skills, as Carroll, $\mathrm{Ng}$, and Birch (2009) reported that personal reasons were cited more than academic concerns for attrition.

The purpose of this dissertation was to address this job satisfaction and occupational stress gap with the investigation of graduate students who maintain parttime employment of at least ten hours a week. It was speculated that additional occupational demands may enhance the understanding of the graduate student process. Job satisfaction was measured utilizing the Job Descriptive Index and an overall satisfaction scale. Occupational stress was measured with the Perceived Stress Scale, and gender role was assessed with the Bem Sex Role inventory. Additionally, an open ended question was utilized to determine the three greatest stressors in the graduate student parttime workers' lives. 
Results revealed that sex, gender, and the sex by gender interaction failed to predict significant job satisfaction or occupational stress. However, additional analysis revealed that androgynous individuals had greater job satisfaction than other gender roles, whereas masculine individuals had greater compensation satisfaction than feminine individuals. Qualitative results revealed that academics, balancing realms, and family were the greatest stressors reported by the graduate students. Factor analysis supported the utilization of these established scales in graduate students.

Implications and suggestions for future research were suggested as mechanisms to increase graduate students' satisfaction, such as accurate portrayal of the process and time management workshops. Such initiatives will hopefully mitigate the significant attrition seen in graduate school. 


\section{TABLE OF CONTENTS}

DEDICATION ....................................... iii

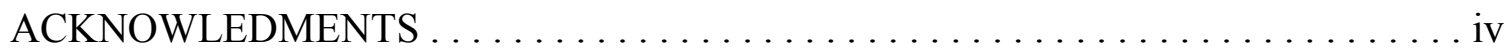

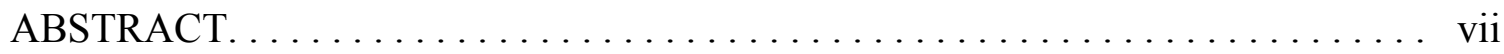

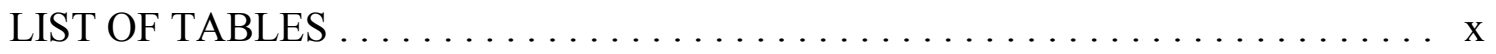

INTRODUCTION $\ldots \ldots \ldots \ldots \ldots \ldots \ldots \ldots \ldots \ldots \ldots \ldots \ldots \ldots \ldots \ldots \ldots \ldots$

LITERATURE REVIEW . . . . . . . . . . . . . . . . . . . . . . 15

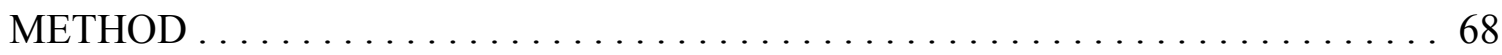

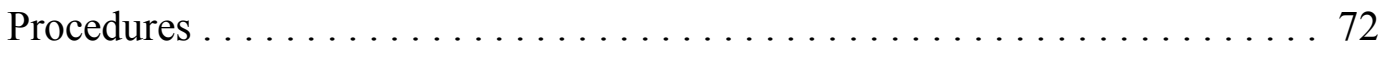

Measures ................................. 75

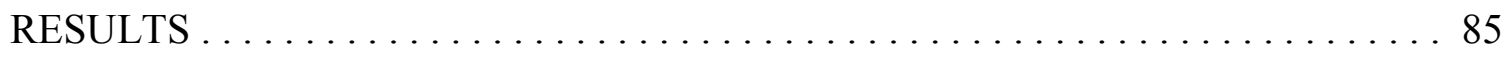

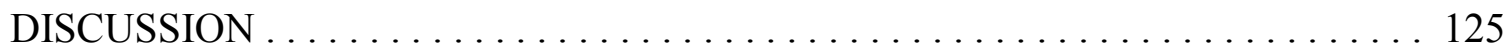

SUMMARY AND CONCLUSIONS.......................... 141

REFERENCES .................................... 152

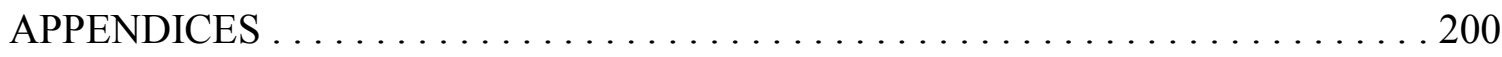

CURRICULUM VITA. .......................................... 219 


\section{LIST OF TABLES}

TABLES PAGE

1. Summary of relevant research ............................ 65

2. Summary of variables, research questions, and statistical analysis . . . . . . 84

3. Race, age, marital status, occupation, and children frequencies . . . . . . . 87

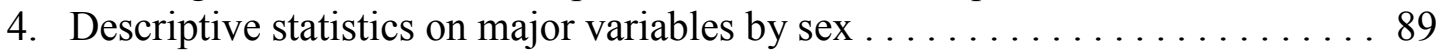

5. Graduate school demographics ........................... 91

6. Gender role composition . . . . . . . . . . . . . . . . . . . . . . . 94

7. Gender role by sex............................. 95

8. Differences across gender role for job satisfaction and occupational stress ... 95

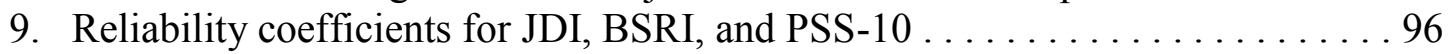

10. Descriptive statistics for occupational stress, gender role, and job satisfaction . . . . . . . . . . . . . . . . . . . . . . . . . . 98 98

11. Intercorrelations analysis. ......................... 99

12. Summary of hierarchical regression with occupational stress as the

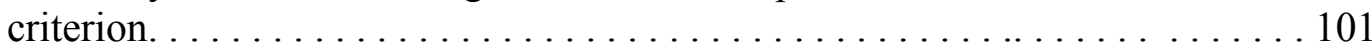

13. Summary of hierarchical regression with job satisfaction as the criterion. ...................................... 103

14. Communalities, Factor Loadings Means, and Standard Deviations for PSS-

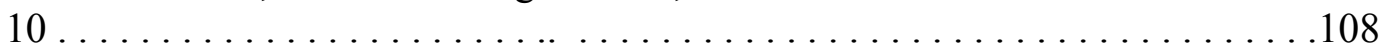

15. Communalities, Factor Loadings Means, and Standard Deviations for BSRI. . . . . . . . . . . . . . . . . . . . . . . . . . . . . . . . 109

16. Communalities, Factor Loadings Means, and Standard Deviations for JDI . . . .112

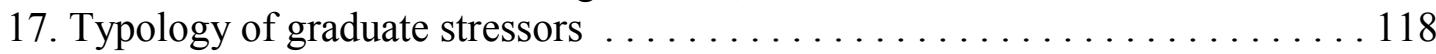

18. Excerpts of open ended stressors . . . . . . . . . . . . . . . . . . 120 


\section{CHAPTER 1}

\section{INTRODUCTION}

Young children readily rattle off what they want to be when they grow up, but few think of crucial values such as job satisfaction and occupational stress until they acclimate into the workplace. With the vast majority of children changing their desired occupations throughout their lifetimes, it is critical to address these values and maintain the productivity in the workplace. This introduction will incorporate the job satisfaction of seasoned professionals and the related research on the upcoming professionals of graduate students. As most research on graduate students has focused on the social support (Carroll et al., 2009) and reasons for attrition (Golde, 2005), this study sought to determine the true experience of the graduate student part-time worker. This examination will provide greater detail into key areas that can be addressed by graduate schools to reduce the high attrition rates for the graduate student part-time worker.

\section{Job Satisfaction Overall}

Job satisfaction is often investigated in terms of compensation (Harris, Anseel, \& Livens, 2008; Jawahar \& Stone, 2011), supervision (Madlock, 2009), and promotions (Kosteas, 2011) as these factors can negatively impact one's occupational stress and productivity. Greater organizational costs, such as attrition and turnover, can often result as consequences of heightened stress and reduced job satisfaction. Interventions that 
focus on increasing job satisfaction (Piccolo \& Judge, 2011) and offering inducements, such as promotions, result in fleeting results on one's job satisfaction (Kosteas, 2011). As workers are working longer hours during the economic recession and experience vast layoffs, these negative effects are likely to magnify (Ryan, 2010). The temporary effects of job interventions and the decreased commitment to the organization have left employers and organizations alike struggling with appropriate job satisfaction interventions.

Though job satisfaction has been studied extensively for decades (e.g., Judge, Bono, \& Locke, 2000), there are few universal solutions for decreased job satisfaction and the negative effects. This is partially due to the individual component of job satisfaction and the differential experiences based on sex, race, and gender (e.g., Kim, 2005). These studies have focused on workers in the workplace or undergraduates in simulated experiments. Surprisingly, there is little research investigating these factors (job satisfaction, gender roles, and occupational stress) on U.S. graduate students who maintain part-time employment and valiantly try to balance these two competing academic and occupational realms. The purpose of this dissertation is to address this job satisfaction and occupational stress gap with the investigation of graduate students who maintain part-time employment of at least ten hours a week.

\section{Graduate Student Attrition}

By 2012, 16,625,000 citizens had earned a master's degree and only 3,191,000 had earned a doctoral degree (U.S. Census, 2012). Students who earned a master's degree were in more applied disciplines, such as applied scientific positions or 
practitioners, whereas doctoral students were in long term disciplines, such as academic careers (Girves \& Wemmerus, 1998). After surpassing the hurdles of the standardized tests, applications, personal statements, and interviews, it would be expected that graduate students would remain devoted and steadfastly pursue their academic studies. However, only $50 \%$ of students who initiate graduate studies persevere with their doctoral program and graduate (Cassuto, 2013; Golde, 2005; Hoskins \& Goldberg, 2005; Nelson \& Lovitts, 2000). It is estimated that between $30-70 \%$ of doctoral students in mathematics fail to complete their doctoral degree (e.g., Cooper, 2000) and this effect is magnified for women and minorities (Herzig, 2002). Though it varies by years, degree, and field, this attrition epidemic is troubling as many qualified individuals may terminate their academic pursuits prematurely and fail to contribute to the profession they diligently labored to gain access to (Cassuto, 2013).

Though there is immense understanding on undergraduate attrition and reasons, little is known about graduate student attrition (e.g., Cooke, Sims, \& Peyerfitte, 1995; Haydarov, Moxley, \& Anderson, 2012; Terrell, Snyder, Dringus, \& Maddrey, 2012). Findings from the undergraduate attrition studies cannot be generalized to graduate students due to the plethora of differences between the two populations (Cooke et al., 1995; Malaney, 1987; Haydarov et al., 2012; Terrell et al., 2012). This research gap could be partially due to the minuscule numbers of graduate students, who do not pay as much tuition as the undergraduates and have shorter tenure in the university, which results in their lowered financial importance to the university. Moreover, the majority of graduate student attrition research has focused within specific colleges (e.g., Haydarov et al., 2012; Middleton, Mason, Stilwell, \& Parker, 1988) or focused on minority graduate 
students due to policy concerns (Haizlip, 2012; Meier, 1991).

Attrition of graduate students is an elusive construct as graduate students have the opportunity to take semesters off or may be enrolled and not actively pursuing degrees (Haydarov et al., 2012). Moreover, this is problematic as online degree programs are not required to report their attrition rates (Howell, Laws, \& Lindsay, 2004). Though it was emphasized as a critical research area over a decade ago (e.g., Baird, 1993; Isaac, 1993), there has been little research conducted on graduate school attrition. When research has been conducted, attrition has been investigated through various mechanisms, such as the graduation rates, retention rates, and attrition rates, which all attempt to determine the actual number of graduate students present in the program. Additionally, as many programs have a time span for when one can complete their degree, this does make it more difficult to determine when someone actively or passively stops attending classes (Haydarov et al., 2012).

In comparison with undergraduate students, graduate students often make more personal sacrifices for their studies and may experience greater negative repercussions of stress if they do not have the social support necessary to mitigate (Carroll, $\mathrm{Ng}, \&$ Birch, 2009; Smith, Maroney, Nelson, Abel, \& Abel, 2006; Steel \& Ovalle, 1984). Novice doctoral students report they are overwhelmed with stress (Smith et al., 2006), living in near poverty (Smith et al., 2006), swamped with reading, and convinced they are unable to survive and graduate from graduate school (Anderson et al., 2000; Golde, 1998). Sadly, many students voluntarily withdraw from the graduate school program with 33\% of doctoral student attrition occurring during the first year where students transfer, withdraw, or settle for lower degrees (Bowen \& Rudenstine, 1992; Golde, 1996; Golde, 
1998; Lovitts, 2001; Smith et al., 2006). Contrary to belief, this is not due solely to individual factors such as lack of intellectual skills or emotional suffering (Golde, 1996). According to Golde's (1996) qualitative study, many withdrawing graduate students did not want to spend six or more years in a program or did not feel they belonged to the correct school. The decision to terminate their academic pursuits is not made lightly as those who leave the program reported feeling depressed and suicidal (Hoskins \& Goldberg, 2005; Lovitts, 2001) and agonized over the decision (Golde, 2005).

In contrast to master's students, doctoral students were more satisfied with their program and had higher grades than master's students (Girves \& Wemmerus, 1988). When students are more satisfied, such as the graduate students at the southeastern university investigated in Cooke et al.'s (1995) study, in the business, education, and engineering departments, they are more likely to stay at the university. Congruently, Wasburn-Moses (2008) found in their study of graduate students across 78 disciplines the students were mostly satisfied. However, there is a lack of research on the satisfaction of graduate students, particularly those who work part-time.

Lovitt's (2001) exit interviews provide evidence that the decision to leave is not due simply to the dearth of academic skills as $70 \%$ of former students revealed personal reasons for their attrition. Follow up questions revealed that $49 \%$ cited academic reasons, followed by personal reasons (23\%; Gardner, 2009). Medical students reported personal reasons $(36.4 \%)$ as the main reason for transferring or withdrawing from the university (Kruzicevic et al., 2012). Additionally, pressure from outside forces also was cited as a contributing factor as increased workload resulted in withdraw or a longer tenure in graduate school among full-time workers who attended graduate school (Carroll, Ng, \& 
Birch, 2009). Past research (e.g., Lovitts, 2001) has also indicated that supportive cohorts and mentors could also mitigate this attrition (Terrell et al., 2005). Though the mentors and relationship with professors mitigated potential attrition (Haizlip, 2012; Park, Perry, \& Edwards, 2011), the attrition epidemic may be due to the competing realms of work and school life, and the role overload students experience.

\section{Occupational Stress}

Such high attrition rates may be partially attributed to the multiple competing realms that the graduate student experiences, which all demand the full scope of the graduate student's attention. Though several researchers have mandated the need for reduced stress among interns and licensed professionals (e.g. Haizlip, 2012; Lamb et al., 1987), little research has been initiated for graduate students. Admission to graduate school precedes the onset of multiple life changes (Goplerud, 1980; Smith et al., 2006) where one transitions from undergraduate student to a graduate student with a different set of expectations, potentially moving to a different geographical location, and the possible separation from family and friends. Novice graduate students report highly stressful events during their first six months of their graduate school experience. Most of these stressors were due to the academic realm (Goplerud, 1980; Lovitts, 2001). Those with greater social connections with either faculty or cohort experienced less stressors and were less negatively affected by stress (Goplerud, 1980; Haydarov et al., 2012). Instead of investigating the balancing act of these realms, much of the research has focused on the stress of such graduate students or the influence of social support (Clark, Murdock, \& Koetting, 2009; Gelso \& Lent, 2000; Haydarov et al., 2012; Magoon \& Holland, 1984). 
Additionally, graduate students, particularly counseling students, may be disillusioned with graduate school and not prepared to balance graduate school and working directly with the clients (Clark et al., 2009). Counseling students often struggle more than other graduate students as this is their first experience working directly with clientele and the clientele's emotional issues. Though many students struggle valiantly to balance personal (family and social relationships) and professional lives (academics and occupations; Gaensbauer \& Mizner, 1980), there is surprisingly little research on how students balance these two realms (Clark et al., 2009; Greenhaus \& Parasuraman, 1987; Smith et al., 2006). This is particularly problematic as overwhelmed students may become disheartened with their career choice and voluntarily remove themselves from the program (Clark et al., 2009). Also, few studies have examined why some graduates stay while others leave, instead focusing more on the recruitment of qualified candidates (Girves \& Wemmerus, 1988; Haydarov et al., 2012).

It is commonly believed that doctoral students have more complex lives than they did in the past (Anderson, Gumport, Rowan, \& Schneider, 2000) due to family demands, economic concerns, and responsibility to school and others, which drastically increases stress in their lives (Smith et al., 2006). Students are preoccupied that they are neglecting their family responsibilities, and the need for external employment to support living expenses reduces the time that they have to work on their dissertation. Moreover, they feel overloaded by the personal, occupational, and academic realms that are constantly competing with each other (Smith et al., 2006), which result in increased stress for the graduate student. Many graduate students reported stressors such as low stipends and multiple jobs, which infringed on school and relationships, and stress over time pressure 
and finding a job (Moyer, Salovery \& Casey-Cannon, 1999). Many graduate students reported they would have graduated sooner if they had focused less on the family and reported that professors tried to discourage them, through lack of support, guidance, or greater focus on their own careers than assisting their advisees (Moyer et al., 1999). Not surprisingly, under high stress career choice satisfaction diminished for counseling doctoral students (Clark et al., 2009). Moreover, the students' innate need to exceed as a student, professor, and researcher, often resulted with the graduate student sacrificing personal relationships to become a more competitive candidate (Fickey \& Pullen, 2011).

Although there is little research on graduate students in many of the disciplines, several studies have been conducted on medical students and residents' stress. According to Dunn, Iglewicz, and Moutier (2008), mental health worsens throughout medical school (e.g., Tyssen, Vaglum, Gronvold, \& Ekeberg, 2001) and may continue into postgraduate training (e.g., Dunn et al., 2008; Rosal et al., 1997; Tyssen et al., 2001). One characteristic that may lead to such heightened stress is the medical student who is accustomed to being the top of their class, where the integration into a class of very bright students discourages the student. Additionally, the thought of not being the best student results in anxiety and the student may become discouraged with the curriculum. Another stressor may result when the family becomes at odds with the medical student's primary focus on medical school and their studies (Dunn et al., 2008). Though many medical students are resilient to such stress, this becomes problematic when students begin to buckle under the stress and become more vulnerable to burnout.

Moreover, there are several publications denoting the psychological distress that medical students are under (Chan, 1991; Chew-Graham, 2003; Firth-Cozens, 2003; 
Okasha, Lotaif, \& Sadek, 1981). However, these stressors do vary throughout their academic careers, as emotional concerns are more a concern for first year students and academic concerns are more problematic in later years. Those who experience lower than expected academic performance reported more stress and anxiety than their counterparts (Chew-Graham, 2003; Stewart et al., 1977; Stewart et al., 1999). Moreover, there was a positive correlation between long hours and burnout and first year residents reported stressors such as sleep deprivation, hours, and increased patient care (Lue, Chen, Wang, Cheng, \& Chen, 2010). Even though there are vast studies investigating medical students and the effects of burnout and stress on their satisfaction, there is a gap in the research related to stress and burnout of general disciplinary graduate students.

\section{Gender role}

Though graduate students have seldom been investigated in terms of job satisfaction and stress, there is more research on differences across biological sex in regards to the graduate experience. Ferreira (2003) found that there were significantly larger attrition rates from chemistry and biology for female students. These findings were echoed in a study of Canadian graduate students (Singer, Cassin, \& Dobson, 2012) as females expected child rearing to disrupt their careers more than men to a significant degree and were significantly more likely to pursue private practice over academic careers due to the flexibility a private practice afforded. Adamo (2013) also found that females were significantly less likely to become academic scientists citing the long hours and time constraints. This role conflict is echoed in Wyss and Tai (2010) who found female scientists reported greater conflict between the work and family, which indicates that females feel the need to trade off work and family commitment. 
This is especially problematic for graduate students who are also mothers as they have to worry about child care additional expenses and may be considered less serious of a student (Lynch, 2008). Latina female graduate students report the need to have more balanced expectations (Levya, 2011). Even without the additional stressor of motherhood, many females often report they have more lenient treatment and have to fend off sexual harassment (Mehta, Keener, \& Shrier, 2013). Moreover, gender stereotypes emerged in Sallee's (2011) qualitative article where male students changed language around female students and complained when a new female professor received new lab space. Even though the female students are increasing in graduate school programs, many do not see their abilities as equal to their male counterparts (Sallee, 2011).

The attrition epidemic leads many qualified potential employees to leave the field before their careers even start. By addressing the student's stress and the impact it has on their quality of life, this can shift the focus to graduate school as a more positive learning environment instead of a learning boot camp. This dissertation tries to fill the gap by investigating the relationship of stress, satisfaction, sex, and gender roles in graduate students and to determine the relationships amongst the variables. This, coupled with the qualitative stressors, will begin the process of identifying problematic areas for such students and increase the retention of qualified individuals.

The overarching research question in this study is investigating the variables of occupational stress, job satisfaction, gender roles, sex, and the interaction in graduate student part-time workers. The specific research questions are listed at the end of Chapter 2. 


\section{Rationale}

As previously noted, a gap exists in the literature for the graduate student population (e.g., Haydarov et al., 2012; Isaac, 1993). Though previous researchers had indicated the need for research on graduate students who were pursuing master's degree, this has been largely unaddressed (Haydarov et al., 2012; Isaac, 1993). Though the attrition rate for traditional programs hovers around $50 \%$, distance lead programs and doctoral distance lead programs can hover around 60 to 70\% (e.g., Rovai, 2002; Terrell, 2005) due to various factors (Terrell et al., 2012). Moreover, this wastes the resources of the institution, faculty, and graduate students (Gardner, 2010; Golde, 2005; Terrell et al., 2005). Such high attrition rates may even discourage other aspiring professionals from attending programs. This is problematic as this could result in reduced standards to fill seats in such programs, which in turn may result in higher attrition in these qualified programs, which would just magnify the attrition problem.

The complex nature of attrition across programs has made it difficult to understand the attrition and apply universal solutions to decrease it (Terrell et al., 2012). However, recent research by Grama and Sorin (2011) found that workers cannot attain excellent performance on their own, but instead need the support of supervisors and coworkers. The same principles apply within graduate school as Terrell et al. (2005) found that higher student to student interaction and higher student to mentor interaction can reduce this. Therefore, it may be the case that the same principles of mentorship and collaboration in the Human Resource sphere are upheld in graduate school and can be used to partially mitigate the attrition.

Attrition is especially problematic as this prevents qualified professionals from 
reaching career goals. If attrition continues to become problematic, this may result in prolonged availability in these specialized jobs. As many universities require a master's degree or higher to teach in university settings, this may potentially result in lower quality classes for the future generations of professionals attending such universities. Human Resources (HR) can enable the determination if additional admission requirements need to be added to help enroll the most qualified potential participants in graduate school. As many attend graduate school to pursue another career goal, this might result in greater stress in their current working environment. Therefore, the attrition of graduate students affects not only the current professors, students, and their respective families, but has widespread effects for everyone in the U.S.

\section{Limitations}

The experience of being a graduate student is unique as the student must contend with two equally important, but conflicting demands. The more time one spends at school, the less time he/she has at work and vice versa. Many graduate students complain that they cannot wait until they graduate so they have only one job to contend with. Due to both school and work feeling like two separate jobs, the model that is proposed for graduate student part-time worker may not be effective or relevant to other working populations. This does limit the generalizability to the model, but it is somewhat addressed by the utilization of a diverse group of graduate students from an array of academic programs. Additionally, the qualitative data will allow the researcher to determine which "job component" is more stressful to the graduate student part-time worker.

The limitations in this study are that this study was conducted solely on graduate 
students in two southeastern states and not the entire United States. Two of the schools were public universities, while the majority of the participants were associated with private and/or religiously affiliated universities. This may limit the generalizability, as graduate students who attend in these states in rural and urban areas may have differential characteristics than those who attend schools in larger metropolitan areas. The students who participated in the study came from more the human services sides of the university (e.g., psychologists, human resources, educators, medical students, and occupational therapy students) and may have differential characteristics than those in sciences or in law. These human services fields in and of themselves may result in greater stress to begin with due to their increased contact with clients.

In addition, students who participated in this study from the links posted on social media sites or from faculty sent emails may experience less social isolation due to these personal contacts. These characteristics may have led individuals who were either highly stressed or who experienced low stress to complete the survey compared to those who felt indifferent to the surveys. The researcher utilized current graduate professors to forward the email to current students so they may have been more inclined to complete the study than those who were just emailed an anonymous survey.

Lastly, there may have been some response bias. Since the survey is internetbased, graduate students may have ignored the emails, utilized a different email address unknown to the researcher, or did not fill out the questionnaire. Additionally, those who filled out the questionnaire might have been biased in their responses. Lastly, the population might have experienced more stress around the time of exams and deadlines, so the timing of the study was crucial. 
Moving forward from the introduction, a review of relevant literature of occupational stress, job satisfaction, and gender roles will be discussed. Lastly, the method section will discuss how the study will be conducted.

\section{Definitions}

The core definitions used for this dissertation are defined below:

1. Job satisfaction - the degree to which one is satisfied with the subcomponents of their job (Fischer, 2000; Moorman, 1993; Zhu, 2013)

2. Occupational stress - a relationship between the employee and the work environment that is appraised by the person as taxing or exceeding his/her resources and endangering his/her wellbeing (Lazarus \& Folkman, 1984)

3. Sex - biological characteristics differentiating men and women (Bem, 1974)

4. Gender role - is socially determined and is the extent to which one portrays himself/herself with feminine or masculine characteristics (Bem,1974)

5. Masculine - one scores high on the masculinity subscale and low on the femininity subscale (Bem, 1974)

6. Femininity- one scores high on the femininity subscale and low on the masculinity subscale (Bem, 1974)

7. Undifferentiated- one scores low on both the femininity and masculinity subscales (Bem, 1974)

8. Androgyny- one scores high on both the masculinity and femininity subscales (Bem, 1974) 


\section{CHAPTER II}

\section{LITERATURE REVIEW}

This chapter presents a review of job satisfaction within the theoretical framework of equity theory. Equity theory and the related job satisfaction components of compensation, work, promotion, supervision, and coworkers are discussed. Next, the constructs of occupational stress, gender roles, and sex are analyzed by showing their relationship with job satisfaction.

\section{Job Satisfaction}

In organizational research, job satisfaction is the most frequently studied variable (e.g., Spector, 1997; Judge et al., 2000) and has been studied extensively for decades (e.g., Judge et al., 2000). Job satisfaction is differentiated into affective and cognitive job satisfaction that addresses the core construct of job satisfaction, but focus on differential aspects of satisfaction (Moorman, 1993; Thompson \& Phua, 2012; Zhu, 2013). Whereas affective job satisfaction centers more on the emotional aspects of the job (Thompson \& Phua, 2012; Zhu, 2013), cognitive job satisfaction examines the subcomponents of the job and the degree to which one is satisfied with these subcomponents (Moorman, 1993; Zhu, 2013). Though affective job satisfaction may alert employers about a worker's status regarding satisfaction, cognitive job satisfaction will enable the employers to pinpoint the problem areas that need to be addressed, which is inherently valuable in its 
own right.

As previously noted, affective job satisfaction is defined as an overall or global feeling employees have about their job in general and assesses how they subjectively evaluate their overall job satisfaction (Thompson \& Phua, 2012; Zhu, 2013). In contrast, cognitive job satisfaction is an objective judgment examining the subcomponents of the job and evaluating both the job facets, such as promotional opportunities, compensation, working conditions, and outcomes. Cognitive measures remove the influence of emotions and examine whether the worker is satisfied with the working conditions, pay, and supervision (Moorman, 1993; Zhu, 2013). Though affective and cognitive job satisfaction clearly examine and are defined as focusing on different aspects of the job satisfaction construct, these lines are blurred in practice. Often job satisfaction is defined affectively by researchers, but is measured incorrectly through a cognitive job satisfaction measure that asks the workers to analyze their satisfaction in a way consistent with cognitive job satisfaction (Brief, 1998; Brief \& Roberson, 1989, Fisher, 2000; Thompson \& Phau, 2012; Zhu, 2013). This conflicting practice of defining satisfaction one way and measuring it the other way is no longer acceptable in the field (Brief \& Weiss, 2002). Such practices greatly hinder the advancement of job satisfaction as a field, as findings may be misleading or hidden under such inconsistent measurement practices.

Despite the previous objection by Brief and Weiss (2002), many researchers have investigated whether such cognitive and affective job satisfaction measures assess the same overall job satisfaction construct. The theoretical idea that affective job satisfaction is simply the summation of the cognitive components (Locke, 1969) has largely been discredited. In reality, less than $25 \%$ to $50 \%$ of the variance in affective job satisfaction 
can be explained through the utilization of cognitive job satisfaction (e.g., Ferrat, Dunham, \& Pierce, 1981). One cannot simply sum up the individual components of job satisfaction (Scarpello \& Campbell, 1983; Thompson \& Phua, 2012) as not all components are considered, and the facet measures may not encompass and measure all components of the job of which the employee derives satisfaction from (Brief \& Weiss, 2002; Thompson \& Phua, 2012). Based on Scarpello and Campbell's review, the lack of correlation signifies that the individual facets of the job do not appear to underlie the same unitary job satisfaction construct (Thompson \& Phua, 2012). The idea of considering job satisfaction only in terms of cognitive or affective measures is problematic because they differentially predict criterion (Brief \& Wise, 2002; Thompson \& Phau, 2012). These previously mentioned studies provide further evidence (Fisher, 2000) that affective and cognitive job satisfaction measures are differentially caused and do not measure the same unitary construct (Thompson \& Phua, 2012). Therefore, when designing a research study the research questions must guide which measure is utilized so one can accurately assess the construct in question.

The usage of global measures of job satisfaction (affective measures) can result in the misleading conclusion that there is no difference in job satisfaction, but significant differences emerge when one examines facet measures (Campbell \& Campbell, 2003). For instance, in Campbell and Campbell's (2003) study of Singaporean employees' job satisfaction and intention to quit, males and females did not significantly differ in their response about overall job satisfaction. However, this conclusion from the global measure is not completely accurate, for when Campbell and Campbell included job facets, they found differential facets of satisfaction amongst the sexes. For instance, factors such 
as opportunity for advancement and the work itself were not significant predictors of intention to quit for females, whereas for males, not only was opportunity for advancement considered, but so was organizational support. Utilizing global job satisfaction measures in these instances would have been problematic and would not have allowed the determination of the job satisfaction differences by sex. Based on Campbell and Campbell's results, when examining demographics such as sex, it may be useful to utilize cognitive measures of job satisfaction in order to determine where differences lie and to suggest areas for future research.

Although job satisfaction is usually defined as an affective reaction, which would seemingly involve an emotional component, there is little research conceptualizing job satisfaction as an emotion (Fisher, 2000). For the purpose of this dissertation, job satisfaction will be defined as the degree to which one is satisfied with the subcomponents of their job. In addition, a global measure of job satisfaction will also be utilized. At this current time, there is a plethora of research on job satisfaction; the review will focus on job satisfaction within the theoretical framework of equity theory followed by a discussion of compensation, work, promotion, supervision, and coworkers.

\section{Equity Theory}

Job satisfaction is critical to employers due to its relationship with productivity and turnover (Tata, 2000). There are numerous job satisfaction theories in the academic and practitioner sectors, ranging from Herzberg's two-factor theory of job satisfaction to expectancy theory (Greenberg, 1990). The most predominant theory discussed in research and in practice is equity theory (Adams, 1965; Disley, Hatton, \& Dagnan, 2009). 
Equity theory (Adams, 1965) consists of evaluations of outcomes to inputs, which is similar to one's objective decision on whether they are satisfied with subcomponents of the job (Moorman, 1993). Equity theory has been utilized in a variety of applied research studies of subjects such as teachers (Taris et al., 2001), hospital workers (Griffith \& Gaertner, 2001) and nurses (Schaufeli, Van Deirendonck, \& Van Gorp, 1996). The current study is grounded in the equity theory framework.

\section{Equity theory}

The underlying principle of equity theory is that the employee puts forth contributions, such as hours worked and the quality of his/her work, and expects to receive organizational outcomes such as promotions, raises, and recognition (Adams, 1965: Disley et al., 2009). The two main components of equity theory are inputs and outcomes (Disley et al., 2009). The contributions that employees provide in the system are defined in this theory as inputs (Disley et al., 2009). Some examples of inputs Disley et al. (2009) provided include the quality of his/her work, hours worked, effort, seniority, personality traits, intellectual abilities, and the skills that the employee brings to the workplace (Adams, 1965; Disley et al.). In turn, outcomes, according to Disley et al., include employee's pay, promotional chances, opportunities to increase their skills, and status received in the organization (Adams, 1965; Disley et al.; Lambert, 2011). Though this theory was proposed in the 1960s, the basic tenets as mentioned above still appear relevant in the modern world.

\section{Types of conditions}

The inputs and outcomes discussed in the previous paragraph are often studied in 
regards to job satisfaction. In equity theory, the degree of equity is determined by the employee's perception of whether she/he has received a fair distribution of outcomes in relation to their inputs (Adam, 1965; Lambert, 2011). The employees judge the fairness of outcomes received by comparing them with a comparable other. The comparable other is another employee in the organization that is chosen based on similar tenure, experience, and background as that of the employee making this comparison (Adam, 1965; Lambert, 2011). Employees determine if an equitable relationship exists through an assessment of their input/outcome ratio to a comparable other's input/outcome ratio to determine if relatively equal outcomes are provided (Adam, 1965; Lambert, 2011). The employee uses this assessment to determine if she/he receives roughly equivalent outcomes to the comparable other based on their respective inputs into the system (Disley et al., 2009; Lambert, 2011). This enables the individual to determine if they receive a fair distribution of rewards and job opportunities, which in turn affects job satisfaction and commitment to the organization.

There are three conditions that can result from this input/output assessment: overpayment, underpayment, and equitable conditions (Adams, 1965; Lambert, 2011). Overpayment is where one receives greater outcomes (promotions or raises) than what their inputs (hours worked, quality of work) warrant, whereas the underpayment condition is where one puts forth greater inputs, but is not compensated accordingly. These conditions are experienced differentially based on the personality types under the equity sensitivity section. In an equitable condition, the employee feels she/he puts forth similar inputs and receives similar outcomes to the comparable other (Adams, 1965; Lambert, 2011). This preferred equitable condition results in employee's satisfaction 
(Disley et al., 2009). The employee gauges there to be a fair distribution of employergranted outcomes in relation to the inputs. Since employees' pay is confidential, employees are subjective in their judgments. Employees who are unaware of coworkers' pay often overestimate the pay of those at the same organizational level (Milkovich \& Anderson, 1972). The more knowledge employees have about the fairness of the pay process, the more satisfied they are (Jawahar \& Stone, 2011). Even though the pay may be kept confidential, it is vital to share the administrative processes used to determine such pay to increase satisfaction by reducing pay misconceptions. Otherwise, employees will not believe their inputs will impact the outcomes, resulting in the decrease of their productivity.

When there is either an overpayment or underpayment condition, the employee perceives an unequal distribution of outcomes based on their inputs (Adams, 1965). In the overpayment condition, the employee views herself/himself as having roughly equivalent inputs, such as hours worked and quality of work, as that of her/his comparable other. However, the employee making the assessment may feel that she/he receives more organizational outcomes than his/her comparable other, resulting in the imbalanced input/outcome ratio (Lambert, 2011). Though research proposes that the employee will work longer hours or perform higher quality work to remedy this inequitable relationship (Adams, 1965), in practice it has been found employees use cognitive adjustment to justify their overpayment. This cognitive justification may consist of thoughts such as, "I take on more important projects," or "I add more benefit to the department by my . . ." (Watson, Storey, Wynarczyk, Keasey, \& Short, 1996). Such cognitive adjustments reduce this unequal ratio as well as inequitable feelings, thus 
resolving the tension (Watson et al., 1996). As most individuals tend to perceive themselves being better than average, it is not surprising that individuals in an overpayment condition often make such cognitive adjustments, which results in an equitable condition and satisfaction occurs.

Though the inputs may be the same, the employees' judgment of whether she/he is underpaid or overpaid for his/her work can drastically affect his/her perceptions of organizational fairness and satisfaction (Disley et al., 2009). In the underpayment condition, the employee views herself/himself putting in roughly equivalent inputs, such as hours worked and quality of work, as their comparable other, but the employee still feels that she/he has received less organizational outcomes (Adams, 1965). Another underpayment condition that may exist is when the employee has higher inputs than the comparable other, but receives similar outcomes. When workers feel that their contributions are not rewarded fairly, they will engage in actions to increase their rewards from the organization (Adams, 1965; Greenberg, 1990). Research has found that the employees lower the quality of the work, engage in thievery, or work fewer hours to modify this imbalanced relationship (Mars, 1973). Moreover, coworker's pay has the ability to positively or negatively impact the employee's satisfaction with their own pay (Linz \& Semykina, 2012). Such self imposed actions reduce the inner turmoil where employees feel their inputs far exceed their employer-granted outcomes and try to reduce such tension, which remedy the imbalanced ratio which results in an equitable condition and satisfaction.

When an overpayment or underpayment condition results, employees actively seek to reduce these inequitable feelings. In these cases, employees internally make 
adjustments such as changing their comparable other, their perception of skills, and/or their evaluation of intrinsic job satisfaction (Williams, McDaniel, \& Nguyen, 2006). These previously mentioned actions or adjustments will reduce feelings of inequity as this will correct the imbalance ratio of inputs to outcomes. For instance, Greenberg (1989) found that workers who had their pay reduced during the recession changed their cognitive perception of their job as more satisfying and reduced their inequitable relationship through cognitive means (Williams et al., 1996). These actions are all used to reduce the discomfort employees feel when they produce quality work, but do not feel they are compensated accordingly. Such actions reduce the feelings of inequity, resulting in an equitable condition and job satisfaction.

One such way to reduce an inequitable inputs-to-outcomes ratio is through cognitive adjustments. Cognitive adjustments, where the employees rationalize their skill sets or contributions, are often used to justify an overpayment condition. The adjustments may be more extreme when employees feel they are underpaid. In some instances, the cognitive adjustments will not reduce the tension because employees may reduce these inequitable feelings through overt actions, such as theft or the reduction of their quality of work. As indicated in these instances, Greenberg's (1990) findings support Mar's (1973) proposition that employees may resort to theft in order to equalize the underpayment condition. Greenberg studied manufacturing workers whose pay was decreased by $15 \%$ for ten weeks instead of being laid off. This pay reduction resulted in an underpayment condition as the workers worked the same hours as before the reduction, but received fewer organizational outcomes, paving the way for higher theft ratios (Greenberg, 1990). These results varied based on how employees were informed of pay 
reduction rationale. One manufacturing plant had the rationale for the pay cut clearly explained and provided the opportunity to question the managers, whereas in the second plant the workers were not given such a detailed explanation. When the rationale for the pay cut was clearly explained to the workers, it aroused lesser feelings of an underpayment condition and reduced theft (Greenberg, 1990). The information provided to the employees resulted in a cognitive adjustment to reduce inequity instead of an overt action such as theft to reduce the inequitable conditions.

Underpayment and overpayment conditions both result in the employee taking some overt or internal action in order to reduce this inequity. Most research typically focuses on either the underpayment conditions or the overpayment condition and how one rectifies these conditions through theft or cognitive adjustments. Some researchers (e.g., Perry, 1993) found the strongest support of the equity theory with those in the underpayment condition, whereas others have found the strongest empirical support with the overpayment condition (e.g., Van Yperen, Hagedorn, \& Geurts, 1996). Evidence for equity theory is particularly strong in how people evaluate underpayment conditions (Greenberg, 1990; Mowday, 1991) and how employees attempt to reconcile underpayment conditions to be equitable (Adams, 1965; Allen \& White, 2002). When employees are in the underpayment condition, they report reducing the quality of work, hours of work, or in some instances engage in theft to increase their organizational rewards. In reality, those in the overpayment condition tend to make cognitive adjustments to reduce their inequity in an effort to reduce the internal tension and lead to increased job satisfaction. 


\section{Equity Sensitivity: Benevolents, Entitleds, and Equity Sensitive}

Equity theory initially did not predict how individuals reacted to underpayment or overpayment conditions and fell slightly out of favor for several years (Allen \& White, 2002). However, equity theory surged with popularity again with the addition of the equity sensitivity construct, which was later incorporated into equity theory (Allen \& White, 2002). Equity sensitivity is defined as how sensitive individuals are to overpayment and underpayment conditions (Allen, Takeda, \& White, 2005; O'Neill \& Mone, 1998). The addition of equity sensitivity to equity theory has resulted in enhanced prediction of job satisfaction amongst other variables when applying equity theory (King \& Miles, 1994; King, Miles, \& Day, 1993; O’Neil \& Mone, 1998). The addition of the equity sensitivity constructs leads to a greater understanding of individual differences seen in the research (O’Neil \& Mone, 1998).

There are three personalities that emerge under the equity sensitivity construct: Benevolents, Equity Sensitives, and Entitled (Huseman, Hatfield, \& Miles, 1985, 1987). Equity sensitive workers prefer to have an equitable relationship between inputs and outcomes. In contrast, Entitleds and Benevolents each emphasize one portion of the input/outcome ratio. Entitleds focused more on the outcome as they prefer to be overcompensated for their contributions, whereas Benevolents focused more on the quality of their work and contributions and were less concerned with their outcomes (King et al., 1993). While Entitleds prefer overpayment conditions and while Benevolents become more tolerant of the underpayment conditions, Equity Sensitives desire to be in the equitable condition (King et al., 1993). Although Benevolents, Entitleds, and Equity Sensitives can fall under equitable, overpayment, or underpayment 
conditions, they respond better when they are in the situation that best suits their innate personality desires (O’Neil \& Mone, 1998). For instance, if the Equity Sensitives' ratio of inputs/outcomes becomes imbalanced, the individual will attempt to remedy this situation. Though each classification of Benevolents, Entitleds, and Equity Sensitives may fall into overpayment, underpayment or equitable conditions, the responses under such situations are based on their personality types. Furthermore, the different personality types explain the failure to address imbalanced ratios when they are in their preferred situation under the equity sensitivity theory.

While equity theory explained some of the variance in job satisfaction, equity sensitivity filled a pronounced gap by addressing personality types, and explained why some employees were more comfortable in an underpayment condition. Benevolents do not innately desire to be in the underpayment condition, where they are paid less than their comparable other. In contrast, Benevolents will be more accepting of the condition than Entitleds or Equity Sensitives who would seek to remedy such perceived injustice. This is due to the Benevolents' focus on the inputs such as their personal judgment of the quality of their work and the amount of work they put in. Likewise, the Entitleds would be provoked under conditions of underpayment, even terminating the working relationship because their preferential condition is the overpayment condition. They instead would seek to maximize their contributions. Lastly, the Equity Sensitive wants to have balanced inputs/outcomes and will remedy this imbalanced ratio. The response among the personality types depends on the payment conditions in the workplace. Equity Sensitivity theory considers such conditions and allows workers to predict how they would respond under various conditions. 
Miller's (2009) study investigated these categorizations by surveying one sample of college students to determine the best factor structure. Then he also conducted confirmatory factor analysis on the two-factor structure in the second sample. Miller confirmed the existence of both Entitleds and Benevolents utilizing the Equity Preference Questionnaire. Those classified as Entitleds preferred to receive more from the organization than they put in (overpayment condition), and job satisfaction decreased when they were underpaid or paid equitably. In contrast, Benevolents were not as focused on the rewards they received from the organization and were more concerned with their work quality, the underpayment condition (Allen \& White, 2002; Miller, 2009). Though Benevolents did not strive to be in the underpayment condition, they did not suffer the same type of dissatisfaction as that of Entitleds. The equity sensitivity construct recognizes that workers have unique reactions under the various conditions that lead to differential outcomes with the employment relationship. Therefore, once the worker's personality type is discovered, the employer will be able to accurately predict how the employee will respond under payment conditions and address their concerns.

King et al. (1993) corroborate Miller's findings that Entitleds put more importance on tangible outcomes whereas Benevolents focus on their own contributions, such as inputs. Similarly, Allen and White (2002) found the low pay conditions resulted in the Entitleds feeling less rewarded, which resulted in them performing less work or transferring. In contrast, when the Benevolents were put in the same situation, they were significantly less likely to reduce their effort or transfer/quit. This is due to their heightened comfort level in the underpayment condition. Also, Allen and White (2002) found that Entitleds were more sensitive to pay differences whereas Benevolents had a 
higher workload pay threshold, where they were more comfortable with inputs that were not necessarily rewarded with expected outcomes (underpayment condition). Succinctly, Benevolents desire or are more comfortable in an underpayment condition; Equity Sensitives desire an equitable condition, and Entitleds prefer the overpayment conditions.

\section{Equity theory and job satisfaction}

Equity theory is commonly used to explain job satisfaction as employees desire organizational outcomes for their inputs. Intuitively, the implication of this theory makes sense as employees want to be paid fairly and do not desire to be paid less than they feel they deserve. Employees who do not feel their inputs are rewarded fairly become dissatisfied with their environment (Adams, 1965). They expect organizations to be fair and when injustice in payment occurs (Alexander \& Ruderman, 1987) this results in decreased performance, increased absenteeism, and increased turnover among other outcomes (Tata, 2000). Because equity sensitivity has also been found to be significantly related to job satisfaction (King \& Miles, 1994) it can be used to predict employee reaction (e.g., Huseman et al., 1985; King \& Miles, 1994) when they compare themselves to their comparable other (a person in the organization with similar experience, education, and background as the employee making the adjustment). As previously discussed, Benevolents focus their attention on the quality of their inputs and are less concerned with their outcomes. In contrast, Entitleds desire to have greater outcomes despite the quantity or quality of their inputs. For instance, Benevolents were more satisfied in cases of underpayment whereas Entitleds were more satisfied in overpayment conditions (O’Neil \& Mone, 1998). This example shows that workers respond differently based on their personality types under the various payment conditions. 
O’Neil and Mone (1998) found that job satisfaction and equity sensitivity with the Equity Sensitivity Instrument (Huseman et al., 1985), among other relationships, were significantly correlated $(r=.21, p<.01)$. This correlation indicates that when the input to outcome ratio is balanced, an employee is more satisfied. Moreover, there was a significant relationship between equity sensitivity and intent to leave. This relationship signifies that when employees have an imbalanced input to outcome ratio, employees suffer from increased turnover intentions and are more likely to leave the organization (King et al., 1993). Shore (2004) came up with congruent findings as Benevolents in his study reported greater pay satisfaction, the highest pay fairness, and lowered turnover intentions, compared to Entitleds and Equity Sensitives. However, Shore did not find significant differences in terms of overall satisfaction between Entitleds and Equity Sensitives (Shore, 2004). Therefore, equity theory is important in workplaces as it can greatly influence employee performance and increase satisfaction, thereby reducing turnover (Greenberg, 1990). As such, one must address satisfaction issues that are important to the individuals in order to prevent any organizational consequences such as reduced productivity or turnover of high quality workers.

Despite one's personality subtype, equity theory provides credence to the utilization of facet measures of job satisfaction. Commonly investigated facet sources of job satisfaction are supervision and work itself, which are often examined in terms of one's input (Disley et al., 2009), whereas the comparable other is often examined as the facet satisfaction with one's coworker. Similarly, the most frequently investigated outcomes of equity theory, compensation and promotions, are often investigated as sources of job satisfaction. Van Yperen (1995) found that those who experienced an 
underpayment condition were more likely to report desires to leave the organization. Though this under benefited relationship was echoed in Van Dierendonck, Schaufeli, and Buunk (1996) study, where Van Dierendonck et al. also found that those who exhibited the overpayment condition felt higher emotional exhaustion from the imbalanced ratio (Disley et al., 2009). The feelings of inequity elicit negative feelings, which incrementally increase job dissatisfaction over time (Disley et al., 2009). Moreover, Watson, Storey, Wynarczyk, Keasey, and Short (1996) confirmed that the overpayment condition lead to greater job satisfaction and the underpayment condition was associated with significantly lower levels of job satisfaction. However, when managers expect to stay in the same position for several years, they make a cognitive adjustment that was previously described to reduce these inequities (Watson et al.). Therefore, equity theory not only explains the disproportional sources of satisfaction in the workplace, but also explains how the combination of the facet measures of satisfaction can lead to differential outcomes and organizational outcomes. The Job Descriptive Index is the most well known facet measure of job satisfaction and consists of five facets. These five facets will be discussed in this section: promotion, coworkers, supervision, work itself, and compensation.

\section{Compensation}

Compensation is investigated in the realm of job satisfaction and people in general feel undercompensated instead of overcompensated (Harris et al., 2008; Jawahar \& Stone, 2011). This could be partially attributed to employees' cognitive beliefs and perceptions as employees typically perceive themselves as better than average performers

(Alicke, Klotz, Breitenbecher, Yurak, \& Vrendenburg, 1995; Jawahar \& Stone, 2011). 
As noted in Jawahar and Stone (2011), employees become concerned with pay when they are paid less than the market or when there are unfair pay procedures within the organization (SHRM, 2007). This is particularly problematic in the current economy where many organizations during the recession required employees to take on additional work and persist with pay freezes and little to no raises to keep organizations productive (Ryan, 2010). Therefore, employees may feel their contributions are not fairly rewarded, which in turn can reduce productivity and lead to higher organizational costs.

Compensation does not guarantee that an employee will like his/her job better (Piccolo \& Judge, 2011). In reality, the relationship between compensation and job satisfaction is a weak relationship. Management and organizations often conclude that increasing compensation will increase overall job satisfaction, but this is not the case. Though Williams et al. (2006) did not report a correlation of overall satisfaction and compensation, Williams et al. found a weak relationship between pay increase and pay satisfaction $(r=.08)$. Piccolo and Judge (2011) found an even smaller correlation in their meta-analysis between compensation and satisfaction. They determined that pay had little to do with job satisfaction and the overall correlation was .15. In fact, Piccolo and Judge found that lawyers had less job satisfaction than child care workers although there was a huge compensation disparity between the groups. Though a raise can increase satisfaction temporarily, Piccolo and Judge suggest that in order to increase job satisfaction, employees and employers need to focus on other job attributes. For instance, Fischer and Boehr (2011) found that autonomy is more important to employees than compensation, which was echoed by Williams et al. Therefore, pay is not the sole factor that contributes to employee satisfaction as there are other factors that play an important 
role in one's job satisfaction.

In fact, some workers crave work/life balance over increased compensation (Branch, 2011). Though accountants who are paid a competitive salary report greater satisfaction with their compensation (Branch, 2011), this does not appear to hold true for lawyers. Dinovitzer and Garth (2010) found that law associates at large firms would be willing to trade their lavish compensation for less hours and greater work/ life balance. In contrast, Devoe, Lee, and Pfeffer (2010) found that those who were paid hourly were more willing to sacrifice free time for more money, but this finding was reversed for salaried workers, where $39.7 \%$ of those salaried were willing to trade compensation for free time. In summary, the more hours one worked per week, the less they were willing to trade free time for more money (Devoe et al., 2010). Rice (2011) suggested that due to the workers' desire for free time based on their working hours, companies should ensure that compensation packages are competitive, and that the focus should than showcase elements of the jobs that would increase job satisfaction. This further supports the finding that compensation is not the sole factor for job satisfaction, so other areas need to be examined.

On the other hand, job satisfaction may also be effected not just by one's satisfaction with net pay, but instead on how one gauges the importance of pay and the value placed on it by the individual employee. Dissatisfaction in pay differs by sexes as men place a higher value on pay and appraise it as a symbol of their worth to the organization (Tata, 2000), whereas women value interpersonal relationships more (Deaux, 1976). In multiple settings, men were paid higher than females (De Kock, Felce, Saxby, \& Thomas, 1987; Toutkoushian, Bellas, \& Moore, 2007), but male academic staff 
employed in the UK were significantly more dissatisfied with pay (36.2\%) compared to female academic staff (18.7\%, Smith, 2009). Regardless of the culture, women were more likely to rationalize the reason why their comparable other was paid more in underpayment conditions than men (Allen et al., 2005) and may expect to be paid less throughout their careers - a lowered expectation which may account for their higher rates of their satisfaction with their pay, a commonly investigated facet of job satisfaction (Gasser, Flint, \& Tan, 2000; Iverson, 2000; Smith, 2009). Despite this both male and female staff expressed more satisfaction with their pay than faculty of both sexes, which may suggest an interaction of pay and status incentives, where one's role results in a perceived expectation of what one should earn, resulting in differential pay satisfaction (Smith, 2009). Men were more likely to cite pay as a reason for leaving (De Kock et al., 1987). This lowered importance on pay for women (Crosby, 1982) is speculated to be partially due to women's awareness that female performance roles may not be rewarded monetarily and they seek out different factors for satisfaction (Mednick \& Tangri, 1972). Socially, it is commonly ingrained that females can earn less as they are not the sole economic provider in the family and females were less likely to evaluate whether they received a fair distribution of rewards (Tata, 2000). As previously noted, this can lead to embers of dissatisfaction brewing.

Though compensation is commonly reported by surveyed employees as one of the top five satisfaction factors for most employee groups, HR professionals typically rank pay as a lower source of satisfaction (Fox, 2011). In a SHRM study, HR professionals reported that the ability to use their skill set, their supervisor-employee relationship, and communication with senior management, work itself, and the autonomy to make 
decisions were higher sources of satisfaction. Compensation is viewed as only a necessity (Fox, 2011). This reverberates the previous sentiment that if employees do not value the job characteristic, it is not worth trying to increase their satisfaction.

\section{Supervision}

A strong predictor of employee turnover is their relationship with their immediate boss (Longo, 2010; Ryan, 2010). Of the employees who believed they had a positive relationship with their immediate boss who cared about their well being, $94 \%$ reported they were planning on staying with their current company. In contrast, only $43 \%$ of employees who did not believe their boss cared about their well being planned to stay in the same organization (Ryan, 2010). In combination with reduced turnover intentions, employees with a better relationship with their boss had improved workplace performance (Ladebo, 2008; Vadenberghe, Bentein, \& Stinglhamber, 2004). Moreover, the quality of supervisor interaction has been positively related to feelings of employees' effectiveness (Livni, Crowe, \& Gonsalvez, 2012). This finding is mirrored internationally, as $84 \%$ of Canadian employees reported bad supervision/bosses as the main reason for their attrition from the company and a source of dissatisfaction (CMA Management, 2008). In combination with reduced turnover intentions, employees with a better relationship with their boss had improved workplace performance (Ladebo, 2008; Vandenberghe et al., 2004). Therefore it is critical to develop effective bosses and managers in order to retain qualified professionals. Otherwise, the talent and productivity of the entire company is at risk (CMA Management, 2008). Even though all employees are not equally valued by the organization, it is critical that bosses maintain effective relationship with higher performers to mitigate these effects. 
A positive relationship with one's supervisor can mitigate potentially negative employment occurrences, such as turnover and reduced performance (Madlock, 2009). An employee's job satisfaction is affected by their perception of managerial control and fairness in the workplace, which can also reduce employment related outcomes (Long, Bendersky, \& Morrill, 2011). Livni et al. (2012) found that a positive alliance and effective supervision resulted in lower levels of burnout and higher satisfaction and wellbeing in nurses in the public and drug and alcohol sector, and these findings were similar in a study of Finnish mental health and psychiatric nurses (Hyrkas, 2005). Sterner (2009) mirrored this finding and found that $36 \%$ of the variance in counselors' job satisfaction was explained by the quality of their supervisor working relationship and this same relationship lead to greater job satisfaction. Similarly, Hall (2007) found that nurses in academic centers experienced less occupational stress and increased job satisfaction when they had supportive supervision. Further evidence for the potential impact a boss can have on employees' job satisfaction was mirrored across several populations, where a supportive boss was linked to higher job satisfaction for military nurses (Zangaro \& Johantgen, 2009), in employees who had severe mental illnesses (Rollins, Bond, Jones, Kulka, \& Collins, 2011), and also reduced turnover intentions for Italian nurses (Galletta, Portoghese, Penna, Battistelli, \& Saiani, 2011) and obstetricians in third world countries (McAuliff et al., 2013), and greater commitment for elderly nurse caregivers (Rodwell, Noblet, Demir, \& Steane, 2009). Supervisor support was also related to lower occupational stress and reduced job satisfaction in Dell employees (Steinhardt, Dolbier, Gottlieb, \& McCalister, 2003). Therefore not only can one's boss hold the key to future success in the company, but the degree of support and rapport can directly affect one's 
satisfaction with the overall job.

When there is a perceived abuse in the relationship, (either verbal or emotional), we see drastic effects on job satisfaction. Abusive supervision is even more harmful for the employees' satisfaction than a simply ineffective boss. Supervisors are the most frequently cited offenders of workplace bullying (Hauge, Skogstad \& Einarsen, 2007; Zapf \& Einarsen, 2003). Expectedly, bystanders of bullying and targets of bullying suffered lowered job satisfaction (Harris, Harvey, Harris, \& Cast, 2013), but workplace bullies reported increased job satisfaction (Hauge et al., 2007). Those who perceived their supervisor as abusive were more likely to leave the organization (Rodwell, Brunetto, Demir, Shacklock,\& Farr-Wharton, 2013; Tepper, 2000). Employees who remained in the organization reported lowered job satisfaction, lowered life satisfaction, conflict between family and work, and higher psychological distress. Not to mention these same employees were more likely to report that they stayed at their jobs only because it was too costly for them to leave rather than that they liked their job (Tepper, 2000). The effect of abusive supervision was magnified when the employees had limited external employment opportunities (Tepper, 2000). Tepper, Moss, and Duffy (2011) further this linkage through their proposal of a causal relationship where dissimilarity between the boss-subordinate dyad results in conflict, which in turn results in more negative evaluations of subordinate performance and heightens the perceptions of abusive supervision (Leary et al., 2013). Thirty-two percent of Canadian employees reported their bosses did not treat people fairly and $28 \%$ reported their boss ruled by intimidation and fear (CMA Management, 2011). The effects of abusive supervision can even spill over into other spheres of the worker's personal life (Carlson, Ferguson, Perrewe, \& 
Whitten, 2011). In work/family conflict, $16 \%$ of the variance was explained by abusive supervision (Carlson et al., 2011). Selden and Downey (2012) found similar effects and noted that it appeared that the relationship with the boss is more important than once conceptualized. These findings support that negative bosses can greatly impact the employees' life outside of the organizational walls, which can in turn affect their satisfaction with the work itself and promotional opportunities.

\section{Promotion}

Promotions and opportunities for promotion are one of the highest sources of satisfaction by the employees in Ozturk and Hancer's (2011) study. In graduate school, the idea of promotions is relevant as these advanced degrees allow them to move upward in their careers or seek better employment within the same company. For federal white collar workers, a scarcity of promotional opportunities resulted in decreased job satisfaction (Ting, 1996) and is the most frequently cited reason for attrition of federal workers migrating to private sector jobs (Kim, 2012); this negative relationship between promotional opportunities and attrition was again found in a study of IT workers (Kim, 2012). This same finding was repeated for nurses in military hospitals, though this effect was stronger for military nurses than their civilian counterparts in such institutions (Zangaro \& Johantgen, 2009). This opportunity for promotions and job satisfaction relationship did not hold true for Greek Special Education teachers as they experienced high job satisfaction despite their dissatisfaction with promotional opportunities, which may be due to their heightened awareness of fewer promotional opportunities to begin with (Platsidou \& Agaliotis, 2008). With the lack of promotional opportunities, standardization of promotional criteria seems to help moderate job dissatisfaction and 
productivity (Wan, Sulaiman, \& Omar, 2012). In a study of Malaysian employees, all employees agreed that there needed to be standards by which employees were promoted to reduce the misconception that promotions were not necessarily tied to one's work. This is problematic, as employees who are dissatisfied will have lower motivation, which results in lower job satisfaction and lower productivity (Wan et al., 2012). Though promotions are a common source of satisfaction, it is not feasibly possible that all employees are promoted on a regular basis.

It is not only an actual promotion, but also expected promotion that seems to be related to job satisfaction. In fact, Saygi, Tolon, and Tekogul (2011) found that one's opportunities for promotion were more instrumental to Turkish fish facilities than the effect of pay on one's overall job satisfaction. This is echoed in Garcia-Izquierdo, Moscoso, and Ramos-Viillagras (2012) who found clear promotional procedures increased thoughts of procedural justice, which in turn is related to job satisfaction. When promotions were rewarded unfairly or doled out unequally this resulted in reduced satisfaction (Saygi et al., 2011). Furthermore, Kosteas (2011) found that workers who perceived a promotion will be forthcoming in the next two years had higher job satisfaction, but past promotions had a fading impact. For past promotion recipients who had the expectation of another promotion within the next two years, the awareness of promotional opportunities created the same impact as a $69 \%$ increase on one's hourly wage (Kosteas, 2011). It appears that promotions or opportunities in the future may have more of an impact on job satisfaction than what is commonly believed in organizations.

It is essential to use fair promotional procedures, such as standardized criteria, to allot promotions in order to prevent a culture of distrust and view of promotional 
procedures as unfair (Wan et al., 2012). This is particularly important when the applicant passed over for promotion still remains in the organization (Ford, Truxillo, \& Bauer, 2009). When employees evaluate those who received the promotion, they will evaluate the recipient's tenure, experience, and education. Occupational stress and resentment may grow in the former employee if they feel they were passed over for a promotion they rightly deserved (Ford et al., 2009). However, Lam and Schaubroeck (2001) did not find detrimental effects on job satisfaction amongst those who were passed over for promotions and the incremental increase in satisfaction due to promotions had returned to previous, pre-promotion levels in Hong Kong bank tellers. In some instances, the perceived increase in job satisfaction by the promotion was offset by the increase in occupational stress (Johnston \& Lee, 2013). Johnston and Lee found that the positive benefits of the promotions (control and increased decision making) had dissipated and turned to pre- promotion levels within three years. Though all decision making criteria is critical, objective and standardized criteria are particularly important as this may affect one's turnover intentions. It is more important than ever to increase communication and attempt to rebuild trust in organization (Koster, 2011). Increased promotional chances are more likely to reduce role ambiguity, retain qualified workers, and lead to greater satisfaction with the organization.

Do promotions lead to enhanced job satisfaction? Johnston and Lee (2013) examined this critical question in their research utilizing data from the Household Income Labor Dynamics in Australia (HILDA), which was collected in nine waves from 2002 to 2010 in Australia. Many workers, regardless of geographic location, desire promotions and believe the hierarchical moves will lead to increased wages, more interesting work, 
and greater satisfaction. Coupled with this promotion, are increased job demands and increased hours, which are understood to have a detrimental effect on job satisfaction. Workers who had been promoted in the previous years indicated that the promotion had the greatest effects on the three components: stress (0.16), satisfaction (0.14), and job security (0.18), but the promotion had no impact on the employees' perceived fairness of pay. Employees adapt to the promotion and these positive effects quickly fade. Further evidence for adaption exists as pay fairness and job security return nearly to their prepromotion levels. In the first two years after promotion, workers tend to experience increased stress and work longer hours, but job satisfaction remains higher until three years after promotion. Despite these negative findings, workers everywhere still strive for promotions as they believe it to be the antidote to subpar satisfaction and dissatisfaction with pay.

\section{Coworker}

Social support, characterized by supportive coworkers, is often investigated in the area of job satisfaction. Social support can moderate the relationship between stress and satisfaction to increase one's satisfaction (Bellman, Forester, Still, \& Cooper, 2003). Irrespective of sex, social support tends to increase one's organizational commitment. Though women tend to use social support more than men, Bellman et al.(2003) found that social support moderated the relationship between job satisfaction and several other variables not pertinent to this study. Thus, increasing social support can greatly enhance job satisfaction (Bellman et al.). In a study of university staff in the United Kingdom, social support was positively related to increased job satisfaction (Mark \& Smith, 2012). The support of coworkers can form a buffer and increase employee job satisfaction. This 
is particularly important to organizations and employees working with challenging client populations such as those who directly care for the intellectually disabled (Disley et al., 2009). Staff who feel overwhelmed and dissatisfied with pay may experience lower stress and job dissatisfaction if social support is present (Disley et al., 2009). Social support has been reported in diverse populations to be a way to reduce stress and increase satisfaction (e.g., Berry, 2012; Sloan, 2012; Sundin, Hochwalder, Bildt, \& Lisspers, 2007). Even if promotional opportunities are not there or the work is challenging, the support or admiration of coworkers seems to mitigate the effects of stress on job satisfaction.

\section{Work}

In addition, the work environment or inherent motivation from performing the job can enhance or diminish an employee's job satisfaction. A study of 5000 recentlygraduated lawyers (Dinovitzer \& Garth, 2010) found that new associates at large law firms reported less job satisfaction than those at smaller firms. Though the former group may have larger compensation and greater professional opportunities, many novice lawyers in large firms reported dissatisfaction even though the work is similar to those at lower status law firms. In fact, only $26 \%$ of those from a top law school report extreme satisfaction measured on a Likert-type scale in their decision to become a lawyer, whereas $49 \%$ of those at less prestigious schools report extreme satisfaction in the same decision (Dinovitzer \& Garth, 2010). In fact, 59\% of the former group expressed intent to leave their employer in two years, exhibiting their lower job satisfaction and reduced commitment to the organization. Novice lawyers report they would settle for lower pay and fewer hours that will result in greater work/life balance (Dinovitzer \& Garth, 2010). 
Even the status at the prestigious firms does not guarantee happiness and efforts must be taken to maintain high quality employees.

These previous findings allow critical insight into the satisfaction of employees that the work itself may occupations where salaries are considerably less (Chesters \& Baxter, 2011). This passion for the industry was investigated in a study of dental assistants and childcare workers in Queensland, Australia. Despite both being in the care industry, childcare workers reported less satisfaction with their work (59\%) compared to dental assistants (72\%). Though the childcare workers and dental assistants were both intrinsically motivated to enter the profession, childcare workers' expectations were not rewarded and therefore had a negative effect on satisfaction. These findings could also be attributed to the meaning that one finds in his/her work, which can lead to increased performance if one believes that his/her actions can affect the organization or his/her goals (Cranston \& Keller, 2013). One's ability to control his/her environment leads to greater satisfaction, which indicates that work characteristics and motivation can both affect one's satisfaction.

By the same token job responsibilities can negatively impact job satisfaction. A supervisor may experience stress — as they are accountable for another's behavior — may feel overloaded, and may not have the capacity to cope (Zellars, Hochwarter, Lanvich, Perrewe, \& Ferris, 2011), which can lead to guilt and affect job satisfaction (e.g., Hochwarter et al., 2007). Likewise, perceived over-accountability makes managers feel overworked and reduces job satisfaction (e.g., Perrew et al., 2005). Though some experienced increased job satisfaction with accountability for others (e.g., Zellar et al., 2011), all managers initially felt a sense of task overload. Even so, there is only a 
moderate correlation between long hours and negative health effects (e.g., Van der Hulst, 2003) and it is dependent upon whether rewards are provided or if there are other

pressures to work overtime (e.g., Van beek, Taris, \& Schaufeli, 2011;Van der Hulst \& Geurts, 2001). Therefore innate characteristics of the jobs can lead to job dissatisfaction.

\section{Sex differences}

Research on job satisfaction and sex differences has been contradictory as some studies have found women have more satisfaction (e.g., Kim, 2005; Perie \& Baker, 1997; Sharma \& Jyoti, 2006; Soares, Jacobs, Yu, Shen, \& Lewark, 2012) whereas other studies found men had higher job satisfaction (e.g., Price \& Wulff, 2005; Weaver, 1974). In contrast, some studies have found no differences in sexes across job satisfaction (e.g., Moore, 2009; Zontek, DuVernois, \& Ogle, 2009), which has been reiterated in a variety of populations: airplane pilots (Rast \& Tourani, 2012), university faculty (Bashir, Jianqiao, Jun, Ghazanfar, \& Kahn, 2011), IT professionals (Ghazzawi, 2010), nurses (Torkelson \& Seed, 2011), and accountants (Fogarty, 1996). This is supported by findings that sex differentials are more complex as there are some conditions where men are more satisfied than women and vice-versa (Carlson \& Mellor, 2004).

Nevertheless, men and women often cite different job-related consequences of job satisfaction. Male assembly workers had lowered commitment and turnover, whereas female assembly workers had higher turnover attrition as a result of decreased satisfaction (Lovett \& Galy, 2003). Men reported salaries as the main reason for leaving the organization and reported their job as more satisfying than female nurses (Rajapakse \& Rothstein, 2009). In some professions, females reported that they were more likely to 
change jobs than males citing a lack of control in their jobs (Campo, Weiser, \& Koneig, 2009; Chisholm-Burns et al., 2012). However, Rajapaksa and Rothstein (2009) found males were more likely to leave the nursing profession than females. Females were also less satisfied with their promotional opportunities (Okpara, 2005). Female IT employees were more satisfied with family friendly HR policies, but training and development opportunities did not significantly affect their job satisfaction. The same training opportunities were the highest job facet contributing to job satisfaction for male IT workers (Kim, 2012). Therefore, reports are mixed on which facets affect job satisfaction for the sexes. However, the next variable discussed is occupational stress, which has a consistent relationship with job satisfaction.

\section{Occupational Stress}

Occupational stress is defined as a relationship between the employee and the work environment that is appraised by the person as taxing or exceeding his/her resources and endangering his/her wellbeing (Lazarus \& Folkman, 1984). As their approach suggests, stress is not inherent in the person or the environment, but instead is based on the interaction. Stress is only experienced if employees perceive that they do not have the resources to cope with these demands (Lazarus \& Folkman, 1984). A stressor is only a stressor if the employee perceives it as such. Thus, employees can vary in their responses to the stressor based on whether they perceive it as a stressor or not.

\section{Stress Domains and Type of Stressors}

There are three domains of stress proposed by Pestonjee (1973): job and organization, social, and the intra psychic, further distinguished between on the job 
stressors and off the job stressors. Social stress is concerned with stress from nonwork life; however, job and organization stress is the focus of this dissertation, as it pertains to organizational stress. Though organization stress (henceforth known as occupational stress), social and the intra psychic composes the overall stress construct, each subcomponent of the stress construct is unidimensional. Nevertheless, it is possible for work and life to spill over and cause stress in other domains of the employee (Kendall \& Muenchberger, 2009).

Work-related role stressors are amongst the most widely researched construct in organizational behavior (Bole \& Babin, 1994; Onyemah, 2008). Stress is characterized by a physiological response such as anxiety and tension, whereas stressors are environmental prompts that lead one to experience stress (Onyemah, 2008). Stressors are further differentiated between the challenge stressor or hindrance stressor (Onyemah, 2008). A challenge stressor is appraised by the individual as promoting growth and achievement. In contrast, a hindrance stressor is one that hinders growth (Podsakoff, LePine, \& LePine, 2007). Though these differentiated stressors which are carefully defined in empirical research, the research on these stressors have just recently begun to emerge and is scarce.

Challenge stressors are characterized as work related demands or circumstances that have potential gains for individuals whereas hindrance stressors tend to constrain or interfere with an individual's work achievement. However, challenge and hindrance stressors result in differential consequences in the organization. Hindrance stressors result in increased turnover intention and reduced job satisfaction. Some example of challenge stressors refer to things such as workload and responsibility, whereas hindrance 
stressors include red tape (Cavanaugh, Boswell, Roehling, \& Bourdreau, 2000). These same results were confirmed in Boswell, Olson-Buchanan, and Lepine (2004) and LePine, LePine, and Jackson (2004), and Podsakoff et al. (2007). Lepine et al. believe that challenge stressors are positive as one is able to successfully cope with stress which increases the person's motivation and increase our ability to grow (Boswell et al.) which reduce the negative impact of the stressor (Widmer, Semmer, Kalin, Jacobshagen, \& Meier, 2011). This could be partially explained by one's emotional resources as those who are higher in emotional stability are better equipped to cope with job stress (Rubino, Perry, Milam, Spitzmueller, \& Zapf, 2012). Challenge and hindrance stressors partially explain why our performance is improved under some stressful conditions and hindered over others.

However, these two realms are rarely examined separately in organizational behavior research (Johnston \& Lee, 2013). In one study, challenge and hindrance stressors were associated with increased job strain and $37 \%$ of the variance in job satisfaction could be attributed to these stressors (Podsakoff et al., 2007). This is potentially problematic as such stressors can either lead to better organizational outcomes, therefore desired by the organization, or worsen organizational performance, and should be addressed by the organization to mitigate any negative occupational consequences. Therefore, stressors do not have an equal effect on job performance and satisfaction, which again enforces the individual differences in occupational stress.

\section{Causes of Stress}

Although role stressors, such as role conflict, role ambiguity, and role overload 
are commonly researched sources of stress, these are not synonymous with the stress construct and instead are stressors (Onyemah, 2008). In the next section, role conflict, role overload and role ambiguity will be discussed.

\section{Job Demands}

The global nature of work is constantly increasing the demands placed on the employee (Nurmi, 2011). Many employees feel that there are not enough hours in the day and they are working longer and harder than ever before and report suffering from role overload (Menzies, 2005). These feelings of work overload are not simply an American phenomenon. In Japan, specific words are utilized to describe suicide due to work overload (karo-jisato) and death due to overwork (karoshi; Kanai, 2006; van Beek et al., 2011). As jobs become more stressful and less satisfying, employees are becoming increasingly less committed to their employers and experiencing less life and job satisfaction (Jamal, 2005). These increased job demands result higher occupational stress which reduced employee's effectiveness.

Role overload is where one feels they do not have the resources necessary to cope with the job demands placed on them (Barhem, 2008). Stress cannot be avoided (Pestonjee, 1999) as things are often outside of our control (Avinash, 2006; Kavitha, 2009). One such commonly cited sources of role overload is the increased amount of information that the employee must filter through every day (Barhem, 2008). The increased information provided by email, technology, and work websites lead many to feel they do not have enough resources to cope with demands (Cho, Rangolam, Schaefer, \& Sandlin, 2011). The constant need to respond and be knowledgeable has begun to take 
its toll on workers and has become overwhelming.

With the changing nature of the economy, many employees report that they have begun to take on additional roles and responsibilities that they had not previously encountered. Klassen (2011) also investigated this phenomenon in grade school and secondary school teachers. Despite the change in grade level, overall stress, stress from workload, and stress from students were negatively related to job satisfaction. Brewer and McMahan-Landers (2003) also investigated the relationship between occupational stress and job satisfaction in special education teachers. The focus of their study was the difference in the stress experienced when the stressor was a frequently experienced stressor versus an intense stressor experienced at one time. Brewer and McMahanLanders found there was a stronger relationship between the frequency of the stressor and job satisfaction than the intensity of the stressor and job satisfaction, which indicates that stressors over time have a stronger impact on satisfaction than just one stressful event. Repeated exposure to negative clients or negative environments can lead to the deterioration of satisfaction.

Role overload has been cited as one of the major sources of stress in populations such as the Association of Women's Health, Obstetric, and Neonatal nurses (Kath, Stichler, Erhart, \& Schultze, 2012), sexual and substance abuse counselors (Wallace, Lee, \& Lee, 2010), and for workers in the U.S. (Kuchinke, Cornachione, Oh, \& Kang, 2010). However, role overload is not always cited as a source of stress and (e.g., Hauge et al., 2010; Idris, O’Driscoll, \& Anderson, 2011) indicating that other stressors may explain the variance in stress (Barhem, 2008) and again focusing on the individual components of stress. 


\section{Role Ambiguity}

Role ambiguity results when an employee does not understand or lacks understanding of their job's requirements, performance expectation or critical aspects of the job (Chen, Mao, \& Hsieh, 2012). Role ambiguity often results in lowered work performance and other employment outcome (Chen et al., 2012). Chen et al. 's(2012) study of hotel employees found that younger employees $(r=-.38, p<.05)$, those with higher education $(r=.25, p<.05)$, and those who had not been at the organization long $(r$ $=-.24, p<.05)$ experienced significantly more role ambiguity as they were unclear of their position in the organization. In a longitudinal study of Malaysian academic employees, the correlation between role ambiguity and strain measured in both times $(r=$ $0.46, r=0.33)$. This same finding was echoed in substance abuse and sexual abuse counselors (Wallace et al., 2010), the Association of Women's Health, Obstetric, and Neonatal nurses (Kath et al., 2012), and global managers (Barhem, 2008).

Often times, role ambiguity, role conflict, and roles overload are examined in the same study. In a study of Norwegian Central employees, job demands showed a weaker correlation with the job satisfaction (Hauge et al., 2010). When examining job satisfaction, role ambiguity $(\beta=-0.18)$ and role conflict $(\beta=-0.18)$, coupled with decision making authority explained $31 \%$ of the variance in job satisfaction, but job demands did not add incremental variance. Within Hauge's same study role conflict ( $\beta$ $=.017)$ and role ambiguity $(\beta=0.15)$ explained $13 \%$ of the variance in stress but job demands did not add any incremental variance, which indicates that employees feel more uncomfortable overloaded than in ambiguous situations. 


\section{Work-Family Conflict}

Role conflict occurs when employees have competing demands for their time and energy (Idris et al., 2011, Ivancevich \& Matteson, 1980) and is often investigated in regards to the impact it has on the family (work-family conflict). Work-family conflict is a form of role conflict when the demands of work and family are incompatible and competing for resources (Kahn et al., 1964; Higgins \& Duxbury, 1992). For instance, Yu, Lee, and Chuang (2010), found that role ambiguity had significant positive interference on work-family conflict as the confusion carried on to the home environment.

These problems are magnified when one has the technology at home to maintain long working hours (Duxbury, Higgins, \& Mills, 1992). Employers expect their employees to put in extra time and take jobs with no standard work schedule (Olsen \& Dahl, 2008; Presser, 2005). Duxbury et al. (1992) found that those who had work computers at home worked significantly more hours and more overtime than those who did not have capability to work at home. This negatively impacts one's personal and family time (Wallace et al., 2010). Olsen and Dahl (2010) found that irregular work hours resulted in greater distress and work-family conflict for both men and women. Moreover, if one has high work-family conflict at time one, they are more likely to exhibit work-family conflict at time two (Kinnunen, Feldt, Mauno, \& Rantanen, 2010). This is problematic due to the spillover one sees in both their personal and professional lives.

This effect was magnified in households were both parents work, which places numerous demands on their times (Duxbury et al., 1992). Women in such households 
reported they spent more time on childcare than their husbands and had significantly less personal time, as women take time away from their personal sphere in order to spend more time with their children. Their husbands also spent more time with their children at the expense of their personal time, but this was significantly lower than their wives.

\section{Sex Differences in Stress}

Furthermore, stress is experienced differently by sex. Women have consistently experienced higher occupational stress than men (e.g., Galankaskis, Anastasios, Helen, Catherine, \& Christine., 2009). Many women still believe they must work twice as hard as their male counterparts (Parker \& Griffin, 2002) and often feel that their contributions are dismissed in group meetings, which can lead to increased occupational stress (Maki, Moore, Grumberg, \& Greenberg, 2005). It is believed that women may be less effective at coping with stress or may be exposed to greater levels of stress, which leads them to experience higher occupational stress (Galankaskis et al., 2009). This is in contrast to a published meta-analysis of 15 studies conducted over 15 years earlier (Martoochio \& O'Leary, 1989) which found no differential experience of stress across the sexes. These inconsistent findings on sex differences in regards to occupational stress have led many to question the true nature of the stress relationship across sex, which hinders the advancement of the literature.

Regardless, women still have higher occupational stress even when demographic variables such as age, sex, and educational requirements are controlled (Galankaskis et $a l ., 2009)$ and experience greater work-family conflict than men (Bole, Wood \& Johnson, 2003). Congruently, Fotinatos and Cooper (2010) found women exhibited poorer mental 
and physical well being than men, even though their job satisfaction did not significantly differ. Females reported more stress from the organizational structure and relationships with people than men did (Fotinatos \& Cooper, 2010). Therefore, it is essential to note which stressors are causing such adverse effects on females due to their association with health consequences. A possible explanation for these contradictory findings about sex and occupational stress is the stronger relationship of gender roles to the variables of occupational stress and job satisfaction (Eichinger, 2000).

\section{Gender roles and occupational stress}

Research on stress has primarily paid attention to organizational and personal outcomes, but there is a research gap when it comes to gender roles (Jacobs, Tytherleigh, \& Cooper, 2010). Jacobs et al. (2010) investigated females working in more masculine roles and males working in more feminine roles. Jacobs et al. found statistically significant higher levels of stress were reported by women working in more masculine roles compared with those in more gender-congruent roles for five stressors. In contrast, men working in gender-incongruent roles reported significantly lower levels of stress than those in masculine jobs in regards to work-life balance and overload (Jacobs et al.). Conway (2000) also found workers with a higher degree of masculinity exhibited less stress and depression than workers with a higher degree of femininity (Wu \& Shih, 2010). In $\mathrm{Wu}$ and Shih's study of Taiwanese bank workers, workers who were more masculine reported significantly less stress than feminine bank workers. Therefore, it appears beneficial to display more masculine characteristics in the workplace as it is linked to a lower experience of stress. 
In the same token, Mori, Nakashima, Yamazaki, and Kurita (2002), compared males and females in regards to their sex role orientation and occupational stress in a study of Japanese workers both in the private sector and in national agencies. Women scored higher on femininity and also scored higher on stress outside of the workplace. Men with high job demands and stress outside the workplace and higher femininity were associated with a reduced quality of mental health. Women who scored high in femininity with stress outside the workplace had higher job stress. When females were unmarried, had high consciousness of being a woman, and had high masculinity, this also was related to a reduced quality of mental health. Furthermore, both men and women with high femininity reported greater family and workplace support. Married men also had higher masculinity, which may be due to societal pressure to behave a certain way. Therefore, it follows that femininity can sometimes be disadvantageous to workers and negatively impact well being along with job satisfaction.

\section{Gender Roles}

Though sex is biologically determined, gender role is socially determined and is the extent to which one portrays himself/herself with feminine or masculine characteristics $($ Bem,1974). Gender refers to the non-biological characteristics such as whether one displays: 1) non physiological characteristics appropriate for females and/or males, 2) traits that are culturally appropriate for males and/or females, and 3) labels for social categories such as feminine, masculine, undifferentiated, and androgynous (Bem, 1974; Borna \& White, 2003). As Korabik (Borna \& White, 2003) noted, prior to the 1940s, gender and sex were considered synonymous and a unidimensional construct. It was not until the 1940-60s that it was denoted as two-dimensional, and then from the turn 
of century till now, gender has been viewed as multidimensional. Borna and White noted that the terms 'sex' and 'gender' are still used interchangeably today in empirical literature, which can lead to greater confusion for researchers and can hinder the ability to find relevant articles.

In the past gender has been viewed as opposing sides of the continuum (Bem, 1993), with masculinity as the polar opposite to femininity. When sex and gender were separated out, the realization occurred that the sexes do not fit neatly into one side of the spectrum (Miller, Faulk, \& Huang, 2009). This prior conception that one could only be either masculine or feminine did not allow the valid hypothesis that someone having both high masculinity and femininity (known as androgyny). Androgynous individuals did not perform these same ritualistic behaviors and varied their behavior based on the situation and performed equally well at sex typed or non sex typed behaviors (Bem, 1975).

\section{Gender role differentiation}

These classifications are essential in organizations, as they describe how men and women differ and interact and lead to better predictions about how one act in certain settings (Nicholson, 1996). The masculine characteristics consist of agreeing with traits such as competitiveness and aggressiveness, whereas the feminine characteristics consist of traits such as empathy and nurturing. Androgyny is the idea that men and women can exhibit behaviors, attitudes, and roles from both the masculine and feminine subset (Bem, 1984; Spence \& Helmerich, 1981).

Masculine men and feminine females are more likely to engage in gender stereotypical activities, whereas undifferentiated and androgynous individuals are less 
likely to engage in stereotypical activities. Masculine males and feminine females are more likely to recognize traditional masculine and feminine characteristics, and this internalization results in sex typed behavior. Bem (1974) believed those who were androgynous were healthier and more effective in society than sex typed individuals (Spence, 1983, 1982). For instance, principals, teachers, and counselors who were androgynous experienced lower stress and higher job satisfaction (Schuttenberg, O'Dell, \& Kaczala, 1990), which was also found in a study of special educational teachers (Eichinger, Heifetz, \& Ingraham, 1991). Eichinger (2000) found in her study of special educators that androgynous women and men suffered less emotional exhaustion, depersonalization, and achieved higher personal accomplishment.

\section{Gender roles in the workplace.}

Today, females hold only $3.6 \%$ of CEO positions in Fortune 500 companies (Bosker, 2012). This may be partially explained by gendered organizations, where masculine skills are viewed as more valuable to the organization than feminine skills (Britton, 1997). This furthers the stereotype that women are not equal to men and minimizes their contribution to the workplace. Since the migration of females into the workplace, the idea of a "glass ceiling" has existed where the pure essence of being a female hindered career advancement (Hoobler, Wayne, \& Lemmon, 2009). Even in modern society, many female employees are still viewed as nonworking caregivers by some coworkers (Hoobler, 2007; Hoobler et al., 2009). This stereotype can result in increased stress and undermine women's chances of a promotion (Hoobler et al., 2009). Acker (1992) noted that organizations assign roles and responsibilities based on division of sex types that enhance this inequality. Females may become involved in sex-specific, non-essential 
positions and become "stuck in dead end jobs," which enhances the employees' strain in these situations (Acker, 1992). Furthermore, what happens when female workers display more masculine characteristics such as aggression and competiveness?

\section{Masculinity}

Masculinity, which is characterized as aggressiveness and competitiveness, is beneficial in organizations that cater to the individualist lifestyle. In spite of care giving stereotypes, when women hold executive jobs or are in higher organizational levels, they are often viewed as possessing more masculine characteristics. Ledet and Henley (2000) reported that women in higher organization positions were rated more masculine than men or women at lower organizational levels by undergraduates. Surprisingly, these same students rated women in higher organizational positions as possessing just as much masculinity as males at the same organizational level. Even so, Ledet and Henley (2000) found this differential only between high and low organizational positions, as the vice president was rated higher in masculinity than the shipping clerk. There was no significant difference found in the masculinity levels between the vice president and regional manager in the vignettes. The results of Ledet and Henley's study suggest that masculine females are not penalized at higher organizational levels for displaying nonstereotypical gender behaviors, but instead are rewarded for more masculine displays of behavior.

These same findings persist at the worker level of the organization. The Israeli high tech industry is a uniquely masculine environment where women are viewed as acceptable workers as long as they act like men with masculine characteristics, work long hours, and focus on team performance (Frenkel, 2008). Traditional feminine roles, such 
as caring for children, are incompatible with long working days, which may often last as long as 12 hours. The masculine women in this culture feel uncomfortable with staying at home to be the primary caregiver. Likewise, women perceived the work-family conflict between personal and organizational time to be a personal issue that should not affect or addressed by the organization (Frenkel, 2008). By the same token, women in more male-dominated firms felt the need to perform more masculine characteristics, and were rated less positively by others in the firms when they displayed more stereotypically feminine behaviors (Ely, 1995). These findings tend to suggest that women are still struggling to reconcile their feminine and masculine characteristics at work and wrestle with which identity to display in the organization.

Similar results were found in Rolston's (2010) qualitative study of female coal miners. Women reported they felt they needed to work harder and circumvent their femininity in order to be portrayed as "one of the guys," but still reported high job satisfaction. Balancing masculine and feminine characteristics is an ongoing struggle for female miners as female miners did not want to appear to be too masculine. In discussions with male coworkers, female miners tended to use less technical knowledge, sound more uncertain, and did not use as much declarative knowledge so they would not portray themselves as too masculine. In contrast, when females used more declarative knowledge and sounded as though they had expertise, females were more likely to be respected by their crews and treated as equal. This same struggle occurs in Afghan doctors (Schexneider, 2010), who shied away from attributing their success to feminine characteristics. Instead, they cited past instances of masculine traits, such as assertiveness, speaking up and competitiveness, which led to their success in the field 
(Schexneider, 2010). These same struggles were reported by female firefighters who reported that negative attitudes by male coworkers affected their job satisfaction and ability to change policy (Sinden et al., 2013). Therefore, females feel the need to revise their femininity to portray a more tempered type of masculinity in the workplace and portray more feminine characteristics outside of the workplace, which leads to an ongoing identity struggle for female miners, doctors, and IT workers alike.

Just as one's career can be classified as more masculine, the graduate school process can indoctrinate this attitude at early stages. For instance, Sallee (2011) found that the Aerospace and Mechanical Engineering department graduate school instilled masculine characteristics such as aggressiveness. The nature of conversations also differed when females were not around, and many male students felt that female students and female faculty were accepted just due to their biological characteristics and not necessarily their work quality. These results were mirrored in early stages of one's career, starting in graduate school. Female students reported that increased time in child rearing disqualified them from certain grant funding and coincided with a reduction in hours to part-time status where loans were not offered and a longer time spent working on their dissertation. This, along with increased feelings of isolation, can result in one's sense of loneliness and can result in attrition from the program (Lynch, 2008). Lynch's findings of the disadvantage of being female were confirmed by Sakamoto's (2006) study, where female spouses reported that, in many instances, the traditional caregiver role circumvented their career goals and caused varying levels of frustration. These studies provide evidence that even at higher levels of degree attainment that masculinity and femininity are often in conflict. 
Masculinity is seen as a benefit for women, but what happens when males display their masculinity. In certain industries, there are stereotypes that males must adhere to in order to advance. For instance, Pettersson (2006) found that for truck drivers, masculinity is embodied in the idea of being the provider or the father. The truck driver portrays himself as being responsible for both the family and business. Therefore, truck drivers prided themselves on fulfilling traditional male roles where they provided for the family. The men preferred to spend their working time as the stereotypical provider of the family, whereas those who were not as devoted to their work were viewed as more feminine, because it, "was the man's job to provide" (Pettersson, 2006). Norvilitis and Reid (2003) had similar findings in regards to masculinity. Norvilitis and Reid found executive functioning was related to masculine roles, where those who were more masculine were rated as having higher executive functioning. This finding was also mirrored by Grinnel (2002) where male leaders were rated higher in masculinity by participants. Therefore, those who are higher in the organization are consistently rated as possessing more masculine characteristics.

Dodson and Borders (2006) conducted a similar study looking at men in traditionally masculine jobs (i.e., engineers) and traditionally feminine jobs (i.e., counselors). Exhibition of sex typed characteristics seem to be of the utmost concern for men rather than females (Leung, 1988). Engineers focused on sex type characteristics, but did not differ in the low ratings they gave to the status of their chosen profession, whereas counselors were more concerned with that status others allotted their position. Engineers had higher anti-femininity scores and higher toughness scores than school counselors. By the same token, these anti-femininity and toughness had less than $10 \%$ of 
variance explained. Correspondingly, school counselors had higher job satisfaction than engineers with a moderate effect size (.53). For both engineers and school counselors, higher work-family conflict resulted in lower job satisfaction. However, masculinity was related to higher job satisfaction in Chinese workers as found in Ngo, Foley, Ji, and Loi (2014). This is echoed by Johnson et al. (2006), who found in their study of undergraduates that masculinity was also positively related to well-being and femininity was negatively related to well-being.

Irrespective of sex, those who worked in nontraditional field (females working in masculine jobs and men working in feminine jobs) were found to have statistically higher levels of stress than those in more gender traditional roles (Jacobs et al., 2010). Women, regardless of masculinity or femininity, had higher stress-related health problems, but women in more masculine roles reported higher levels of stress than other role groups (Jacobs et al., 2010) combined with difficult personal choices about their family life. Therefore, it appears that though displaying more masculinity may help advance females in the workplace, this can result in negative personal consequences for the females.

\section{Femininity.}

Though it may be beneficial for women to display masculine characteristics in their own careers, the same pattern of displaying femininity in nontraditional jobs for males is not always as beneficial (Cross \& Bagilhole, 2002). Cross and Bagihole's qualitative study found that men either distance themselves from their female coworkers or try to maintain masculinity in nontraditional roles such as nursing or teaching. In Great Britain, men and women still tend to work in different industries, but men who worked in nontraditional jobs reported some pressure from others to enter a more 
masculine field. The participants in this study reported that they felt they were different from other men, felt they were doing less manly work, and had their sexuality questioned due solely to their nontraditional career choice. Additionally, men in nontraditional jobs tried to keep a distance between their personal and professional identities and remarked that they had deliberately chosen their career path, whereas some women may have stumbled into their career. In these situations, men either proclaimed their female coworkers had more masculine characteristics, that they themselves had no feminine characteristics, or stated that the jobs required more traditional male masculinity. This is all done to maintain a high degree of masculinity despite their perception of their job as less than masculine.

As a matter of fact, Fisher (2011) found that some careers do require men to display more feminine characteristics. Fisher examined the masculinity and femininity displayed in male and female nurses and male engineers. Though male nurses scored lower than female nurses on femininity, they still scored higher on femininity than male engineers. More male nurses were classified as androgynous or feminine than masculine, yet this does not appear to negatively affect their job satisfaction. Rochlen, Good, and Carver (2009) also found that men in nontraditional jobs tend to report similar job satisfaction and social support of men in more traditional fields. It appears that the addition of feminine characteristics was seen as beneficial to these males in the workplace, which is contradictory to the previous findings.

Indeed males may also forgo traditional gender roles to increase their job satisfaction (Warde, 2009). Though some of the men reported having fallen into nontraditional work, such as counseling and teaching, when other opportunities were not 
available, they reported higher job satisfaction and felt they made a difference in their community. One participant reported he needed things such as empathy and compassion to succeed in the field, and some of the men who started with him did not feel they had the skills to succeed and did not stay in the career. Participants did not feel they had to sacrifice their masculine identity in order to fulfill their professional role, nor did male social workers report problems interacting in a sensitive or caring manner. Similarly, Wallen, Mor, and Devine (2014) found that when gender identity and professional identity overlapped this increased job satisfaction and reduced intent to quit in male nurses.

In male-dominated firms, feminine traits were rated less positively in regards to promotional chances by male coworkers (Ely, 1995). Female employees reported feminine traits were less favorable and did not feel their firms valued feminine traits, such as nurturing and empathy (Ely, 1995). Yet, in some industries, being female could be seen as a benefit. In regards to customer service positions, females were preferred over male workers, but females still were rated higher when they were in more masculine positions in comparison to the males in more feminine roles (Mohr \& Henson, 1996). Conversely, experiment two within this same paper found the opposite effect where people penalized females in traditional male roles (Mohr \& Henson, 1996). For instance, in traditionally feminine careers, such as special education feminine gender roles are often applauded and suffer less burnout (Eichinger, 2000). Therefore, the gender role preference may vary based on the work environment, as in more blue collar organizations it may be more beneficial to show more masculine characteristics, whereas feminine characteristics may be more prevalent in the nursing field. 
Eddleston, Veiga, and Powell (2006) also investigated managerial preferences for emotion-based or status-based facets of job satisfaction to determine if these factors differed by gender role or sex. Eddeslton et al. (2006) investigated femininity and masculinity schemas that were based on Bem's sex role inventory. Those managers who scored higher on the femininity subscale placed more importance on emotionally based aspects of the job such as work relationships and support, and those feminine characteristics were negatively related to satisfaction. Therefore, feminine characteristics displayed by females may put one at a disadvantage when trying to climb the organizational ladder.

\section{Summary}

Please see Table 1 for pertinent studies. Though companies often strive to increase satisfaction to reduce turnover, the organization may not focus on the correct component to increase job satisfaction for all employees. Many organizations and employees believe that increased compensation is the antidote for employment maladies (e.g., Jawahar \& Stone, 2011), but there is only a moderate relationship between pay and satisfaction (e.g., Piccolo \& Judge, 2011). Similarly, a promotion only temporarily increases satisfaction. Despite this, an ineffective boss (Longo, 2010; Ryan, 2010) and lack of promotional opportunities (Johnston \& Lee, 2013; Kim, 2012) are commonly cited sources of dissatisfaction and attrition across populations. Research on satisfaction and sex differences is contradictory, as some studies have found women have more satisfaction (e.g., Kim, 2005) whereas other studies found men had higher satisfaction (e.g., Price \& Wulff, 2005; Weaver, 1974). In contrast, some studies have found no differences in sexes across job satisfaction (e.g., Moore, 2009). 
Less controversial is the well established link between stress and satisfaction. Decades of research across various demographics and occupations has illustrated this linkage (Brewer \& McMahan-Landers, 2003; Cotton, Dollard, \& de Jonge, 2002; Lu, Shiau, \& Cooper, 1997; Walsh et al., 2010). The influence of the stress experience on the sexes is inconsistent; some studies have found women experience more stress (e.g., Maki et al., 2005; Michael et al., 2009), and other researchers have found no established relationship (Martocchio \& O’Leary, 1989).

This could be potentially explained through one's gender role, which impacts job opportunities and promotional opportunities (Eichinger, 2000). Moreover, those who display non sex typed roles may experience greater satisfaction (e.g., Warde, 2009), but tend to suffer increased occupational stress from such behavior (Jacobs et al., 2010), resulting in vast internal conflict for employees (e.g., Schexneider, 2010).

The inconsistent findings on the main variables (occupational stress, job satisfaction, gender roles, and sex) of this dissertation have been investigated in college students (Schexneider, 2010) and professionals (Eddleston, Powell, \& Powell, 2006) alike, but rarely examined in graduate students in the U.S. as far this researcher can tell. This research strives to fill the apparent gap in the literature by examining the relationship amongst these variables in U.S. graduate students of both sexes and determining the impact on sex compared to gender roles. 
Table 1:

Summary of relevant research

\begin{tabular}{|c|c|c|c|}
\hline Researchers & Year & Variables & Results \\
\hline $\begin{array}{l}\text { Brewer \& McMahan- } \\
\text { Landers }\end{array}$ & 2003 & $\begin{array}{l}\text { Occupational Stress } \\
\text { Job Satisfaction }\end{array}$ & $\begin{array}{l}\text { The frequency of stressor had } \\
\text { significantly stronger effects on job } \\
\text { satisfaction than intense infrequent } \\
\text { stressors }\end{array}$ \\
\hline Campbell \& Campbell & 2003 & $\begin{array}{l}\text { Job Satisfaction } \\
\text { Sex }\end{array}$ & $\begin{array}{l}\text { Though global measures of job } \\
\text { satisfaction did not show } \\
\text { differences across sexes, the usage } \\
\text { of facet measures allowed these } \\
\text { significant differences to emerge }\end{array}$ \\
\hline Mori et al. & 2002 & $\begin{array}{l}\text { Sex } \\
\text { Gender Role } \\
\text { Stress }\end{array}$ & $\begin{array}{l}\text { Females reported significantly } \\
\text { higher occupational stress as did } \\
\text { those who scored higher in } \\
\text { femininity }\end{array}$ \\
\hline Jacobs et al. & 2010 & $\begin{array}{l}\text { Sex } \\
\text { Gender role } \\
\text { Occupational Stress }\end{array}$ & $\begin{array}{l}\text { Females working in more } \\
\text { masculine roles reported } \\
\text { significantly higher levels of stress }\end{array}$ \\
\hline Ely & 1995 & $\begin{array}{l}\text { Sex } \\
\text { Gender Role }\end{array}$ & $\begin{array}{l}\text { Women in more male-dominated } \\
\text { firms felt the need to perform more } \\
\text { masculine characteristics, and were } \\
\text { rated less positively when they } \\
\text { displayed more stereotypically } \\
\text { feminine behaviors }\end{array}$ \\
\hline Sallee & 2005 & $\begin{array}{l}\text { Gender role } \\
\text { Graduate Students }\end{array}$ & $\begin{array}{l}\text { Graduate students reported a more } \\
\text { masculine culture, where females } \\
\text { admittance was seen as a result of } \\
\text { biological characteristics and not } \\
\text { quality }\end{array}$ \\
\hline Schexneider & 2010 & $\begin{array}{l}\text { Gender Role } \\
\text { Sex }\end{array}$ & $\begin{array}{l}\text { Female Afghan doctors refused to } \\
\text { acknowledge feminine } \\
\text { characteristics and attributed } \\
\text { success to masculine } \\
\text { characteristics }\end{array}$ \\
\hline Smith et al. & 2009 & $\begin{array}{l}\text { Graduate Students } \\
\text { Occupational stress }\end{array}$ & $\begin{array}{l}\text { Graduate students reported feeling } \\
\text { overwhelmed due to competing } \\
\text { realms of personal, occupational, } \\
\text { and academic realms }\end{array}$ \\
\hline
\end{tabular}




\section{Research Questions}

\section{Question 1:}

(a) Does sex significantly predict occupational stress?

(b) Does gender role significantly predict occupational stress?

(c) Does the gender role and sex interaction account for a significant amount of variability in occupation stress over and above that accounted for sex and gender role?

Question 2:

(a) Does sex significantly predict job satisfaction?

(b) Does gender role significantly predict job satisfaction?

(c) Does gender role and sex interaction account for a significant amount of variability in job satisfaction over and above that accounted for sex and gender role?

Question 3:

Does gender role relate to differential results for job satisfaction and occupational stress?

Question 4:

Does degree type lead to differences in job satisfaction and occupational stress?

Question 5:

What are the major stressors that graduate students part-time workers face? 
Question 6:

What are the factor structures of the following instruments?
(a) JDI
(b) BSRI
(c) PSS-10 


\section{CHAPTER III}

\section{METHOD}

This chapter discusses the procedure, measures, and data analysis utilized to answer the overall research question investigating the relationship of occupational stress, job satisfaction, sex, and gender roles in graduate students and to determine the relationships amongst the variables.

\section{Research Design}

One of the most effective and useful methods for collecting data on people's behaviors and attitudes for over 80 years has been the survey methodology (Dillman, Smyth, \& Christian, 2009), and the advent of the technological age has increasingly made this methodology a passive and over utilized method of collecting data escalated by technology. However, web surveying has multiple advantages such as reduction in errors from manual data entry and reduction in costs. This benefit was coupled with the disadvantage of limited access to subsets of the population who do not have the ability or the technology to complete a web survey. There is also no comprehensive list of internet users to randomly select from (Dillman et al., 2009).

The survey design method was utilized in this dissertation as the graduate student part-time workers were generalized to the bigger population of graduate student part-time workers. Moreover, the data was gathered from series of questions (Dillman et al., 2009). To enhance the effectiveness of this survey design, the tailored survey design method was 
utilized. The tailored survey design method "involves using multiple motivational features in compatible and mutually supportive ways to encourage high quantity and quality of response to the surveyor's response" (Dillman et al., 2009, 16). Underlying this tailored design method are three major assumptions: (1) a scientific method to conducting sample surveys to reduce common survey errors, such as coverage, sampling, nonresponse, and measurement errors, (2) procedures to interact and work together to encourage all potential members of the sample to respond to the survey, and (3) procedures that build a positive social exchange and encourage response through components such as sponsorship, the population, and survey questions (Dillman et al., 2009).

There are four potential errors that can result when utilizing the survey methodology. Coverage error results when not all members of the population have the opportunity for taking part in the survey and those who are excluded from such surveys have differential characteristics than those who took the survey (Dillman et al., 2009). As all graduate students are issued a university domain email address and the researcher utilized the email addresses to reach out to potential participants, the researcher perceives the chance of this error to be minimal. The second error that can result is sampling error, where not every person in the population has the opportunity to be sampled. The researcher recognizes that this is a possibility as she utilized purposeful and snowballing sampling, discussed later in this chapter. The third recognized error is non-response error, where those who answer the survey are different from those who do not respond (Dillman et al., 2009). There are several potential valid reasons for lack of response: the students may not regularly check their university provided email, may have considerable time 
constraints when asked to participate, and may not feel strongly enough about the material. The last potential error is measurement error, which is the result of poor questioning, design, or survey construction (Dillman et al., 2009). The researcher believes that this risk was minimized due to the use of preexisting measures with adequate reliability and validity.

The survey design method can be viewed as a social exchange, where individuals actions are motivated by the returns they expect to gain from others (Blau, 1964; Dillman et al., 2009). The application of the idea of social exchange to the survey methodology is a subtle way to increase participation as the perceived rewards of completing the survey are often considered minimal. There are several ways to increase the number of participants such as: increasing the perceived rewards for responding, reducing the perceived costs of responding, and establishing trust, where individuals believe the rewards will outweigh the costs of responding (Dillman et al., 2009). The researcher utilized the majority of Dillman et al.'s (2009) suggestions to increase the benefits of participating in the survey. These suggestions were: provide information about the survey, ask for help or advice, show positive regard, say thank you, support group values, give tangible rewards, make the questionnaire interesting, provide social validation, and stress the limited opportunity to participant. Before entering the online survey tool, the researcher provided information about the survey in order to inform participants on how the survey could potentially benefit them and why it is important. The researcher also explained in the cover letter that the answers in the survey could potentially help current and future graduate students by making the experience more positive, and provided her contact information in case of questions or if anyone wanted to know the results. The 
tangible reward option was incorporated by allowing the individual the opportunity to enter a raffle to win one of two $\$ 50$ gift cards.

\section{Procedures and Participants}

\section{Participants}

The participants for this study consisted of graduate students currently enrolled in a graduate program and working at least 10 hours a week as an assistant, intern, or external employment. Working hours were determined based on the requirements for most university-sponsored assistantships. Participants were recruited primarily from two southeastern states and the surrounding areas. This area was chosen due to the researcher's previous connections with the universities. Of the five schools chosen, three are classified as private or religious based and two are public universities.

This study utilized purposeful sampling in order to gain access to the graduate student part-time workers sample. Purposive or convenience sampling is where the researcher selects a sample because it is feasible and relatively representative of the population they desire to study (Harris, 1995; Nolan \& Heinzen, 2012). Additionally, snowball sampling was utilized. Snowball sampling is where participants were asked to share the link on their own social media sites or to forward it to other individuals they know who meet the survey requirements to complete the instruments. Moreover, the researcher posted the survey on several school associated Facebook sites after the participants were initially recruited on the various school sponsored listservs. These steps were all taken to elicit more participation. 


\section{Sampling.}

To achieve adequate statistical power, Stevens (2002) suggested at least 15 participants per predictor variable. Gender roles, masculinity, occupation, and femininity were all utilized as predictor variables, which results in the need for at least 150 participants to achieve a respectable level of statistical power. According to Cohen, multiple regression with six predictors and medium effect size would require 102 participants, whereas ANOVA would require 215 participants with six predictors and small effects. As factor analysis was also conducted, it is recommended to have at least 200 participants (Whitley, 2001), which resulted in a minimum sample size of 200. This was exceeded with the 236 participants.

\section{Procedure}

The initial contact to the participant came from a faculty member or current graduate student at each of the schools. This followed Dillman's design method (2009), and provided the official sponsorship or authority from the university. The faculty member or current graduate student forwarded the customized email to the school's listserv and asked them to complete the instrument. If the faculty member or staff member were content with the researcher directly contacting the students than this third part contact was not utilized. Additionally, the researcher asked the faculty or current graduate student to publicize this on the school's social media sites. Additionally, the students were encouraged to repost this information on their social media sites and forward it to others who meet the participation requirements.

Participants had the unique surveymonkey link provided to them in the email. 
Upon clicking the link, participants were taken directly to the informed consent tab and to the survey. The components included in this unique survey tool are the: (a) informed consent, (b) qualifying questions, (c) Perceived Stress Scale (PSS-10), (d) Job Descriptive Index (JDI), (e) Bem Sex Role Inventory (BSRI), (f) qualitative stress measure, and (g) demographics.

The participants first encountered the informed consent page. Those who did not click "I agree" signifying their consent were not allowed to continue further in the questionnaire. Next, the participants encountered two qualifying questions to ensure that these individuals resided in the desired states and met the participation requirements. The participants were asked "Which state do you reside in?" with the choice of Kentucky, Ohio, and other. The second qualifying question "How many hours a week on average do you work?" provided the option of less than ten hours a week or 10 or more hours a week. Students who did not pick the southeastern states or who worked less than 10 hours a week, were thanked for their time and excluded from the study. Once these questions were answered, the participants entered the actual data collection component the study.

The survey components of the PSS-10, JDI, BSRI, and qualitative components were counterbalanced in order to prevent any ordering events (Nolan \& Heinz, 2012). Ordering effects are where answers from previous questions affect one's answers to the later questions. For instance, by always asking about their qualitative stressors and then their overall stressors, this may lead to inflated stress scores. Similarly, if participants are always asked about stress and then job satisfaction, this may bias the results. The utilization of counterbalancing, where the presentation of the instruments are alternated, 
prevented this order effect from occurring (Nolan \& Heinz, 2012). Though the quantitative components are required for survey participation, the qualitative component was optional. The questionnaire took no more than 15-20 minutes to complete.

At the end of the survey, the participants were asked several demographics such as age, race, and degree type. The last question of the survey asked participants where they learned of the study and allowed them the option of providing their email address to win the raffle of one of two $\$ 50$ gift cards. To encourage participants to share this information to their own networks, the participants were encouraged to tell those in their own network to indicate the aforementioned participant's email address in the question of where they heard of the study. The email address was entered into the raffle so the aforementioned person had multiple chances of winning the raffle. The information provided for the raffle was kept separate from the main database to protect confidentiality and destroyed once the raffle drawing took place.

Due to the usage of social media sites, graduate students who met the requirements and resided within this geographical base were also included in the analysis, even if they did not attend one of the five schools. In these instances, these participants were likely alumni of one of the five schools who were seeking a higher degree elsewhere in the region or a friend of a student currently in the geographical region. Participants who did not meet these previous qualifications or had incomplete responses were discarded from the study. All participants were notified that their responses were confidential and used solely for academic purposes. The instruments had no identifying information. Those who initiated and did not complete the survey were tallied to determine if any response bias exists. 
The researcher followed a modified Dillman method (2009). After two weeks, the researcher sent out a reminder email and then another email in weeks after that. Due to the multiple methods of reaching out to the participants, there is a chance that someone may have completed the instruments more than once. In order to prevent this, the researcher verified no email addresses were duplicated, and the answers were not identical. If any duplicates had emerged, these would have been removed from the dataset to prevent bias. Once the desired participation was achieved, the researcher notified the raffle winners.

\section{Measures}

\section{Demographics}

Graduate students were asked their sex, year in school, ethnicity, race, marital status, number of children in household, income level, type of program, year in program, and the degree they are pursuing. This was included to determine if there are differences in stress or satisfaction based on these variables.

\section{Job satisfaction}

Job satisfaction was measured utilizing the Job Descriptive Index (JDI; Smith, Kendall, \& Hulin, 1969), which is the most popular measure of job satisfaction and has the most research associated with it (Balzer et al., 1997; Kinicki, McKee-Ryan, Schriesheim, \& Carson, 2002; Rain, Laine, \& Steiner, 1991). This cognitive measure of job satisfaction assessed how satisfied the participant was with every component of their job and allowed them to examine each area of their job individually. The JDI consists of 72 items and measures satisfaction as it pertains to five facets of work: the work itself, 
pay, opportunity for promotions, supervision, and co-workers. Participants were asked to indicate their satisfaction to each item with a "Y" (yes), "N" (no) or "?" (unsure/not applicable). Two subscales contains 9 items (pay and promotion) and three subscales contain 18 questions each (work itself, supervision, and coworkers). The five facets of the JDI served as the dependent variables in MANOVA.

\section{Reliability.}

Average reliability estimates for the JDI based on a meta-analysis are .86 (pay), .87 (promotions), .92 (coworkers), .90 (work itself) and .91 (supervision; Balzer et al., 1997; Kinicki et al., 2002). Additionally, reliability estimates from the 1997 revision based on 1600 participants resulted in acceptable reliability from Cronbach's coefficient alpha from .86 to .91 . Prior research conducted with the same instrument by the researcher resulted in acceptable Cronbach's coefficient alpha levels: .85 (pay), .83 (promotions), .82 (coworkers), .85 (work itself), and .88 (supervision; Church, 2007). Though internal consistency reliabilities of greater than .90 are highly preferred (e.g., DeVellis, 2002; Henson, 2001), Cronbach's coefficient alpha's in the $.70-.80$ ranges are acceptable and .80 to .90 are considered good levels of reliability (DeVellis, 2002). These Cronbach's coefficient alpha levels are good levels according to DeVellis.

\section{Validity.}

Kinicki et al.(2002) confirmed the existence of the five factor model and its divergent validity, which was further supported by past meta-analysis. Additionally, Smith et al. (2009) also cited support for the construct validity of the JDI. Moreover, Ironson et al. (1989) reported the JDI had divergent validity. In a study of Portuguese 
health professionals, the five factor model of the JDI was confirmed (McIntyre, McIntyre, \& Mendonca, 2010). There are also strong validity estimates as the JDI relates to other job satisfaction scales and measurements (Smith et al.). Validity was also confirmed with the single facet measure of job satisfaction listed below with correlations ranging from .60 (supervision) to pay (.72), with overall correlations of .66 (Nagy, 2005). Moreover, the average correlation with work stress across these five facets were -.25 (Kinnicki et al.) and coworker, work, and supervision satisfaction were positively related to poor health symptoms. Lastly, the JDI has positive correlations associated with life satisfaction (Kinicki et al.).

\section{Overall job satisfaction}

In addition, a global scale was used to assess overall job satisfaction. Participants were asked "Overall, how satisfied are you with your job?" This item was measured on a seven point Likert-type scale from 1 (Very Dissatisfied) to 7 (Very Satisfied). Past research (e.g., Nagy, 2005) has demonstrated a single question measure of global satisfaction has comparable reliability and validity compared to global job satisfaction measures with more questions. Single global job satisfaction measures correlate quite high $(r=.67)$, with measures of overall job satisfaction (Nagy, 2005).

\section{Occupational stress}

Occupational stress was measured with a self-report 10 item Perceived Stress Scale (PSS; Cohen, Kamarck, \& Mermelstein, 1983). The PSS measures participants' perceived global stress over the previous month to determine which situations in their lives are perceived as stressful. This measure was developed to take into account the 
perception of stress, and assess personal and contextual factors as well as the intensity of stress (Cohen et al., 1983). The PSS accounts for unpredictable events, uncontrollable events, and overloading, which are commonly recognized sources of stress. The PSS was designed for use with the general population with at least a junior high school education (Cohen et al., 1983). Additionally, half the items on the measure are reversed coded, and the instrument is measured on a five point Likert-type scale ranging from 0 (Never) to 4 (Very Often). The PSS provides an overall stress scale and two subscales of perceived helplessness (items 1, 2, 3, 6, 9, 10) and perceived self efficacy $(4,5,7,8$; Hewit, Flett, \& Mosher, 1992; Roberti, Harrington, \& Storch, 2006).

\section{Validity.}

The original PSS's concurrent and predictive validity was assessed with the relationship between life event and perceived stress (Cohen et al., 1983). The results indicated in the three groups: college sample 1 recruited from dormitories, college sample 2 recruited from Introductory Psychology classes, and smoking cessation groups (college student sample 1 in dormitories and college student sample), indicated there were moderate correlations with the PSS and life events.

Factor analysis revealed that the PSS-10 consisted of two factors: the first was adapting symptoms and the second was coping ability in a study of adolescent psychological inpatient (Hewitt, Flett, \& Mosher, 1992), which are now referred to as perceived helplessness and perceived self efficacy (Robert et al., 2006: Örücü \& Demir 2009). Martin, Kazarian, and Breiter (1995) reiterated this two factor structure. This two factor structure was supported in a study of Thai population (Wongpakaran \& 
Wongpakaran, 2009) and in university students (Örücü \& Demir 2009). In policewomen it accounted for $62.41 \%$ of the variance though the subscales were named differently (Wang et al., 2011). Construct validity was confirmed as it was associated with greater health-seeking, poorer health, and less life satisfaction (Cohen \& Williamson, 1988). Lastly, there were positive correlations with Beck's Depression inventory (Wang et al., 2011).

\section{Reliability.}

Though a 14 item measure exists, Cohen and Williamson (1988) recommend the superior ten item measure due to its superior reliability and validity (Örücü \& Demir, 2009). The PSS-14 resulted in Cronbach's alpha coefficient of .75, with $41.6 \%$ of variance explained, whereas the PSS-10 results in $48.9 \%$ variance explained and alpha coefficient of .78. The PSS-10 appears to be as good as or better measure stress than the PSS-14. This reliability is consistent internationally in Turkish students (.84; Örücü \& Demir, 2009), in Thai population (.85; Wongpakaran \& Wongpakaran, 2010), and in police women (.86; Wang et al., 2011). In the PSS-10, the overall Cronbach's coefficient alpha for the overall subscale was .84 (Örücü \& Demir, 2009). The subscales of the PSS10 were comparable and sufficient for perceived helplessness (.83) and perceived selfefficacy (.71) factors resulted in acceptable reliability (Örücü \& Demir, 2009). The results of Örücü and Demir indicate that the PSS-10 has high reliability and validity in university students. Similarly, Wang et al. (2011) found respectable levels of reliability of Cronbach's alpha for the whole scale (.86), and the subscales (.86 and .87; Wang et al.). 


\section{What are your main stressors?}

As this study examined graduate students who are also in the workplace, it also contained a qualitative component to investigate the formulation of greater differentiation among stress categories. The graduate students were asked in an open ended question, "What are the three main stressors in your life?." Miles and Huberman's (1994) rationale is when the concept has been previously defined, such as occupational stress, a tight wellstructured instrument is a logical choice. Structural coding (Saldana, 2009), which is appropriate for open-ended survey responses will be employed. This component is utilized to determine if school or employment leads to higher stress, so these stressors can be reduced and possibly mitigate graduate school attrition in the future. The stressors were originally classified into school, work, and personal stressors. "Work" was defined as any complaints related to an assistantship, job or internship, whereas "school" was related to the complaints regarding papers, tests and assignments. "Personal life" consisted of comments regarding activities of free time and relationships. Once the data was sorted into these categories, these were further differentiated into subcodes to extract more differentiation among the overall stressor categories.

Qualitative factors are beneficial as they add much needed depth to stress studies, but are more difficult to test (e.g., Grebner, Elfering, Semmer, Kaiser-Probst, \& Schlapbach, 2004; Mazzola, Schonfeld, \& Spector, 2011). However, this difficulty has resulted in the underutilization of qualitative methods and rarely reviewed findings (Mazzola et al., 2011; Noblet \& Gifford, 2002). Mazzola et al. (2011) emphasized the need for greater utilization of qualitative measures of occupational stress as the qualitative measures add rich detail on the actual stressors of the experience whereas the 
quantitative method just tabulates one's stress levels and allows the identification of stressors (Mazzola et al.; Schonfeld \& Farrell, 2010).

\section{Bem Sex Role Inventory (BSRI)}

The short form of the BSRI was completed by the participants to assess their gender roles, and consists of two subscales: Masculinity and Femininity. The Masculinity subscale is composed of 10 items that are typically viewed as more desirable for a man, such as independent, competitive, and aggressive. The Femininity subscale is composed of 10 characteristics typically viewed as more feminine, such as compassionate and sympathetic (Choi et al., 2011). The other 10 items once composed a Social Desirability subscale, but after Pedhazur and Tetenbaum's (1997) review, these items are now viewed as strictly filler items (Choi et al., 2011). Participants are divided into four categorizations (androgynous, feminine, masculine, and undifferentiated) through a median split of the two scores of masculinity and femininity (Carpenter, 2011). Furthermore, the factor structure has been contested since its creation.

\section{Factor Structure of the BSRI.}

The BSRI was composed under the theoretical orientation and objective to capture the two universally acceptable categories of appropriate behavior for each sex as

understood by society and the degree to which individuals incorporate or internalize these characteristics (Bem, 1979). In order to determine socially acceptable characteristics for a male or female, Bem initially had independent judges rate 200 traits as culturally desirable or undesirable for either the masculine or feminine subtype (Bem, 1979). These independent judges only rated one sex in order to prevent contamination of the scales 
through preconceived bias based on their earlier ratings. By participants indicating on the early editions of the BSRI, which characteristics best describe themselves on the masculine, feminine, or social desirability subscales, one would be able to determine whether the individual adhered to the preconceived notions of masculinity or femininity, was androgynous, or undifferentiated (Bem, 1974). The social desirability subscale's conceptualization was altered after Pedhauzer and Tetenbaum's (1974) scathing review that the subscale failed to maintain its structure in repeated factor analysis, and is now viewed and labeled strictly as filler material (Bem, 1979).

Initially, researchers continued to test the hypothesis of participants scoring high on solely the masculinity or femininity subscales (Bem, 1974). This prior conception that one could only be either masculine or feminine was troublesome, as it did not allow the valid hypothesis of someone being high on both the masculinity and femininity subscales and low on both subscales. This also did not allow for the plausible hypothesis that males could be feminine and females could be masculine. The latter would indicate that one would be motivated to diminish or abstain from nontraditional sex typed behaviors in order to ensure they fit with the culturally acceptable gender stereotypes (Bem, 1974). One way to categorize people into gender roles are through a two-way specification based on two scores (masculinity and femininity), which would yield four groups: masculine, feminine, androgynous, and undifferentiated (Bem, 1974). According to Bem, to be classified as masculine, one scores high on the masculinity subscale and low on femininity subscale; whereas the feminine classification suggests a high score on the femininity subscale and a low score in masculinity (Bem, 1974). By the same token, those classified as undifferentiated score low on both the femininity and masculinity 
subscale, whereas the androgynous score high on both subscales.

Despite the consensus on sex role classification, the foundational dimensions of Bem's Sex Role Inventory (BSRI) have been contested by researchers for decades, even after the resolution of the social desirability subscale. The BSRI was originally thought to consist of a two factor subscale of masculinity and femininity developed to represent Bem's orgthogonal representation of gender (Bem, 1974). Thirty years later, Choi and Fuqua (2003) found that researchers varied in the number of factors retained after analysis, indicating an acceptance of between two to four factors. Choi et al. (2009) expanded upon that discrepancy, noting that up to 11 factors have been reported. Thus, the four original subtypes may not be accurately representing the combination of Masculinity and Femininity. Though the Feminine subscale is relatively one-dimensional, Masculinity results in two subscales: a more instrumental factor (known as Power or Assertive) and an autonomy factor (known as Social Control; Choi et al., 2008). Past research has indicated that three factors typically underlie this measurement: a Femininity factor, Personal Masculinity, and Social Masculinity (Choi et al., 2008). Despite the discrepancy of the subscales of masculinity, gender roles still lead to differential experiences of the working environment.

As this scale was created prior to the infiltration of women in the workplace, one may question whether this scale still maintains its factor structure today? Spence and Buckner (2000) investigated this hypothesis and potential gender effects at the turn of the century. Spence and Bucker found that although women scored higher on all expressive traits besides the trait of loyal, the instrumentality scale revealed fewer significant differences. Though males and females tended to score higher on their respective gender 
subscales, even decades after the scale's creation, the gap between men and women is decreasing on the instrumentality scale (Spence \& Buckner, 2000). However, even though the sex gap is decreasing on the instrumentality scale, its validity has been maintained and still differentiates gender roles. Moreover, Choi et al. (2009) found that though females are still scoring lower on personal masculinity subscale the gap between males and females on social masculinity is decreasing.

\section{Table 2}

Summary of Variables, Research Questions, and Statistical Analysis

\begin{tabular}{|c|c|c|c|}
\hline Research Question & Independent Variable(s) & Dependent Variable(s) & Statistical Analysis \\
\hline $\begin{array}{c}1 \mathrm{a} \\
\mathrm{b} \\
\mathrm{c}\end{array}$ & $\begin{array}{l}\text { Sex } \\
\text { Gender role } \\
\text { Sex*Gender role }\end{array}$ & $\begin{array}{l}\text { Occupational stress } \\
\text { (overall stress score) }\end{array}$ & Hierarchical regression \\
\hline $\begin{array}{l}2 \mathrm{a} \\
\mathrm{b} \\
\mathrm{c}\end{array}$ & $\begin{array}{l}\text { Sex } \\
\text { Gender role } \\
\text { Sex } * \text { Gender role }\end{array}$ & $\begin{array}{l}\text { Job satisfaction (overall } \\
\text { satisfaction) }\end{array}$ & Hierarchical regression \\
\hline 3 & $\begin{array}{l}\text { Gender Role } \\
\text { (androgynous, } \\
\text { undifferentiated, } \\
\text { masculine, feminine) }\end{array}$ & $\begin{array}{l}\text { Job Satisfaction (work } \\
\text { itself, supervision, } \\
\text { coworker, pay, and } \\
\text { promotions) } \\
\text { Occupational stress }\end{array}$ & $\begin{array}{l}\text { MANOVA, ANOVA, } \\
\text { follow-up Tukey } \\
\text { pairwise comparisons }\end{array}$ \\
\hline 4 & $\begin{array}{l}\text { Degree Type (Master's, } \\
\text { PhD/PsyD/EdD) }\end{array}$ & $\begin{array}{l}\text { Job Satisfaction (work } \\
\text { itself, supervision, } \\
\text { coworker, pay, and } \\
\text { promotions) } \\
\text { Occupational stress }\end{array}$ & $\begin{array}{l}\text { MANOVA, ANOVA, } \\
\text { follow-up Tukey } \\
\text { pairwise comparisons }\end{array}$ \\
\hline 5 & Main Stressors & $\begin{array}{l}\text { Work } \\
\text { Personal } \\
\text { School }\end{array}$ & $\begin{array}{l}\text { Content analysis } \\
\text { Deductive reasoning }\end{array}$ \\
\hline 6 & JDI, BSRI, and PSS-10 & & $\begin{array}{l}\text { Exploratory factor } \\
\text { analysis }\end{array}$ \\
\hline
\end{tabular}




\section{CHAPTER IV}

\section{RESULTS}

This chapter is divided into three major sections. The first quantitative section consists of: descriptive statistics, reliability analysis, and the correlations table. The second quantitative section contains the results of the first four and sixth research questions, which were tested with MANOVA, hierarchical regression, and exploratory factor analysis. The last section contains the qualitative results of the fifth research question, which was analyzed with deductive pattern matching and thematic analysis.

\section{Study Background}

The purpose of this dissertation was to address the research gap and investigate U.S. graduate students who maintain part-time employment of at least ten hours a week. The sample consisted of graduate students who attended one of four graduate schools in two southeastern states. The intended sample was for five graduate schools, but delays in the final school's IRB resulted in four schools being included. Three universities were private or a religiously affiliated and one was a public university. Once IRB approval had been granted at University of Louisville, the other universities processed it through their respective university IRBs. Once this additional IRB approval had been granted, the participants were reached out to in one of three ways: personal contact by the chair or

professor within the department (40\%), announcement through social media pages $(10 \%)$, 
or emailed directly from the Listserv provided to the researcher (50\%). Analysis of the data revealed no exact duplicates among the participants in this study. The social media pages utilized in this study were closed pages and only accessible to the cohort of the respective graduate schools. Only members of the current cohort were allowed to see posts on these pages and they were told that part-time employment was a prerequisite in this study. Those individuals who did not indicate part-time employment or enrollment in graduate school in one of these two states were excluded from the study.

Potential participants had to meet two criteria for the study: enrolled in graduate school in one of the two designated states and working between 10 - 32 hours per week. Graduate student part-time workers $(N=3129)$ were contacted directly by the researcher through one of these aforementioned methods and 334 participants clicked on the link (9.3\%). This low response rate is a known limitation of this study. Of the 334 participants, 236 participants were retained for this study. Ninety-eight participants were removed for the following reasons: did not consent to proceeding in the study $(n=1 ; 1 \%)$, not enrolled in graduate school in the two required states $(n=15 ; 15.3 \%)$, were full-time employees $(n=45 ; 45.9 \%)$, did not complete any instruments beyond the consent page ( $n$ $=23 ; 24 \%)$, and completed only one of the three scales $(n=14 ; 14.3 \%)$. To determine the percentages for the respective categories, the number of removed participants for each category was divided by the total number of participants removed $(n=98)$ to illustrate the main reasons for the participants' exclusion in this study. 


\section{Initial Statistical Analysis}

\section{Descriptive}

To ascertain the characteristics of the graduate student part-time worker, a multitude of demographics were collected in addition to the variables for the primary quantitative analysis. Age, income, graduate program, and occupation were entered in a free response text box by the participants, whereas race, year in the program, marital status, and number of children were chosen from preexisting categories in the survey. In the latter variables, an "other" category was provided for participants who did not perceive these predefined categories accurately described them. They were then provided the opportunity to indicate the appropriate classification. The demographics provided an in depth representation of the graduate student part-time worker composition in this study. Table 3 consists of the demographic information.

Age. The majority of the participants in this study (66.8\%) were in the $21-29$ age bracket while the oldest participant was 57 years old $(M=29.29, M d n=27, S D=7.43)$. Though age was entered freely by the participants, this variable was subdivided into several categories to provide a visual representation of the sample composition in Table 3 .

\section{Table 3.}

Race, age, marital status, occupation, and children frequencies

\begin{tabular}{lc}
\hline Demographic Category & Percentage \\
\hline Race $(n=225)$ & 80.9 \\
Caucasian & 6.4 \\
African American & 2.1 \\
Hispanic & \\
\hline
\end{tabular}




\begin{tabular}{|c|c|}
\hline Demographic Category & Percentage \\
\hline Asians & 4.2 \\
\hline Mixed/Biracial & 0.8 \\
\hline Middle Eastern & 0.8 \\
\hline Did not answer/ prefer not to answer & 4.7 \\
\hline \multicolumn{2}{|l|}{ Marital Status $(n=236)$} \\
\hline Single & 55.1 \\
\hline Divorced & 2.1 \\
\hline Married/ Domestic Partnership & 34.3 \\
\hline Engaged & 3.4 \\
\hline In relationship/partnership/cohabitating & 1.3 \\
\hline Did not answer/ prefer not to answer & 3.8 \\
\hline \multicolumn{2}{|l|}{ Number of Children $(n=218)$} \\
\hline Zero & 75.2 \\
\hline One & 11.5 \\
\hline Two & 8.3 \\
\hline Three & 3.2 \\
\hline Four & 0.9 \\
\hline Five & 0.9 \\
\hline \multicolumn{2}{|l|}{ Age } \\
\hline $20-29$ & 66.8 \\
\hline $30-39$ & 21.2 \\
\hline $40-49$ & 9.7 \\
\hline $50-59$ & 2.2 \\
\hline \multicolumn{2}{|l|}{ Occupation $(n=225)$} \\
\hline Business/ Professional & 7.6 \\
\hline Education & 12.3 \\
\hline Government/ Security & 1.7 \\
\hline Graduate Assistant (GA) & 18.6 \\
\hline Healthcare & 7.6 \\
\hline Intern & 5.9 \\
\hline
\end{tabular}




\begin{tabular}{lc}
\hline Demographic Category & Percentage \\
\hline Practicum/ Fellowship & 3.4 \\
Research Assistant (RA) & 8.9 \\
Retail/Customer Service & 11.4 \\
Science/ Engineering & 1.7 \\
Social Work/ Counseling & 8.1 \\
Teaching Assistant (TA) & 8.1 \\
\hline
\end{tabular}

Sex. Two hundred twenty-seven individuals answered this question. The majority of the sample $(75 \%)$ was composed of females $(n=171)$, followed by males $(n$ $=56)$, and those who left this question blank $(n=9)$. The disproportional sex representation in the sample and its potential impact on the results are elaborated on in the Discussion section. Table 4 lists the major variables differentiated by sex.

Table 4.

Descriptive statistics on major variables by sex

\begin{tabular}{ccccc}
\hline & \multicolumn{2}{c}{ Females } & \multicolumn{2}{c}{ Males } \\
& Mean & SD & Mean & SD \\
\hline Overall Job Satisfaction & 4.75 & 1.60 & 4.89 & 1.70 \\
Coworker & 40.20 & 10.28 & 37.89 & 11.88 \\
Promotions & 10.27 & 9.30 & 9.89 & 8.85 \\
Supervision & 42.54 & 12.51 & 40.29 & 13.34 \\
Compensation & 12.37 & 8.83 & 13.05 & 9.32 \\
Work itself & 38.40 & 13.52 & 37.59 & 15.85 \\
Overall Stress & 18.73 & 6.86 & 17.47 & 6.59 \\
\hline
\end{tabular}


Race. The majority of the sample were self reported Caucasians followed by African Americans as seen in Table 3. Multiple racial categorizations were provided by participants and were collapsed to protect the confidentiality of the sample.

Marital Status. The majority of the sample was single followed by married individuals. Though domestic partnerships, cohabitating, and engaged couples were also represented, these smaller categorizations were collapsed to protect the confidentiality of the participants. These smaller categorizations may have lacked sufficient power to determine key differences in occupational stress and job satisfaction across marital status.

Income. In this study, there was a wide spread of salaries $(n=108)$ from the smaller subset of the sample that answered this question. This is potentially due to the heterogeneous sample of married, widowed, divorced, and single individuals. The minimum salary was $\$ 600$ dollars whereas the highest salary was $\$ 200,000(M=37303$, $M d n=24000, S D=34535)$. There was one outlier that was removed as they listed the annual income of $\$ 900,000$. This amount was unable to be verified and was removed as a potential typographical error. This potential outlier was also more than $\$ 500,000$ more than the next participant did and significantly skewed the mean. These previously mentioned reasons justified its removal. This data is somewhat biased as the married individuals appeared to report their combined household income instead of their personal income and their incomes trended to the higher end of the income range. As this could not be verified, it was retained and a noted limitation in this study.

Number of children. As seen in Table 3, the majority of the sample reported no children or one child present in their house. This may be potentially due to the ages of 
the graduate student part-time worker and the majority of participants reporting a single marital status.

Degree. As seen in Table 5, the majority of the sample was composed of Master's or MBA students followed by $\mathrm{PhD}$ students. These degrees are representative of the schools composing the sample as they offer more Master's degrees than doctoral or other higher level degrees.

Occupation. Graduate students who seek part-time employment have a variety of options, both inside and outside, the academic world. One's occupation was collected to determine if there were differences in occupational stress or satisfaction between those who work within or outside the walls in which they study. As seen in Table 5, there was a wide variety of occupations represented, with the majority working in academia (GA, TA, and RA). These university based positions are not available for the part-time student, but are available for graduate students who are enrolled full-time. Occupation is examined in later analyses to determine if there are significant differences across occupational stress and job satisfaction.

Table 5.

Graduate school demographics

\begin{tabular}{lc}
\hline Demographic Category & Percentage \\
\hline Year in Program $(n=236,5.1 \%$ did not answer $)$ & 36.4 \\
$1^{\text {st }}$ Year & 29.7 \\
$2^{\text {nd }}$ Year & 9.3 \\
$3^{\text {rd }}$ Year & 9.3 \\
$4^{\text {th }}$ Year & \\
\hline
\end{tabular}




\begin{tabular}{|c|c|}
\hline Demographic Category & Percentage \\
\hline $5^{\text {th }}$ Year & 4.7 \\
\hline $6^{\text {th }}$ Year & 2.5 \\
\hline Intern & 1.7 \\
\hline \multicolumn{2}{|l|}{ Degree $(n=211)$} \\
\hline $\mathrm{MA} / \mathrm{MS} / \mathrm{MBA}$ & 47.5 \\
\hline $\mathrm{PhD}$ & 30.9 \\
\hline PsyD & 8.5 \\
\hline EdD & 1.3 \\
\hline MSSW & 3.0 \\
\hline Not Specified & 4.7 \\
\hline \multicolumn{2}{|l|}{ Program Type ( $n=218,7.6 \%$ did not answer) } \\
\hline Art History and Music & 1.7 \\
\hline Business/ Business Communications/Organizational Design & 4.2 \\
\hline Communications & 0.8 \\
\hline Educational Leadership/ College Student Personnel & 3.4 \\
\hline Engineering & 5.5 \\
\hline English/ Language/Composition/ Literature & 3.4 \\
\hline Governmental/ Public Administration/ Political science & 3.4 \\
\hline Humanities & 2.1 \\
\hline Medical/ Orthodontics/ Pharmacology & 2.1 \\
\hline Nursing/Occupational Therapy & 3.4 \\
\hline Other & 4.2 \\
\hline Psychology & 23.3 \\
\hline Public Health & 2.1 \\
\hline Research & 1.3 \\
\hline Science & 5.5 \\
\hline Sociology/ Social Work & 10.6 \\
\hline Speech Therapy/Art therapy & 2.1 \\
\hline Urban Planning/ Urban affairs & 1.7 \\
\hline
\end{tabular}


Program. As seen in Table 5, a wide variety of graduate programs was represented in the sample. The programs that were provided were representative of the programs at the graduate schools in the sample. The majority of the participants were in psychology and education programs. These programs were not separated by schools as participation was anonymous and the email addresses for the raffle were immediately separated from their results to protect the participant's confidentiality.

Year in Program. As seen in Table 4, the majority of the participants were in the first year of the program followed by second year. This could be partially attributed to the high degree of Masters students who participated in the study and are enrolled in two year programs. This is discussed further in the Discussion section.

Gender role. Participants completed the short form of the BSRI which was utilized to determine their gender role. The BSRI consists of the following: a 10 item femininity subscale, a 10 item masculinity subscale, and 10 items that are simply filler material. The respective items on the masculinity and femininity subscale were composed in order to create a masculinity and femininity subscale for each participant. A median split of masculinity $(M d n=4.90)$ and femininity $(M d n=5.50)$ subscale resulted in the four gender roles. To be classified as androgynous, one had a raw score greater than 5.50 on the feminine subscale and greater than 4.90 on the masculine subscale. Masculine individuals were classified as such with a 4.90 or higher raw score on the masculine subscale and lower than 5.50 raw score on the feminine subscale. Similarly, participants that were classified as feminine had a raw score of 5.50 or higher on the feminine subscale and a raw score less than 4.90 on the masculine subscale. Lastly, undifferentiated individuals had a raw score less than 5.50 on the feminine subscale and 
less than 4.90 raw score on the masculine subscale. Eight individuals did not complete both portions of the BSRI and were not classified into gender roles. Table 6 presents the representation of the gender roles within the sample.

The data were also categorized by the gender role and sex. This was utilized as some have found that feminine females may experience increased job satisfaction under certain conditions and found feminine males may experience reduced job satisfaction under other occupational differences (e.g., Jacobs et al., 2010; Ledet \& Henley, 2000). Table 7 illustrates the classification of gender role by biological sex. As seen in Table 6 and 7, both males and female participants were primarily classified as androgynous.

Table 6.

Gender role composition in the sample

\begin{tabular}{ccc}
\hline Gender Role & $\mathrm{N}$ & Percentage \\
\hline Androgynous & 69 & $29.2 \%$ \\
Feminine & 57 & $24.2 \%$ \\
Masculine & 50 & $21.2 \%$ \\
Undifferentiated & 52 & $22.0 \%$ \\
\hline
\end{tabular}


Table 7 .

Gender role by sex

\begin{tabular}{ccc}
\hline Gender Roles & Males* & Females* \\
\hline Androgynous & $16(7.0 \%)$ & $51(22.4 \%)$ \\
Masculine & $14(6.1 \%)$ & $32(14.0 \%)$ \\
Feminine & $10(4.4 \%)$ & $45(19.7 \%)$ \\
Undifferentiated & $16(7.0 \%)$ & $35(15.4 \%)$ \\
\hline *Note: Nine individuals did not indicate their sex and are not included in Table 7
\end{tabular}

Table 8.

Differences across gender role for job satisfaction and occupational stress

\begin{tabular}{|c|c|c|c|c|}
\hline & Androgynous & Feminine & Masculine & Undifferentiated \\
\hline & Mean (SD) & Mean (SD) & Mean (SD) & Mean (SD) \\
\hline Overall Job Satisfaction & $5.48(1.23)$ & $4.51(1.59)$ & $4.38(1.73)$ & 4.61(1.66) \\
\hline Coworker & $39.80(11.10)$ & $40.08(10.52)$ & $37.67(12.21)$ & $40.78(8.91)$ \\
\hline Promotions & $11.25(8.95)$ & $8.75(8.58)$ & $9.80(9.95)$ & $10.61(8.78)$ \\
\hline Supervision & $42.16(12.27)$ & 41.65 (13.49) & $40.26(13.23)$ & $44.66(11.50)$ \\
\hline Compensation & $14.00(8.73)$ & $10.04(7.42)$ & $14.95(8.66)$ & $12.07(9.57)$ \\
\hline Work itself & $42.14(12.15)$ & $37.67(13.25)$ & $37.08(16.35)$ & $37.31(14.01)$ \\
\hline Overall Stress & $18.07(6.82)$ & $19.22(6.01)$ & $16.77(7.77)$ & $19.05(6.78)$ \\
\hline
\end{tabular}

* Note: Bolded numbers are significant $(p<.05)$

\section{Reliability Analysis}

Reliability analysis was conducted on the BSRI, PSS-10, and JDI to ensure that the instruments met acceptable reliability in the graduate student part-time worker population. Failure to meet minimum levels of reliability would diminish the 
generalizability and findings in this dissertation. The Cronbach's coefficient reliability met or exceeded the developer reported reliability for all established instruments in this study: the BSRI (Bem, 1974) and the JDI (Kinnicki et al., 2002), and PSS-10 (Hewitt, Flett, \& Mosher, 1992; Örücü, \& Demir 2009; Roberti, 2006). These reliabilities can be seen in Table 9. Though internal consistency reliabilities of greater than .90 are highly preferred (e.g., DeVellis, 2002; Henson, 2001), Cronbach's coefficient alpha's in the.80 to .90 are considered good levels of reliability. The Cronbach's coefficient alpha levels in the current study have achieved good levels of reliability according to DeVellis.

Table 9.

Reliability Coefficients for the JDI, BSRI, and PSS-10

\begin{tabular}{lccc}
\hline Variable & \multicolumn{3}{c}{ Coefficient of Internal Consistency } \\
& $\begin{array}{c}\text { Number } \\
\text { of Items }\end{array}$ & $\begin{array}{l}\text { Graduate } \\
\text { Students }\end{array}$ & Developer \\
\hline JDI & 17 & .91 & .90 \\
Work itself & 9 & .88 & .86 \\
Compensation & 9 & .92 & .87 \\
Promotion & 18 & .90 & .91 \\
Supervision & 17 & .85 & .92 \\
Coworker & 10 & .90 & .82 \\
F-Scale & 10 & .85 & .86 \\
M-Scale & 10 & .89 & .86 \\
PSS-10 & 6 & .84 & .86 \\
$\quad$ Perceived Helplessness & 4 & .78 & .87 \\
Perceived Self Efficacy & & &
\end{tabular}




\section{Inter-correlations of variables.}

Examinations between facet measures and overall measures of job satisfaction and occupational stress revealed positive significant correlations as expected (Table 10). The overall PSS-10 stress scale correlated positively with perceived self-efficacy, $r(227)$ $=.89, p<.001$ and perceived helplessness, $r(227)=.96, p<.001$. Overall job satisfaction significantly correlated with the JDI subscales: work itself, $r(224)=.44, p$ $<.001$, promotions, $r(222)=.30, p<.001$, supervision, $r(219)=.38, p<.001$, compensation, $r(223)=.22, p<.001$ and coworker, $r(222)=.32, p<.001$. The JDI subscales were positively correlated with each other though compensation did not significantly correlate with several JDI subscales: work itself, $r(228)=.02, p>.05$, supervision, $r(222)=.04, p>.05$, and coworker, $r(227)=.03, p>.05$.

There were several correlations between the major variables in the study. As expected overall job satisfaction and occupational stress were negatively correlated, $r(219)=-.21, p<.001$. Masculinity and femininity were also significantly correlated with several key variables. Masculinity, $r(223)=.08, p>.05$ was positively correlated with overall job satisfaction. Femininity was significantly positively correlated with: overall job satisfaction, $r(221)=.15, p<.05$, work itself, $r(226)=.07, p<.01$, and promotions, $r(223)=.12, p<.05$. Masculinity, $r(223)=-.11, p<.05$ and femininity, $r(223)=-.11, p<.05$ were negatively correlated with occupational stress. Descriptive statistics for all primary variables are shown in Table 10. 
Table 10.

Descriptive statistics for occupational stress, job satisfaction, and gender role

\begin{tabular}{lcccc}
\hline & $\mathrm{N}$ & Mean & MDN & SD \\
\hline Masculinity & 232 & 4.80 & 4.90 & .85 \\
Femininity & 229 & 5.41 & 5.50 & .93 \\
Overall Job Satisfaction & 227 & 4.78 & 5.0 & 1.62 \\
$\quad$ Coworker & 231 & 39.47 & 42.0 & 10.76 \\
Promotions & 229 & 10.11 & 7.00 & 9.21 \\
Supervision & 226 & 41.79 & 46.00 & 12.81 \\
Compensation & 231 & 12.75 & 13.0 & 8.97 \\
Work itself & 233 & 38.06 & 42.00 & 14.08 \\
Overall Stress & 227 & 18.34 & 19.0 & 6.78 \\
Perceived Self Effic. & 229 & 6.04 & 6.00 & 2.71 \\
Perceived Helpless & 234 & 12.32 & 12.00 & 4.52 \\
\hline
\end{tabular}


Table 11.

Inter-correlations among major variables

\begin{tabular}{|c|c|c|c|c|c|c|c|c|c|c|c|c|c|c|c|}
\hline & $\mathrm{M}$ & SD & 1 & 2 & 3 & 4 & 5 & 6 & 7 & 8 & 9 & 10 & 11 & 12 & 13 \\
\hline $\begin{array}{l}\text { 1. Overall Job } \\
\text { Satisfaction }\end{array}$ & 4.78 & 1.62 & -- & & & & & & & & & & & & \\
\hline 2. Work itself & 38.06 & 14.08 & $.44^{* *}$ & -- & & & & & & & & & & & \\
\hline 3. Promotions & 10.11 & 9.21 & $.30^{* *}$ & $.33^{* *}$ & -- & & & & & & & & & & \\
\hline 4. Supervision & 41.79 & 12.81 & $.38^{* *}$ & $.38^{* *}$ & $.25^{* *}$ & -- & & & & & & & & & \\
\hline 5.Compensation & 12.75 & 8.97 & $.22^{* *}$ & .02 & $.26^{* *}$ & .04 & -- & & & & & & & & \\
\hline 6. Coworkers & 39.47 & 10.76 & $.32 * *$ & $.42 * *$ & $.21^{* *}$ & $.44 * *$ & .03 & -- & & & & & & & \\
\hline 7. Masculinity & 4.80 & .85 & .08 & .02 & .06 & -.10 & .10 & -.05 & -- & & & & & & \\
\hline 8. Femininity & 5.41 & .93 & $.15^{*}$ & $.17^{* *}$ & $.12^{*}$ & .04 & -.01 & .11 & -.06 & -- & & & & & \\
\hline $\begin{array}{l}\text { 9. Overall } \\
\text { Stress }\end{array}$ & 18.34 & 6.78 & $-.21 * *$ & $-.12 *$ & -.10 & -.11 & $-.12 *$ & $-.25^{* *}$ & $-.11^{*}$ & -.02 & -- & & & & \\
\hline $\begin{array}{l}\text { 10. Perceived } \\
\text { Self efficacy }\end{array}$ & 6.04 & 2.71 & $-.25^{* *}$ & $-.17 * *$ & $-.12 *$ & -.10 & $-.17 * *$ & $-.24 * *$ & $-.22 * *$ & -.06 & $.89^{* *}$ & -- & & & \\
\hline $\begin{array}{l}\text { 11. Perceived } \\
\text { helplessness }\end{array}$ & 12.32 & 4.52 & $-.16^{* *}$ & -.09 & -.06 & -.10 & -.07 & $-.24 * *$ & -.04 & .01 & $.96^{* *}$ & $.72^{* *}$ & -- & & \\
\hline 12. Income & 37303 & 34525 & .04 & -.04 & $.23^{* *}$ & $.21 *$ & $.31 * *$ & -.06 & $.34^{* *}$ & -.02 & -.08 & $-.17^{*}$ & -.01 & -- & \\
\hline 13 Age & 29.29 & 7.43 & -.08 & -.07 & .09 & -.10 & -.03 & -.08 & $.22 * *$ & -.07 & -.06 & -.04 & -.06 & $.56^{* *}$ & -- \\
\hline
\end{tabular}


Primary Analysis

\section{Hierarchical linear regression analyses}

The first two research questions were analyzed with hierarchical linear regression analyses. The results and assumptions will be discussed in detail for each research question.

Research question 1. The first research question investigated whether sex, gender or the interaction lead to the significant prediction in occupation stress. (1) Does sex significantly predict occupational stress?, (2) does gender role significantly predict occupational stress?, and (3) does the gender role and sex interaction account for a significant amount of variability in occupational stress over and above that accounted for sex and gender role? The assumptions were checked prior to hierarchical regression.

There are five assumptions that need to be met in order to run hierarchical linear regression: (1) linearity, (2) homoscedasticity, (3) normality, (4) collinearity, and (5) absence of outliers. The assumptions of linearity and homoscedasticity were checked through the examination of the residual plots. There was just random scatter around zero with no specific pattern, which satisfied these first two assumptions. The normality of residuals was confirmed through the examination of the normal probability plots as the standardized residual line is close to the straight line. The histogram of the residuals followed the normal curve as well. Evidence of these assumptions can be found in Appendix C. Next, collinearity was checked through the examination of the VIF and tolerance. The VIF was smaller than 10 and the tolerance was greater than 0.1 , which satisfied this assumption for all variables. Lastly, Cook's D and Leverage were utilized 
to check for the existence of outliers. Cook's D was less than one and leverage was close to zero which confirmed there were no outliers present. The verification of the assumptions confirmed hierarchical regression could proceed.

Sex was entered in the first block, masculinity and femininity were entered in the second block, and the interaction between masculinity and femininity and sex were entered in the last block. Occupational stress was the dependent variable. This theoretical process was performed following Kanter's (1977) role strain model that gender incongruent roles result in differential experiences of occupational stress. Due to this, sex was entered first to determine if there were sex differences, followed by gender components, and then the sex by gender interaction. Research question one was not supported as sex, $F(1,207)=1.71, p>.05$, masculinity and femininity, $F(3,205)=.97$, $p>.05$, and sex by gender interaction, $F(4,204)=.96, p>.05$, failed to significantly predict occupational stress (Table 12).

Table 12.

Summary of hierarchical linear regression with occupational stress as the criterion

\begin{tabular}{ccccccc}
\hline Variable & $B$ & $S E B$ & $B$ & $R^{2}$ & $A_{d j} R^{2}$ & $\Delta R^{2}$ \\
\hline 1. Sex & -1.38 & 1.06 & -.09 & .01 & .003 & .01 \\
2. Sex & -1.44 & 1.07 & -.10 & .01 & .00 & .01 \\
M & -.49 & .55 & -.06 & & & \\
F & -.35 & .52 & -.05 & & \\
3. Sex & -2.62 & 1.62 & -.17 & .02 & -.001 & .01 \\
M & .10 & .82 & .01 & & & \\
F & .02 & .65 & .002 & & & \\
Sex x MF & .48 & .49 & .14 & & & \\
\hline
\end{tabular}


Research question 2. This question consisted of three components: (1) does sex significantly predict job satisfaction?, (2) does gender role significantly predict job satisfaction?, and (3) does the gender role and sex interaction account for a significant amount of variability in job satisfaction over and above that accounted for sex and gender role.

The five assumptions were checked for the second research question before hierarchical regression was run: (1) linearity, (2) homoscedasticity, (3) normality, (4) absence of collinearity, and (5) outliers. Linearity and homoscedasticity was verified through the examination of the residual plots. There was just random scatter around zero with no specific pattern, which satisfied these first two assumptions. The normality of residuals was checked through the examination of the normal probability plots and the histogram of the residuals. The diagonal line was slightly skewed on the residual plot and the histogram exhibited a slight negative skew. This was due to the elevated job satisfaction expressed by most participants. As the data mostly fit the normal curve and mostly exhibited a straight diagonal it was decided to proceed with hierarchical regression. Evidence of these assumptions can be found in Appendix D. Next, collinearity was checked utilizing the VIF or tolerance. The VIF was smaller than 10 and the tolerance was greater than 0.1 which satisfied this assumption for all variables. Lastly, Cook's D and Leverage were utilized to check for the existence of outliers. Cook's D was less than one and leverage was close to zero which confirmed there were no outliers present. Hierarchical linear regression was run as planned.

Sex was entered in the first block, masculinity and femininity were entered in the second step, and the interaction between masculinity and femininity and sex were entered 
in the last step in this hierarchical regression. Overall job satisfaction served as the dependent variable. Research question two was not supported as sex, $F(1,213)=.33$, $p>.05$, masculinity and femininity, $F(3,11)=2.14, p>.05$, and sex by gender interaction, $F(4,210)=2.14, p>.05$, all failed to predict variance in overall job satisfaction. Table 13 displays the results of the regression analysis for research question 2. In summary, the results of the hierarchical regression analyses reveal that sex, gender, and sex by gender interaction failed to significantly predict occupational stress or job satisfaction.

Table 13.

Summary of hierarchical linear regression with job satisfaction as the criterion

\begin{tabular}{ccccccc}
\hline Variable & $B$ & SEB & $B$ & $R^{2}$ & Adj $R^{2}$ & $\Delta R^{2}$ \\
\hline 1.Sex & .14 & .25 & .04 & .002 & -.003 & .002 \\
2. Sex & .20 & .25 & .06 & .03 & .02 & .03 \\
F & .17 & .13 & .09 & & & \\
3. Sex & .26 & .12 & .15 & & .02 & .01 \\
M & -.04 & .38 & .17 & .04 & & \\
F & .13 & .15 & -.02 & & & \\
Sex x MF & -.17 & .12 & -.08 & & & \\
\hline
\end{tabular}

\section{MANOVA}

Research questions 3 and 4 investigated whether gender role or degree type 
explained significant variance in job satisfaction (overall job satisfaction and facet measure of job satisfaction [JDI]) or in occupational stress.

Research question 3. This research question investigated whether gender role explained significant variance in job satisfaction and occupational stress. Participants were assigned to the appropriate gender role (masculine, feminine, androgynous, and undifferentiated) by the median split detailed earlier in the chapter. Assumptions were checked to verify that this test could be utilized. There are four assumptions of the MANOVA: 1) the dependent variables are multivariate normally distributed within each group of the categorical independent variable, 2) population covariance matrices of each group are equal, 3) the dependent variables have an interval measurement, and 4) observations are randomly and independently sampled from the population. The third assumption was met as each dependent variable was measured on a continuous scale, with higher numbers indicating higher stress or higher satisfaction. The fourth assumption was met as well. Though purposeful sampling was utilized due to the nature of the study, participants' scores were independent and were unlikely to affect other participant's scores. The first assumption was checked by creating a histogram to determine if the variable followed the normal curve for each level of the independent variable. Overall satisfaction, overall supervision satisfaction, and overall coworker satisfaction were slightly negatively skewed. The Levene's test confirmed this for these variables. Evidence can be seen in Appendix E. Lastly, the second assumption was met by using the Box M test, $F(84,68890)=.83, p>.05$, which indicated that the variance was homogenous across the variables.

The categorical variable of gender role (androgynous, feminine, masculine and 
undifferentiated) served as the independent variable while overall job satisfaction, overall occupational stress, and the JDI subscales (work, supervision, compensation, coworkers, and promotions) served as the dependent variables. The one-way MANOVA revealed that gender role explained significant variance in these variables, Wilk's $\lambda=.82, F(21$, $517.41)=1.78, p<.05$. The effect size $\left(\eta^{2}=.07\right)$ was a medium effect according to Cohen (1988), which indicates that $7 \%$ of the variance in job satisfaction was attributed to gender role classification. Follow up ANOVAs were conducted to determine where gender roles explained significant variances. There were significant differences in overall satisfaction, $F(3,190)=5.34, p<.01$ and overall compensation, $F(3,190)=3.03$, $p<.05$. There were no other significant differences across gender roles. The Tukey test was utilized to determine which gender roles significantly differed from one another on overall satisfaction and overall pay. Androgynous individuals $(M=5.48)$ experienced significantly higher job satisfaction than masculine $(M=4.38)$, feminine $(M=4.51)$ and undifferentiated $(M=4.79)$ participants. Masculine and feminine individuals significantly differed on the compensation subscale. Masculine individuals $(M=14.95)$ experienced more pay satisfaction than their feminine counterparts $(M=10.04)$.

Research question 4. The next research question investigated whether degree was related to job satisfaction and occupational stress. The assumptions were checked to verify that this test could be utilized. There are four assumptions of the MANOVA: 1) the dependent variables are multivariate normally distributed within each group of the categorical independent variable, 2) population covariance matrices of each group are equal , 3) the dependent variables have an interval measurement, and 4) observations are randomly and independently sampled from the population. The third assumption was 
met as each dependent variable was measured on a continuous scale, with higher numbers indicating higher stress or higher satisfaction. The fourth assumption was met as well. Though purposeful sampling was utilized as the nature of the study, the participants' score were independent and were unlikely to affect other participant's scores. The first assumption was checked by creating a histogram to determine if the variable followed the normal curve (Appendix F). This assumption was met. Lastly, the second assumption was assessed by using the Box M test, $F(84,3366.15)=1.30, p<.05$. This failed assumption indicated that the variance was not the same across degree types. In instances such as this, Whitley (2001) recommends to use a more stringent alpha level as way to reduce the violation. In this instance, an alpha level of .025 was utilized and the results must below this $p$-value in order to be significant. Research question 4 was not supported as the results revealed that degree type did not explain significance variance in overall satisfaction, overall occupational stress, and the subcomponents of the JDI, Wilk's $\lambda$ $=.75, F(42,866.49)=1.29, p>.025$.

Lastly, a one-way MANOVA was run to determine if occupation type explained significant variance in the major variables in the study. Occupation served as the independent variable while occupational stress, job satisfaction, and facet measure of job satisfaction served as the dependent variable. Occupation type failed to explain significant variance in the major variables in the study, Wilk's $\lambda=.55, F(96,1202.61)=$ $1.18, p>.05$.

\section{Factor Analysis}

The last quantitative question investigated the factor structure on the three main 
instruments utilized in the study: PSS-10, JDI, and BSRI. Exploratory factor analysis was utilized as there was little research conducted on U.S. graduate students that utilized these instruments. Four criteria were utilized to determine how many factors to obtain: eigenvalue, scree test, previous research, and parallel analysis.

\section{PSS-10.}

Data from the graduate student part-time worker were analyzed with IBM SPSS Statistics 22. Descriptive statistics for the 10 items run in EFA are listed in Table 14. Principal component factor analysis with varimax rotation was performed on the PSS-10. Initially, one factor had an eigenvalue greater than one. The scree test (Appendix G) suggested one to two factors be retained, and past research had suggested a two factor model. EFA was run again with principal component factor analysis with varimax rotation extracting two factors. The first factor had an eigenvalue of 3.31 and the second factor had an eigenvalue of 2.55 . This explained $33.14 \%$ and $25.52 \%$ of the variance in the PSS-10 respectively. Though both factor structures were examined, the eigenvalue greater than one rule and meaningfulness of the structure led to the decision to retain one item. Parallel analysis confirmed the one factor structure. The scree test and parallel analysis results can be seen in Appendix G.

All ten items had a factor loading of .40 or higher as recommended by Stevens (2009). Factor loadings for the PSS-10 can be seen in Table 14. As seen in Table 14, these all had a factor loading of .40 or higher on the factor hereafter known as occupational stress. 
Table 14.

Communalities, Factor Loadings Means, and Standard Deviations for PSS-10

\begin{tabular}{ccccc}
\hline Trait & Stress $(\mathrm{S})$ & $\boldsymbol{h}^{\mathbf{2}}$ & $\mathrm{M}$ & $\mathrm{SD}$ \\
\hline PSS-10 & $\mathbf{. 7 9}$ & .63 & 1.79 & 1.18 \\
PSS-4 & $\mathbf{. 7 7}$ & .60 & 1.20 & .86 \\
PSS-2 & $\mathbf{. 7 7}$ & .59 & 2.03 & 1.04 \\
PSS-3 & $\mathbf{. 7 4}$ & .54 & 2.95 & .90 \\
PSS-8 & $\mathbf{. 7 2}$ & .52 & 1.70 & .95 \\
PSS-5 & $\mathbf{. 7 2}$ & .51 & 1.56 & .84 \\
PSS-6 & $\mathbf{. 6 9}$ & .47 & 1.77 & 1.09 \\
PSS-9 & $\mathbf{. 6 6}$ & .43 & 1.86 & .98 \\
PSS-1 & $\mathbf{. 6 4}$ & .41 & 1.91 & .85 \\
PSS-7 & $\mathbf{. 5 5}$ & .31 & 1.61 & .87
\end{tabular}

Note. $\mathrm{S}=$ Structure coefficients $\mathbf{h}^{2}=$ communalities; Items are masked due to the copyright agreement

BSRI. Principal component factor analysis with varimax rotation was performed on the BSRI. Descriptive statistics for the 20 BSRI items can be seen in Table 15. Initially, three factors had an eigenvalue greater than one. The first factor had an eigenvalue of 5.58, the second factor had an eigenvalue of 3.20, and the third factor has an eigenvalue of 2.55. The scree test (Appendix H) suggested three factors be retained. These factors respectively explained: $27.90 \%, 16.04 \%$, and $12.74 \%$ of variance in BSRI. The eigenvalue greater than one rule, past research, and the scree test confirmed the three factor model. This is contrast to the parallel analysis results, which suggested a two factor model. The scree test and the parallel analysis results can be seen in Appendix H. 
All twenty items had factor loadings of .40 or higher as recommended by Stevens (2009). As seen in Table 15, these all had a factor loading of .40 or higher on the respective factors. The first factor contained all ten feminine items, such as tender, and is known as femininity. The second factor contained six masculine items, (assertive and willing to take stand) which are personality based characteristics. This was named Personal Masculinity. The last factor contained four masculine items (aggressiveness and dominant) that were more social based characteristics and embodied elements of control. This is henceforth known as Social Masculinity (Choi et al., 2009).

Table 15.

Communalities, Factor Loadings Means, and Standard Deviations for BSRI

\begin{tabular}{|c|c|c|c|c|c|c|}
\hline Item & $\begin{array}{l}\text { F1: Femininity } \\
\text { (S) }\end{array}$ & $\begin{array}{l}\text { F2: Personal } \\
\text { Masculinity } \\
\text { (S) }\end{array}$ & $\begin{array}{c}\text { F3: Social } \\
\text { Masculinity (S) }\end{array}$ & $h^{2}$ & $\mathrm{M}$ & SD \\
\hline BSRI- 23 & .86 & -.11 & .15 & .77 & 4.77 & 1.35 \\
\hline BSRI- 20 & .82 & -.00 & .12 & .69 & 5.38 & 1.13 \\
\hline BSRI- 5 & .79 & .03 & -.24 & .68 & 5.60 & 1.28 \\
\hline BSRI-14 & .78 & .18 & -.13 & .66 & 5.62 & 1.16 \\
\hline BSRI- 29 & .78 & -.09 & -.10 & .63 & 5.01 & 1.24 \\
\hline BSRI- 17 & .75 & -.17 & -.05 & .59 & 5.35 & 1.38 \\
\hline BSRI- 8 & .73 & .12 & -.27 & .63 & 5.54 & 1.17 \\
\hline BSRI- 2 & .72 & -.07 & .28 & .59 & 5.41 & 1.26 \\
\hline BSRI- 11 & .60 & .35 & -.29 & .57 & 5.87 & .93 \\
\hline BSRI- 26 & .46 & .39 & -.17 & .39 & 5.53 & 1.69 \\
\hline BSRI- 7 & -.03 & .73 & .31 & .63 & 4.90 & 1.31 \\
\hline BSRI- 25 & .03 & .70 & .28 & .57 & 5.29 & 1.24 \\
\hline BSRI- 1 & -.02 & .65 & .21 & .47 & 5.65 & 1.17 \\
\hline BSRI- 4 & -.01 & .65 & .07 & .43 & 5.96 & .98 \\
\hline BSRI-10 & -.02 & .62 & .48 & .61 & 5.36 & 1.41 \\
\hline BSRI- 16 & .09 & .43 & .39 & .35 & 5.72 & 1.10 \\
\hline BSRI-28 & -.21 & .22 & .73 & .63 & 3.22 & 1.48 \\
\hline BSRI- 13 & -.22 & .27 & .69 & .59 & 3.17 & 1.41 \\
\hline BSRI-22 & -.11 & .45 & .63 & .61 & 4.16 & 1.53 \\
\hline BSRI-19 & .15 & .27 & .40 & .26 . & 4.62 & 1.36 \\
\hline
\end{tabular}

Note. $\mathrm{S}=$ Structure coefficients $\boldsymbol{h}^{2}=$ communalities; Items are masked due to the copyright agreement 
JDI. Principal component factor analysis with varimax rotation was performed on the JDI. Descriptive statistics for the 71 JDI items can be seen in Table 15. Initially fifteen factors had an eigenvalue greater than one that explained $65.54 \%$ of the variance. The scree test (Appendix I) suggested 7 to 11 factors be retained. However, six of these factors contained minuscule items that composed the suggested factor that did not allow for a logical trait interpretation. This led the researcher to consider retaining less factors. The results of the parallel analysis revealed the existence of seven factors, which made conceptual and theoretical sense. This is also more similar to five factor model consistently replicated in empirical research. Principal component analysis was rerun with the extraction of seven factors.

The factor loadings, means, and standard deviations can be seen in Table 16. These seven factors explained $50.38 \%$ of the variance. The eigenvalue for the seven traits were as follows: $7.95,7.18,5.77,4.82,4.02,3.42$, and 2.60. As recommended by Stevens (2009), a cut-off criterion of . 40 was used to evaluate the factor structure. The item "tells me where I stand" did not meet this criteria and was excluded from factor analysis. The first factor explained $11.2 \%$ of the variance and contained 19 items regarding the individuals' work environment. This was named work. The next factor consisted of 17 items regarding the quality of their supervision and was identified as supervisor $(10.11 \%)$. The third factor consisted of eight items regarding promotional opportunities and mirrored the promotional scale in the JDI. This factor is known as promotion $(8.13 \%)$. The fourth factor consisted of nine items regarding compensation and pay. This was named compensation and explained $6.8 \%$ of the variance. The next three factors are the differentiation of the reputed one dimensional coworker subscale. 
The fifth factor contains nine items regarding the personality of their coworkers. This was named personal coworker and explained $5.67 \%$ of the variance. The sixth factor explained $4.82 \%$ of the variance and consisted of the supportive aspects of coworker, which was identified as supportive coworker. The last factor consisted of three items regarding the working ability of the coworker. The working coworker explained the last $3.66 \%$ of the variance. These subscales varied from the well researched and factor validated five factor structure of the JDI. Promotion mirrored the subscale exactly and compensation closely matched the JDI compensation subscale. Implications for the factors are discussed in the Discussion. 
Table 16.

Communalities, Factor Loadings Means, and Standard Deviations for JDI

\begin{tabular}{|c|c|c|c|c|c|c|c|c|c|c|}
\hline Item & Work & Supervise & Promote & Pay & $\begin{array}{c}\text { Personality } \\
\text { Coworker }\end{array}$ & $\begin{array}{l}\text { Supportive } \\
\text { Coworker }\end{array}$ & $\begin{array}{c}\text { Working } \\
\text { Coworker }\end{array}$ & $h^{2}$ & $\mathrm{M}$ & $\mathrm{SD}$ \\
\hline W1 & .78 & .03 & .10 & -.02 & .09 & .16 & .05 & .66 & 2.28 & 1.25 \\
\hline W2 & .74 & .04 & .12 & .03 & .08 & .13 & .17 & .62 & 2.49 & 1.10 \\
\hline W3 & .73 & .04 & .09 & -.01 & -.13 & .01 & .09 & .57 & 2.30 & 1.25 \\
\hline W4 & .72 & .17 & .08 & -.01 & .08 & .04 & -.16 & .59 & 1.82 & 1.43 \\
\hline W5 & .71 & .03 & -.10 & -.03 & -.01 & .09 & .10 & .53 & 2.20 & 1.33 \\
\hline W6 & .70 & .08 & .05 & -.02 & .22 & .03 & .09 & .56 & 2.22 & 1.28 \\
\hline W7 & .70 & .11 & .11 & -.07 & .03 & .20 & -.07 & .57 & 1.70 & 1.45 \\
\hline W8 & .66 & .16 & .15 & .01 & .01 & .10 & .15 & .52 & 2.19 & 1.29 \\
\hline W9 & .66 & .10 & .08 & -.03 & .06 & .09 & .29 & .55 & 2.42 & 1.14 \\
\hline W10 & .65 & .02 & .09 & .04 & -.04 & .18 & -.07 & .47 & 1.89 & 1.42 \\
\hline W11 & .62 & .18 & .14 & -.00 & .08 & .05 & .20 & .49 & 2.42 & 1.11 \\
\hline W12 & .59 & .17 & .18 & -.06 & -.01 & .02 & .28 & .49 & 2.44 & 1.12 \\
\hline W13 & .54 & .03 & .10 & .04 & -.03 & -.05 & -.35 & .43 & 1.08 & 1.44 \\
\hline W14 & .54 & .02 & .10 & .03 & .10 & .04 & -.16 & .34 & 1.18 & 1.44 \\
\hline W15 & .46 & .12 & .16 & -.01 & .06 & -.08 & .39 & .41 & 2.69 & .87 \\
\hline W16 & .39 & .19 & .12 & .08 & .12 & -.01 & .29 & .31 & 2.75 & .79 \\
\hline W17 & .31 & .17 & .22 & .14 & .02 & .04 & .21 & .23 & 2.12 & 1.30 \\
\hline $\mathrm{S} 1$ & .08 & .78 & .06 & -.04 & .08 & .27 & -.09 & .46 & 2.49 & 1.06 \\
\hline $\mathrm{S} 2$ & .03 & .74 & .10 & -.08 & .15 & -.03 & .07 & .59 & 2.56 & 1.05 \\
\hline S3 & .11 & .73 & .06 & .01 & .19 & -.11 & -.06 & .61 & 2.69 & .89 \\
\hline S4 & .12 & .73 & -.05 & .03 & .09 & .06 & -.05 & .64 & 1.99 & 1.35 \\
\hline S5 & .12 & .73 & .07 & .04 & .11 & .06 & -.03 & .56 & 2.43 & 1.14 \\
\hline S6 & .06 & .66 & .18 & .03 & -.04 & .16 & .02 & .50 & 2.37 & 1.20 \\
\hline S7 & .05 & .63 & -.02 & .01 & .01 & .21 & -.03 & .45 & 2.25 & 1.27 \\
\hline $\mathrm{S} 8$ & .09 & .61 & .04 & -.12 & .16 & -.13 & .12 & .46 & 1.98 & 1.39 \\
\hline S9 & .30 & .58 & .02 & .11 & .01 & .26 & .14 & .53 & 2.21 & 1.28 \\
\hline $\mathrm{S} 10$ & -.12 & .57 & .13 & -.04 & .15 & -.05 & -.10 & .40 & 2.08 & 1.35 \\
\hline $\mathrm{S} 11$ & .22 & .56 & .02 & .18 & .06 & -.01 & .36 & .53 & 2.15 & 1.30 \\
\hline $\mathrm{S} 12$ & .25 & .54 & .06 & .02 & -.12 & .23 & .13 & .44 & 2.25 & 1.25 \\
\hline S13 & .21 & .52 & .04 & -.11 & -.06 & .17 & .20 & .40 & 2.73 & .80 \\
\hline S14 & .18 & .51 & -.06 & .02 & -.19 & .31 & .24 & .48 & 2.62 & .94 \\
\hline $\mathrm{S} 15$ & .10 & .50 & .01 & .20 & .19 & -.08 & .40 & .50 & 2.72 & .82 \\
\hline S16 & -.03 & .48 & .10 & .01 & .18 & .01 & -.07 & .27 & 1.68 & 1.44 \\
\hline S17 & .08 & .46 & .07 & .03 & .09 & .28 & .11 & .32 & 2.16 & 1.29 \\
\hline
\end{tabular}




\begin{tabular}{|c|c|c|c|c|c|c|c|c|c|c|}
\hline Item & Work & Supervise & Promote & Pay & $\begin{array}{c}\text { Personality } \\
\text { Coworker }\end{array}$ & $\begin{array}{l}\text { Supportive } \\
\text { Coworker }\end{array}$ & $\begin{array}{r}\text { Working } \\
\text { Coworker }\end{array}$ & $h^{2}$ & $\mathrm{M}$ & SD \\
\hline PR1 & .13 & .10 & .88 & .06 & .03 & .08 & .06 & .82 & 1.01 & 1.31 \\
\hline PR2 & .17 & .09 & .86 & .01 & .00 & .09 & .01 & .78 & .98 & 1.32 \\
\hline PR3 & .12 & .07 & .83 & .02 & .01 & .07 & .00 & .71 & 1.09 & 1.33 \\
\hline PR4 & .19 & .12 & .78 & .03 & .07 & -.01 & .04 & .67 & 1.32 & 1.42 \\
\hline PR5 & .10 & .10 & .78 & .07 & .04 & -.04 & .02 & .63 & .98 & 1.28 \\
\hline PR6 & .08 & .13 & .71 & .19 & -.06 & .22 & .05 & .62 & 1.36 & 1.42 \\
\hline PR7 & .11 & .05 & .71 & -.03 & .04 & -.04 & .01 & .52 & .80 & 1.28 \\
\hline PR8 & .11 & -.05 & .64 & .16 & .01 & .08 & -.02 & .46 & .63 & 1.05 \\
\hline PR9 & .16 & .14 & .53 & .31 & .05 & .10 & .15 & .45 & 1.95 & 1.34 \\
\hline PA 1 & .02 & .05 & .02 & .79 & .05 & .09 & .06 & .57 & 2.71 & .85 \\
\hline PA 2 & -.01 & .04 & -.06 & .75 & -.01 & -.02 & -.02 & .57 & 1.78 & 1.40 \\
\hline PA 3 & .11 & -.08 & .09 & .73 & -.04 & -.04 & .01 & .56 & 1.73 & 1.42 \\
\hline PA 4 & -.04 & .03 & .04 & .73 & .02 & .01 & -.09 & .54 & 1.10 & 1.37 \\
\hline PA 5 & -.01 & .00 & .06 & .69 & .04 & .05 & -.02 & .49 & 1.59 & 1.43 \\
\hline PA 6 & -.00 & .06 & -.04 & .68 & .03 & .04 & -.04 & .47 & 1.06 & 1.37 \\
\hline PA 7 & .02 & .02 & .09 & .66 & -.04 & -.04 & .02 & .45 & 1.53 & 1.44 \\
\hline PA 8 & -.05 & -.08 & .24 & .63 & -.08 & .11 & .17 & .52 & 1.33 & 1.44 \\
\hline PA 9 & -.07 & -.07 & .20 & .63 & -.09 & -.02 & .04 & .45 & .70 & 1.18 \\
\hline PC 1 & .08 & .20 & .03 & -.03 & .74 & .13 & .00 & .61 & 2.58 & 1.00 \\
\hline $\mathrm{PC} 2$ & -.04 & .02 & .02 & .05 & .73 & .16 & -.09 & .57 & 2.52 & 1.05 \\
\hline PC 3 & -.01 & .07 & .05 & .01 & .70 & .11 & .01 & .52 & 2.44 & 1.13 \\
\hline PC 4 & .01 & .14 & -.06 & -.06 & .62 & -.20 & .12 & .46 & 1.83 & 1.43 \\
\hline PC 5 & .04 & .21 & .06 & -.04 & .53 & .27 & -.26 & .47 & 2.63 & .92 \\
\hline PC 6 & .38 & .09 & .06 & -.05 & .49 & .31 & -.03 & .50 & 2.20 & 1.29 \\
\hline PC 7 & .24 & .05 & -.00 & .09 & .50 & .20 & .39 & .50 & 2.60 & .96 \\
\hline PC 8 & .13 & .13 & .03 & -.15 & .49 & .31 & .17 & .42 & 1.78 & 1.43 \\
\hline PC 9 & .20 & .10 & .10 & .02 & .40 & .31 & .08 & .32 & 1.65 & 1.44 \\
\hline $\mathrm{SC} 1$ & .16 & .02 & .13 & .06 & .13 & .68 & .05 & .53 & 2.31 & 1.20 \\
\hline $\mathrm{SC} 2$ & .08 & .16 & .18 & -.02 & .22 & .59 & -.00 & .69 & 2.54 & 1.05 \\
\hline $\mathrm{SC} 3$ & .04 & .26 & .10 & .01 & .17 & .54 & .05 & .40 & 2.60 & .98 \\
\hline $\mathrm{SC} 4$ & .41 & .08 & .05 & .07 & .24 & .53 & -.05 & .53 & 2.26 & 1.26 \\
\hline SC 5 & .08 & .15 & -.06 & .01 & .13 & .53 & .33 & .44 & 2.51 & 1.05 \\
\hline SC 6 & .16 & .16 & -.03 & .13 & .21 & .44 & .14 & .33 & 2.05 & 1.34 \\
\hline WC 1 & .04 & .17 & -.07 & .01 & .47 & .13 & .55 & .58 & 2.30 & 1.20 \\
\hline WC 2 & .12 & -.05 & .20 & -.01 & -.14 & .16 & .54 & .40 & 2.27 & 1.19 \\
\hline WC 3 & .24 & .04 & .03 & -.06 & .05 & .41 & .54 & .53 & 2.75 & .7 \\
\hline
\end{tabular}

Note. $\mathrm{S}=$ Structure coefficients $\boldsymbol{h}^{2}=$ communalities; Items masked due to copyright agreement 


\section{Qualitative Analyses}

While quantitative data enables one to identify the parsimonious and succinct findings, qualitative data is richer in context and allows "one to understand the world as seen by respondents" (Patton, 2002, p. 21). Research Question 5 focused on the investigation of the main stressors that graduate student part-time workers face. The inclusion of the qualitative component of stress was based on Mazzolla et al. 's (2011) recommendation to provide richer detail to the study than simply a numerical representation of stress. The aim was to develop a useful typology to categorize graduate student stressors.

\section{Analysis.}

Content analysis, where one studies open ended responses, was conducted on the fifth research question "What are the three biggest stressors in your life?" Such inquiry enables the understanding of the participants' world without the usage of predetermined categories. Using naturalistic inquiry also allows one to remain flexible to the emerging themes as the data directs them through a deeper understanding of the topic (Patton, 2002). The challenge, however, is to reduce the vast amount of raw data to significant patterns or themes. The reduction of any qualitative data and attempts to identify core consistencies and meanings is better known as content analysis (Patton, 2002).

\section{Thematic Analysis.}

The researcher yields to Miles and Huberman's (1994) suggestion that one should start with three to four initial codes with loose meaning and finalize these categories after a greater understanding of the data occurs. Based on previous research (e.g., Gardner, 
2009; Golde, 1998; Lovitt, 2001; Steele \& Orvalle, 1984), it appeared that the three greatest stressors for graduate students were work, school, and family. These were the initial codes or patterns utilized in this study. The researcher began with the qualitative database exported from the surveymonkey site. As the participants had responded to an open ended numbered box in the survey asking them to list the stressors in their lives, the initial task was to differentiate the individual stressors reported by each participant. This step resulted in 584 stressors reported by the 213 participants. The number of stressors reported by each participant ranged from zero to four stressors. The individual stressors were placed into the school, work, and personal categories. Though these categories were broad in nature, this enabled the initial categorization of the data into analysis unit and enabled the sorting and chunking of data (Miles \& Huberman, 1994). Table 18 consisted of the quotes that were most telling in regards to the stressors experienced in this category.

Once the self reported stressors were categorized into these three initial categories, these were expanded to eight categories and refined in later analysis as suggested by Miles and Huberman (1994). The top three stressors were: academic $(n=155 ; 26.5 \%)$, balancing realms $(n=106 ; 18.2 \%)$, and family relationships $(n=98 ; 16.8 \%)$, which accounted for $61.54 \%$ of all the stressors reported. The remaining stressors were: money $(n=70 ; 12.0 \%)$, work $(n=69 ; 11.8 \%)$, life issues $(n=43 ; 7.4 \%)$, future $(n=33 ; 5.7 \%)$ and not specified $(n=10,1.7 \%)$. These categorizations were developed from the data and were the second set of categories utilized by the researcher. Once the data had been categorized into the eight stressors, these were further organized by the researcher into underlying themes within each stressor. In order to be considered a unique theme, the 
researcher utilized the self chosen restriction that two or more stressors must underlie the theme. This was later redefined as the categories became too narrowly defined and were expanded onto to broader categorization of themes. Under each of these categories, several themes emerged from the data, which clarified the nature of the overall stressor. Table 17 summarizes the typology of graduate student stressors and each category is discussed in greater detail in the section below.

Academic. The most commonly reported stressors from the graduate school parttime worker population pertained to the academic realm. This category contained any stressors that were related to the academic experience that graduate students faced such as: dissertation/ thesis, class load, and coursework. This stressor had several underlying themes as seen in Table 17. Though these self reported stressors encompassed the entire range of the academic experience, course load and assignments were the biggest stressors in this category.

General academic concerns and the dissertation/thesis process were respectively the the second and third most reported themes in the Academic category. Again, students reported the overall academic concerns and centered on the dissertation or thesis. Many students reported being concerned about the amount of work involved with the dissertation, the "strenuous" process, and the lack of significant results. As the workload, dissertation and thesis are the capstones of the graduate experience, it is not surprisingly to see these mentioned as stressors. Additionally, many students reported fears or difficulties obtaining assistantships, practicums, and internships. Though the Work stressor had initially been hypothesized by the researcher to include assistantships, practicums, and internships, this was collapsed into the school category as participants 
reported more problems with obtaining these positions instead of the actual position requirements themselves. 
Table 17:

Typology of graduate student stressors

\begin{tabular}{|c|c|c|c|c|c|c|c|}
\hline $\begin{array}{l}\text { Academic } \\
(n=155)\end{array}$ & $\begin{array}{l}\text { Balancing } \\
\text { Realms } \\
(n=106)\end{array}$ & $\begin{array}{l}\text { Family } \\
(n=98)\end{array}$ & $\begin{array}{l}\text { Money } \\
(n=70)\end{array}$ & $\begin{array}{l}\text { Work } \\
(n=69)\end{array}$ & $\begin{array}{l}\text { Life Issues } \\
(n=43)\end{array}$ & $\begin{array}{l}\text { Future } \\
(n=33)\end{array}$ & $\begin{array}{l}\text { Not Specified } \\
(n=10)\end{array}$ \\
\hline $\begin{array}{l}\text { Course load/ } \\
\text { Assignments } \\
(n=63)\end{array}$ & $\begin{array}{l}\text { Balancing } \\
\text { Realms } \\
(n=69)\end{array}$ & $\begin{array}{l}\text { Family } \\
\text { Relationships } \\
(n=25)\end{array}$ & $\begin{array}{l}\text { Money } \\
(\text { General }) \\
(n=59)\end{array}$ & $\begin{array}{l}\text { Job } \\
\text { Responsibilities } \\
(n=25)\end{array}$ & $\begin{array}{l}\text { Health Issues/ } \\
\text { Exercise } \\
(n=15)\end{array}$ & $\begin{array}{l}\text { Job Market } \\
(n=15)\end{array}$ & $\begin{array}{l}\text { Workload/ } \\
\text { Deadlines } \\
(n=6)\end{array}$ \\
\hline $\begin{array}{l}\text { Academic (General) } \\
(n=33)\end{array}$ & $\begin{array}{l}\text { Time } \\
\text { Management } \\
(n=37)\end{array}$ & $\begin{array}{l}\text { Spouse/ } \\
\text { Romantic } \\
\text { Relationship } \\
(n=20)\end{array}$ & $\begin{array}{l}\text { Debt/ Student } \\
\text { Loans }(n=7)\end{array}$ & $\begin{array}{l}\text { Work (general) } \\
(n=24)\end{array}$ & $\begin{array}{l}\text { Living/ } \\
\text { Relocation } \\
\text { issues }(n=8)\end{array}$ & $\begin{array}{l}\text { Future } \\
\text { (General)/ } \\
\text { Goals }(n=7)\end{array}$ & $\begin{array}{l}\text { Performance/ } \\
\text { Other }(n=4)\end{array}$ \\
\hline $\begin{array}{l}\text { Dissertation/ Thesis } \\
(n=15)\end{array}$ & & $\begin{array}{l}\text { Personal } \\
(n=19)\end{array}$ & $\begin{array}{l}\text { Daily expenses } \\
(n=4)\end{array}$ & $\begin{array}{l}\text { Job Prospects/ } \\
\text { Insecurity } \\
(n=8)\end{array}$ & $\begin{array}{l}\text { "Me Time"/ } \\
\text { Personal } \\
\text { Needs }(n=7)\end{array}$ & $\begin{array}{l}\text { Graduation } \\
\text { Uncertainty } \\
(n=6)\end{array}$ & \\
\hline $\begin{array}{l}\text { Assistantship/ } \\
\text { Practicum/ } \\
\text { Internship }(n=12)\end{array}$ & & $\begin{array}{l}\text { Children } \\
(n=16)\end{array}$ & & $\begin{array}{l}\text { Boss/ Coworker } \\
(n=6)\end{array}$ & $\begin{array}{l}\text { Self Esteem } \\
\text { Issues }(n=7)\end{array}$ & $\begin{array}{l}\text { Jobs/ Career } \\
(n=5)\end{array}$ & \\
\hline $\begin{array}{l}\text { Faculty/ Program } \\
\text { Design }(n=14)\end{array}$ & & $\begin{array}{l}\text { Friends/Pets/ } \\
\text { Roommates } \\
(n=10)\end{array}$ & & $\begin{array}{l}\text { Training/ } \\
\text { Promotions } \\
(n=4)\end{array}$ & $\begin{array}{l}\text { Sleep/Focus } \\
(n=6)\end{array}$ & & \\
\hline $\begin{array}{l}\text { Research/Lab } \\
\text { Hours }(n=8)\end{array}$ & & $\begin{array}{l}\text { Serious } \\
\text { Illnesses/ } \\
\text { Death }(n=8)\end{array}$ & & $\begin{array}{l}\text { Multiple jobs } \\
(n=2)\end{array}$ & & & \\
\hline $\begin{array}{l}\text { Lack of Progress/ } \\
\text { Program } \\
\text { Expectation }(n=7)\end{array}$ & & & & & & & \\
\hline Comp exams $(n=3)$ & & & & & & & \\
\hline
\end{tabular}


Balancing Realms. As previously mentioned, the original categorizations of the stressors had the three realms separately defined (work, school and family). This category evolved from the data as a large portion of participants reported stressors concerned with the balancing of multiple realms, such as family, work, and school, and the need to devote time to one area and forsake others. As seen in Table 18, time spent on school was at the expense of their family. Additionally, several other participants reported the conflict between the need for financial stability and its encroachment on academic time.

Family Relationships. Similar to the balancing realm stressors, feelings of neglecting or ignoring their personal relationships in pursuit of academic achievements were cited by several graduate students who are part-time workers. Many reported that this resulted in fights with their loved ones or the termination of friendships. This is particularly problematic as social support is a known buffer to reduce the negative impact of stress on one's job satisfaction (Bellman et al., 2003; Clark et al., 2009; Mark \& Smith, 2012).

Money. Money was the fourth most reported stressor by participants. This is not unexpected as many graduate students enter graduate school prepared for student loans, stipends to support their academic lives, and a debt to be repaid later. Such effects were previously noted by Moyer and Salovey (1999) and Smith et al. (2006).

Work. This stress is closely linked to the previous stressor. In graduate school, employment may be somewhat limited as the job must be flexible enough to accommodate the graduate school curriculum. One such problem cited by several 
Table 18.

Excerpts of open ended stressors

\begin{tabular}{|c|c|c|}
\hline Academic & Balancing Realms & Family \\
\hline $\begin{array}{l}\text { Writing my thesis, writing my } \\
\text { thesis, writing my thesis. } \\
\text { Seriously. }\end{array}$ & $\begin{array}{l}\text { Part-time worker"... ha - talk about } \\
\text { getting into lab at } 7 \text { am and not } \\
\text { leaving until } 8 \mathrm{pm} \text { almost every day } \\
\text { so I can have the weekend off - } \\
\text { maybe when you are going for your } \\
\text { PhD in something like } \\
\text { communications. Classes at the } \\
\text { same time as completing lab work } \\
\text { and expected to go to journal club } \\
\text { and seminars whilst completing } \\
\text { experiments and gathering data. }\end{array}$ & $\begin{array}{l}\text { Feeling inadequate as a parent } \\
\text { because so much of my time is } \\
\text { spent at work, thinking about } \\
\text { work, and complete school work } \\
\text { for my degree. }\end{array}$ \\
\hline $\begin{array}{l}\text { Data not showing anything } \\
\text { usable. }\end{array}$ & $\begin{array}{l}\text { Wife and daughter are stressful } \\
\text { because I feel the pull and need to } \\
\text { be home with them, but I'm a phd } \\
\text { graduate student and it's difficult to } \\
\text { balance priorities. }\end{array}$ & $\begin{array}{l}\text { Being away from family/small } \\
\text { support network. }\end{array}$ \\
\hline $\begin{array}{l}\text { Not enough time to read } \\
\text { everything AND produce } \\
\text { results. }\end{array}$ & $\begin{array}{l}\ldots \text { I never have a free second. } \\
\text { Also, the schoolwork that } \\
\text { accompanies my class is a bit } \\
\text { excessive. Working, student } \\
\text { teaching, and completing all of my } \\
\text { schoolwork is my biggest stressor. } \\
\text { I am also stressed that I don't see } \\
\text { my friends enough. None of them } \\
\text { are still in school so it's hard for } \\
\text { them to relate to my situation... }\end{array}$ & $\begin{array}{l}\text { Being able to spend quality time } \\
\text { with my wife. }\end{array}$ \\
\hline $\begin{array}{l}\text { Too much school work due all } \\
\text { around the same time. }\end{array}$ & $\begin{array}{l}\text { Due to financial need I have had to } \\
\text { return to part-time work. The } \\
\text { demands of the academic load are } \\
\text { quite extensive and for the first half } \\
\text { of my academic career did not have } \\
\text { to work. I now find myself in a } \\
\text { place that requires that I work and } \\
\text { it is very difficult to juggle part- } \\
\text { time work, school commitments, } \\
\text { family and taking care of myself. }\end{array}$ & $\begin{array}{l}\text { Having a pathetic excuse for a } \\
\text { love life. }\end{array}$ \\
\hline $\begin{array}{l}\text { The biggest stressor in my life is } \\
\text { the lack of academic support in } \\
\text { guidance towards a career. }\end{array}$ & $\begin{array}{l}\text { Not enough time to do all the things } \\
\text { for school, professionalization, and } \\
\text { anything personal or social. }\end{array}$ & $\begin{array}{l}\text { Not enough time for social } \\
\text { things. }\end{array}$ \\
\hline $\begin{array}{l}\text { Advisor infrequent, poor } \\
\text { feedback. }\end{array}$ & Never having a day off. & \\
\hline
\end{tabular}




\begin{tabular}{|c|c|c|c|}
\hline Money & Work & Future & Life Issues \\
\hline $\begin{array}{l}\text { Worried and stressed about } \\
\text { ability to comfortably live } \\
\text { while repaying school loans. } \\
\text { Trying to get finances in } \\
\text { order to meet this } \\
\text { requirement. }\end{array}$ & $\begin{array}{l}\text { Unable to work away from } \\
\text { work with coworkers due } \\
\text { school schedule. }\end{array}$ & $\begin{array}{l}\text { Worrying about } \\
\text { whether I'll } \\
\text { actually be able to } \\
\text { find a job on } \\
\text { graduation. }\end{array}$ & $\begin{array}{l}\text { 1). Have to } \\
\text { sacrifice sleep to } \\
\text { get anything done } \\
\text { 2) can't think } \\
\text { clearly because } \\
\text { brain is tired 3) } \\
\text { constantly } \\
\text { nodding off when } \\
\text { trying to think. }\end{array}$ \\
\hline $\begin{array}{l}\text { Financial constraints of full- } \\
\text { time living on part-time } \\
\text { wages. }\end{array}$ & $\begin{array}{l}\text { Unpredictable work } \\
\text { environment with different } \\
\text { ego. }\end{array}$ & $\begin{array}{l}\text { Uncertainty about } \\
\text { whether or not all } \\
\text { the hard work of } \\
\text { grad school will } \\
\text { pay off later. }\end{array}$ & $\begin{array}{l}\text { Living in a dirty } \\
\text { house with an } \\
\text { empty fridge bc } \\
\text { cleaning, } \\
\text { shopping, and } \\
\text { cooking are lowest } \\
\text { on the priority list. }\end{array}$ \\
\hline $\begin{array}{l}\text { I took an research assistant } \\
\text { position that is good for my } \\
\text { future in academics, but does } \\
\text { not make as much money as } \\
\text { my last job so adjusting } \\
\text { financially has been stressful. }\end{array}$ & Unpredictable work schedule. & $\begin{array}{l}\text { Lastly, I don't feel I } \\
\text { am being prepared } \\
\text { well for my future } \\
\text { career. I am taking } \\
\text { very few classes } \\
\text { that focus on my } \\
\text { actual program of } \\
\text { study and the few } \\
\text { classes I am taking } \\
\text { are } 1 \text { and } 2 \text { credit } \\
\text { hour courses. }\end{array}$ & $\begin{array}{l}\text { Not having } \\
\text { enough time or } \\
\text { energy for self } \\
\text { care. }\end{array}$ \\
\hline
\end{tabular}

graduate students was job uncertainty or the potential for job responsibilities to change.

Moreover, many students reported the workload, personnel, or job requirements as

stressors.

Life issues. The life issues category consisted of stressors that did not involve the three main spheres (academic, work, and family) in the graduate student part-time worker's life, but instead focused on personal care, exercising, and concerns with health. One of the less frequently reported stressors were that many students reported they did 
not have time to exercise or had personal "me" time. This could be potentially explained by the graduate students who are attempting to balance the time consuming demands of graduate school and work. As Clark et al. (2009) and Greenhaus and Parasuraman (1987) notes, when such constraints occur this infringes on one's personal life.

Future. Many graduate students go to graduate school in order to reach their career goals. However, many graduate students reported uncertainty to whether this degree would help them accomplish their career goals, if job opportunities were available, and if the degree was a good investment. Such concerns composed the Future stressor category.

Not specified category. This category consisted of items that were ambiguous in nature. It was unclear during data coding whether "workload" or "deadlines" referred to one's academic or occupational pursuits. This resulted in a need for a category where the stressors did not fit neatly into other categories.

\section{Summary.}

This study utilized hierarchical regression to see if sex, gender, and the sex by gender interaction significantly predicted occupational stress. The results revealed that sex, gender and the sex by gender interaction failed to significantly predict occupational stress. The second research question utilized hierarchical regression to determine if the above mentioned variables significantly predicted overall job satisfaction. Results indicated that sex, gender, and the sex by gender interaction failed to significantly predict overall job satisfaction. Though these aforementioned variables failed to significantly predict occupational stress and job satisfaction, gender roles explained significant 
variance in facet measures of job satisfaction.

Despite the lack of prediction of sex, gender, and sex by gender interaction in regards to job satisfaction and occupational stress, gender role explained significant variance in both overall and facet measures of job satisfaction. A one-way MANOVA was run to determine if gender roles explained significant variance in occupational stress, overall job satisfaction, and facet measures of job satisfaction (compensation, coworker, work itself, promotions, and supervision). Follow-up ANOVAs and Tukey post hoc tests were run to identify these key differences. Androgynous individuals had significantly higher overall job satisfaction than masculine, feminine, or undifferentiated individuals. Masculine individuals also reported significantly higher compensation satisfaction than feminine individuals.

Lastly, a one-way MANOVA was run to investigate whether degree type explained significant variance in occupational stress, overall job satisfaction, and facet measures of job satisfaction (compensation, promotion, supervision, coworker, and work itself). The results revealed degree type failed to explain significant variance. One's occupation also failed to explain significant variance in these above variables.

The breadth of qualitative stressors indicated graduate students cope with a multitude of issues as they attempt to earn an advanced degree. The original groupings were: work, school, and personal relationships. These stressors were expanded and refined using content analysis and structural coding. The expansion and redefinition resulted in eight stressors being retained. The three main stressors were: academic, balancing realms, and family relationships. The academic stressor consisted primarily of work overload, dissertation/thesis, and assignments. The family stressor consisted 
primarily of relationship concerns and caring for one's loved ones- children, family, friends, and pets. The balancing realm stressor consisted of concerns of trying to balance family with school and work. The majority of these self reported stressors consisted of individuals reporting they were neglecting their family (spouse and children) to complete demands of the program. A few individuals reported the inability and frustration of trying to balance work with school. This stressor category primarily consisted of feelings that one was neglecting key personal relationships in their lives in order to complete the degree. These feelings of stress, imbalance, and lack of relationships can result not just in dissatisfaction with the program, but also dissatisfaction with life, and impact both physical and mental health (Anderson et al., 2000; Smith et al., 2006). The remaining stressors were: money, work, life issues, future, and not specified.

These eight categories were examined overall and then were examined separately by occupation and degree type. When the stressors were categorized by degree type, academic was still reported as the greatest stressor for the graduate student part-time worker. Though the stressor did vary somewhat based on occupation, the three stressors of academic, balancing realms, and family relationships remained the three highest reported stressors. Implications of these results are discussed in the Discussion. 


\section{CHAPTER V \\ DISCUSSION}

This chapter begins with a discussion of the major findings, followed by the summary and conclusions. Limitations and future research directions conclude the chapter.

\section{Major findings: Quantitative}

The main purpose of this dissertation was to develop a greater understanding of the graduate student part-time worker in regards to gender roles, occupational stress, and multiple measures of job satisfaction. The research questions underlying this dissertation will be discussed next.

\section{Sex, gender, sex by gender interaction and occupational stress}

The first research question sought to determine whether sex, gender, and the sex by gender interaction predicted occupational stress. This was tested through hierarchical regression. The results revealed that sex did not significantly predict occupational stress, gender and the gender by sex interaction failed to predict significant incremental variance in occupational stress. This is in line with prior research that sex does not result in differential experiences in occupational stress (e.g., Martoochio \& O’Leary, 1989). The true relationship between occupational stress and sex is unclear as some studies have found that women have higher occupational stress (e.g., Galankaskis, Anastasios, Helen, Catherine, \& Christine., 2009), whereas other studies have found there to be no significant differences in occupational stress across sex (e.g., Martoochio \& 
O'Leary, 1989). The findings in this study contradict those researchers (e.g., Galankaskis et al., 2009), who have speculated that females are less effective at coping with such heightened stress. Although the graduate student part-time worker is balancing several realms and several demands at one time, it may be the case that the defined schedule and structure may reduce the ambiguity for both sexes and these sex differences dissipate. As both sexes are experiencing the same stressors, the impact of the stress does not result in the same negative outcomes seen in past research (e.g., Galankasis et al, 2009.). Moreover, the graduate student may perceive the stressors to be worth it to attain the degree, which reduces the negative impact of the stressors. Future research needs to investigate if the allure of the degree offsets the current stressful conditions the graduate student part-time worker is experiencing.

Several of these previously mentioned studies investigated sex and satisfaction differences across multiple organizational levels. Smith (2009) found the effects of stress and satisfaction differed based on the organization level. It appears the experience of occupational stress across sex is more complex than originally believed (Carlson \& Mellor, 2004). The lack of significant findings across graduate students may be due to the lack of hierarchical structure in graduate school. As the graduate students are placed in the same organizational levels and are not differentiated into ability classification, this may reduce the effects of occupational stress that is experienced in organizations where individuals occupy diverse occupational levels. For instance, Smith (2009) found that female and male university staff were significantly more satisfied with their pay than faculty across both sexes. The more horizontal structure in graduate school may prevent the negative effect of occupational stress and job satisfaction from occurring in this 
academic learning environment. Future research where rankings are prevalent, such as in medical school, will determine if this is the case.

Past research has also indicated that the frequency of the stressor has a greater impact on job satisfaction than the intensity of the stressor (Brewer \& McMahan-Landers, 2003). It is possible that the experience of graduate school has led to the habituation of stressors due to the frequent stress of deadlines, papers and tests, thereby dulling the senses to the occupational stress for both gender and sex. Moreover, the majority of participants in this study were first and second year students. Past research has indicated that academic concerns are greater stressors to students as they progress through the program (e.g., Chew-Graham, 2003). Those who are used to excelling at classes may be frightened or anxious about impending comprehensive exams, thesis and/or dissertation. This stress may not be present yet for those in the initial stages of the program, which prevented prediction in occupational stress.

It is possible that the overall stress score does not allow for the clear differentiation of the true experience of occupational stress experienced in graduate school. In this study, the qualitative portion may allow for the greater determination of stressors across gender and sex. Fotinatos and Cooper (2010) found women suffered greater occupational stress from relationships even though their job satisfaction did not suffer. This finding is somewhat supported in the qualitative stressors in this study. Despite the lack of quantitative significance of occupational stress prediction across sex, academic, balancing realms, and family relationships were the three greatest stressors reported by participants in this sample. This echoes Fotinatos and Cooper's findings as the qualitative stressors were primarily reported by the female participants in this study 
and centered mostly around relationship concerns.

The true difference in the occupational stress experience may emerge from gender roles and is not due purely to sex. This is discussed further in the gender role portion. Past research has found those who work in gender congruent or gender incongruent roles do experience differential results of occupational stress. Jacobs et al. (2010) found that women who worked in gender-congruent roles reported less stress than those who worked in masculine roles. Conway (2000) and Wu and Shih (2010) also found that workers with higher degrees of masculinity experienced less stress. The gender roles predominately represented in this study were feminine and androgynous individuals. It may be the case that due to the lower number of masculine individuals in the study that these key differences based on gender roles were not seen. The predominant majors in the study required more feminine characteristics as these were primarily human service focused degrees (e.g., psychology and education). In traditionally feminine careers, such as special education, feminine gender roles are often applauded and individuals suffer less burnout (Eichinger, 2000). Feminine and androgynous individuals may have gravitated towards career paths that their gender roles were well suited for, and these majors may be the reason for the greater representation of feminine and androgynous individuals in the study.

While masculinity and femininity failed to predict any incremental variance in occupational stress over and above sex, both were negatively correlated with occupational stress as seen in Table 11. The significance of the negative correlation warrants further research investigation as past research has indicated that gender roles result in differential experiences of occupational stress (e.g., Eichinger, 2000; Jacobs et 
al., 2010). It is conceivable that higher levels of masculinity and femininity provide a certain buffer against the experience of occupational stress for the graduate student parttime worker, which future research could better determine.

\section{Sex, gender, sex by gender interaction and job satisfaction}

The second research question sought to determine whether sex, gender, and the sex by gender interaction significantly predicted job satisfaction. Sex, gender, as well as, the sex by gender interaction all failed to predict significant variance in overall job satisfaction. The lack of significant findings by sex and gender with respect to job satisfaction is in line with a subset of previous research (e.g., Moore, 2009; Zontek et al., 2009). Once again, this lack of significance is somewhat expected due to the contradictory nature of research findings with respect to job satisfaction and sex. Some scholars have found women have greater job satisfaction (e.g., Kim, 2005; Soeares et al., 2012), others have found men had greater satisfaction (e.g., Price \& Wulff, 2005;

Weaver, 1974), and still others, as previously noted, have found no difference between men and women's job satisfaction. Perhaps it is not purely sex that leads to the differences in job satisfaction, but rather that gender role is the crucial area. This appears to be a plausible hypothesis due to the significance of job satisfaction and gender roles found in several studies and discussed later within this study. Furthermore, this may explain why the findings of sex have been discrepant in the past as not all studies took into account the gender role in their job satisfaction investigation.

The evaluation of job satisfaction by participants may also have resulted in incongruent findings in the research. Affective or overall job satisfaction allows one to focus more on the emotional aspects of the job (e.g., Thompson \& Phau, 2012; Zhu, 
2013), whereas cognitive job facets focus on the subsets of job satisfaction (e.g., Moorman, 1993; Zhu, 2013). The evaluation of job satisfaction is crucial as the overall global evaluation of job satisfaction may not enable the differentiation of key differences in satisfaction across sex. Campbell and Campbell (2003) found in their study that overall job satisfaction did not reveal significant differences across sex. However, the facet measures utilized in Campbell and Campbell's study allowed several significant differences to emerge across facets, such as opportunities for advancement and work itself. The impact of the method used to evaluate job satisfaction is exhibited in this study. There was no difference across sex on overall satisfaction (affective job satisfaction), but the usage of the facet measure of job satisfaction (cognitive) showed key differences across gender role on subcomponents of job satisfaction. It may be the case that the overall measures of job satisfaction are not beneficial in determining the true differences in job satisfaction across sex. Future research will determine if this measurement dilemma occurs in other studies.

The differences found amongst gender roles on job satisfaction may only be seen in facet measures of job satisfaction. Past research has shown managers who scored higher on femininity placed greater emphasis on the emotional aspects of work relationships (Eddeslton et al, 2006). However, the job satisfaction variable included in hierarchical regression was an overall job satisfaction score, which did not differentiate the quality of work relationships from other aspects of the job. The dependent variable of coworker satisfaction was examined in the third research question and is discussed next. It may be the case that asking direct questions on the quality of work relationships would have resulted in determining if these key differences occur for the graduate student part- 
time worker and if prediction of job satisfaction was possible. However, Jacobs et al. (2010) has found that more feminine characteristics had a detrimental effect on job satisfaction. This same impact was not found in this study, which may be potentially due to the nature of the programs students are enrolled in. As these were primarily female dominated and service based programs, the feminine characteristics that are disapproved of in more masculine occupations (e.g., engineer) were more accepted and viewed more favorably. It may also be the case that the male participants in the study may have displayed more feminine traits and approved of the usage of such traits in the program. Future research with a greater inclusion of more masculine programs would allow the determination if programs and gender roles interact in the experience of job satisfaction.

Equity theory, where one evaluates the inputs and outcomes, could also potentially explain these non significant results (Adams, 1965). Past research has indicated that one determines the fairness of the promotions and outcomes in the organization by comparing themselves to a comparable other. As noted in Smith et al. (2006), the typical graduate student has to balance graduate school with the demands in the academic realm and demands in the workplace. It is possible that since the cohort is taking similar classes and working similar hours, that the individuals perceive their comparable others to be equal in regards to their level of inputs. As their inputs are equal and outcomes are readily synonymous, the ratio is viewed as equitable and satisfaction results. It is plausible that these equitable ratios have resulted in satisfaction and diminished any differences seen across sex.

Despite lack of prediction with these variables, both masculinity and femininity positively correlate with job satisfaction. This suggests some type of relationship with 
job satisfaction and gender that warrants future investigation. For instance, Johnson et al. (2006) and Ngo et al. (2014) found that masculine individuals experience greater job satisfaction. It is feasible that it is not simply biological or gender components that lead to this relationship, but the further differentiation of gender into the four gender roles, which is discussed in the next research question.

\section{Gender roles, job satisfaction, and occupational stress}

The third research question focused on the potential variance explained by gender roles on the primary variables (overall job satisfaction, occupational stress, and facet measure of job satisfaction [JDI]) in the study. The results revealed significant differences across the job satisfaction scales, whereas androgynous individuals had significantly higher job satisfaction than all other gender roles. No differences existed in occupational stress across gender roles. With respect to the facet measure of JDI, masculine individuals reported higher compensation satisfaction than feminine participants. There were no other significant differences on the remaining JDI facets: work itself, promotion, supervision, and coworker across gender roles. The significant findings, with respect to androgynous and masculine individuals are congruent with previous research (e.g., Eichinger, 2000; Peterson, 2006; Schuttenberg et al., 1990).

Despite the greater representation of females in this study, androgynous and feminine individuals composed the majority of the sample. Though it was believed at one time that female and male were synonymous with the feminine and masculine classification respectively (Borma \& White, 2003), this study provides further evidence that one can be classified as masculine or androgynous despite his or her sex. Furthermore, androgynous individuals reported significantly higher job satisfaction in 
comparison to the remaining gender roles. This same heightened satisfaction is seen in the occupational realms. Principals, teachers, special education teachers and counselors who were androgynous experienced lower stress and higher job satisfaction (Eichinger et al., 1991; Schuttenberg, O’Dell, \& Kaczala, 1990). The frequency of androgynous individuals in this study could explain the heightened self-reported job satisfaction for the graduate student part-time worker.

One finding that was not reported in this study was the need to circumvent one's femininity or act as one of the guys (Rolston, 2010). If this had occurred, this would have had the potential to negatively affect one's job satisfaction. Schexneider (2010) reported females felt compelled to downplay their feminine characteristics in order to be respected by their colleagues. Despite the vast qualitative stressors reported in this study, no one reported they felt inferior due to their sex or felt they were disrespected. As females in this study did not report the same negative effects due to one's sex, this lack of significant differences across job satisfaction is expected. As the programs reported in the study were primarily and traditionally female dominant fields, perhaps these same gender stereotypes were not seen in the programs. The elimination of such a stressor prevented the negative impact and potential attrition for the female graduate students. Future research would need to investigate this in greater detail to determine if these negative stereotypes were present in masculine dominated programs.

Masculine individuals in this study reported greater compensation satisfaction than feminine individuals. Past research (e.g., Peterson, 2006) has indicated that masculine individuals place a higher emphasis on compensation and the need to provide for their families than their feminine counterparts who placed more influence on intrinsic 
job characteristics, such as control or work relationships and support (e.g., ChisholmBurns et al., 2012; Eddleston et al., 2006). Surprisingly, significant differences in variance explained were not found in masculinity and femininity for intrinsic job satisfaction components. Conceivably it is due to the time restraints reported by the participants in the qualitative stressors. As many report they were unable to spend time with their family and friends due to work and school demands, one would expect that the quality of their work relationships would also suffer. However, femininity was significantly positively correlated with coworkers and work itself as seen in Table 11. Hence, it does appear that feminine graduate student part-time workers appear to have a stronger relationship with these intrinsic factors than masculine individuals as seen in prior research. It is conceivable that the free time the individuals have is spent with their family and close friends, which prevented the significant findings of work relationships in this study.

Similarly, past research has found that pay has a small correlation with one's overall job satisfaction (Piccolo and Judge, 2011; Williams et al., 2006). It is feasible that this is the reason why this was the only significant differences across masculine and feminine individuals. Research has found that men feel they must provide for their family (e.g., Pettersson, 2006) and place a greater emphasis on pay (De Kock et al., 1987; Smith et al., 2009). Men may be more likely to seek out higher part-time paying jobs in order to help out and place greater emphasis on compensation. Moreover, the remaining gender roles may have focused on other aspects of the experience, such as work or the future. This reconciles with previous research that when the work itself was valued, there was less of an influence of compensation and overall job satisfaction (Chesters \& Baxter, 
2011). As many report the degree will help them accomplish their career goals, they may be more willing to overlook their current compensation. Therefore, it appears that the pursuit of the degree may offset the negative impact of debt and lack of money. Future research that directly inquired about the pursuit of the degree and its link to current compensation would provide greater insight into this.

\section{Degree type, job satisfaction, and occupational stress}

Degree type was also investigated to determine if degree explained significant variance in occupational stress, overall job satisfaction, and the facet measure of job satisfaction (JDI). A one-way MANOVA revealed that there were no significant differences in variance explained across any of the major variables. This is in contrast to Girves and Wemmerus (1988) who found that doctoral students reported significantly higher satisfaction than Master's students. As this previous research was conducted last century, it is possible that these satisfaction differences have dissipated with the newer generations of graduate students. This finding may also be partially due to the skewed sample with the higher percentage of Master's degrees. Additionally, the majority of the sample was in the initial stages of the programs. It may be the case that the initial stages of the doctoral program do not allow key differences to be seen across degree type, as the student is still primarily focused on class and the applied process does not occur until later in the program (e.g., Chew-Graham, 2003). Those in the later stages of the doctoral program may have differences in their satisfaction and the findings would have mirrored Wasburn-Moses' (2008) results had they been investigated in later years. The change in stressors during one's tenure in graduate school will need to be investigated in future research. 
Social support is a well-known moderator of the stress and satisfaction relationship (e.g., Bellman et al., 2003). Past research (e.g., Lovitts, 2001) has also indicated that supportive cohorts and mentors could mitigate attrition in graduate school (Terrell et al., 2005). The lack of significant results by degree type may be due to the smaller nature of the universities utilized. The schools in this study had cohorts that ranged from 8-25 students. The tight knit cohort present in these universities may have reduced the potential negative impact of stress on the satisfaction of the graduate student. The positive impact of cohort and supportive classmates has been seen in several universities and is linked to lower attrition (e.g., Lovitts, 2001). The increased cohort usage may be the solution to prevent the negative impact of job satisfaction and occupational stress.

\section{Factor analysis of JDI, PSS-10, and BSRI}

The purpose of the sixth research question was to determine if the wellestablished instruments (PSS-10, BSRI, and JDI) were appropriate to use in the graduate student part-time worker population and if they maintained their consistent factor structure. The results of the exploratory factor analysis revealed the factorial validity of the instruments in the graduate student part-time worker sample in this study. However, only one instrument (BSRI) maintained its three factor model found in previous research (e.g., Choi et al., 2009). This may be due to the unique subset of the population that is balancing both the academic and professional realms.

The three factor structure of the BSRI was supported with exploratory factor analysis utilizing the eigenvalue greater than one rule and scree test. Though the parallel analysis suggested a two factor model, the eigenvalue greater than one rule, the scree test 
and prior research (e.g., Choi et al., 2009) supported the three factor model retained in this study. These three factors, personal masculinity, social masculinity, and femininity, explained $56.7 \%$ of the variance. This is consistent with past research (e.g., Choi et al., 2009) and may be potentially due to the changing nature of society. The items listed on the personal masculinity factor are no longer viewed solely as masculine traits, but instead as beneficial traits for all individuals to possess. Moreover, those in higher organizational levels, such as Vice President or executive levels, are viewed more favorably if they possess masculine traits regardless of sex (Ledet \& Henley, 2000).

Exploratory factor analysis of the PSS-10 revealed that only one factor composed this scale, which explained $50.11 \%$ of the variance. This factor is henceforth known as stress. This is consistent with the original conception of the PSS scale (Cohen et al., 1983). This factor structure was supported with the eigenvalue greater than one rule and parallel analysis. Though the scree test suggested the retaining of two factors, the overwhelming evidence from the eigenvalue greater than one rule and the parallel analysis supported the one factor model. Though the reliabilities were run and were acceptable for the research established subscales, the overwhelming evidence in exploratory factor analysis supported the one factor model and the subsequent MANOVA analyses were run accordingly. In the MANOVA analyses, overall stress was entered as a dependent variable instead of the initially proposed stress subscales. This discrepancy in factor structure may be due to the unique experience of the graduate student part-time worker. They may be so overwhelmed with the different components of stress in numerous areas in their life that these unique subscales (coping and perceived selfefficacy) do not emerge in this population. Though the two factor structure had been 
previously investigated in university students and confirmed (e.g., Örücü \& Demir, 2008), it did not appear that the part-time worker and graduate student qualification was utilized in their study. This factor structure needs to be investigated in future research to determine if the one-dimensional model is the best fit for the graduate student-part time worker.

The well-researched and well validated five factor structure of the JDI was not found in this study of the graduate student-part time worker. The eigenvalue greater than one rule and the scree test suggested the retaining of numerous factors beyond the wellestablished five factor model. Indeed, the principal components factor analysis with varimax rotation initially suggested 15 factors. The researcher determined six of these factors contained one or two items. Moreover, these factors could not be logically interpreted and the researcher could not identify a theme for the overall factor. The researcher determined that the factor analysis needed to be rerun with a restriction on the number of factors to be extracted. The results of the parallel analysis suggested to retain seven factors. The results of the parallel analysis were in line with the interpretability of the factors in this study. Due to this, the decision was made to rerun the factor analysis and only extract seven factors. However, the standard JDI scales were utilized to test the third and fourth research question due to factorial discrepancy. As this five factor model has shown repeated factorial validity in past research, this justified its use in these test. However, the researcher did examine the additional data composed of JDI subscales in a MANOVA. Androgynous individuals had significantly higher job satisfaction than other gender roles, but no other significant differences emerged on the major variables. The seven factors, which explained $50.4 \%$ of the variance, were as follows: work $(11.2 \%)$, 
supervisor $(10.1 \%)$, promotion $(8.1 \%)$, compensation $(6.8 \%)$, personal coworker $(5.7 \%)$, supportive coworker(4.8\%), and working coworker (3.6\%).

The initial extraction could be attributed to the unique graduate student part-time worker population. Perhaps the job satisfaction of the graduate student is affected by both his or her part-time job and academic demands. This spillover from one realm to the other may have led to this increased number of factors extracted from the instrument. For instance, research on the JDI consistently has reported one coworker factor consisting of coworker items. However, in this study, the coworker facet was divided into three factors. It appeared that the graduate student-part time worker evaluated the coworkers not just on their working ability and personal characteristics, but also on their support of the graduate student. The graduate student part-time worker could have appreciated the diligence and working ability of coworkers, but also found that they did not always support the graduate student's academic pursuits. This may have resulted in greater differentiation of the factors not seen in the general population. This was partially confirmed in the qualitative stressor component as many reported that their work and coworkers were not supportive of their advanced degrees. It appears that the graduate student may make additional evaluative judgments on how they are supported in all aspects of their lives, which is reflected in the factor analysis.

To take into account the potential differences that may result across degree type with the additional responsibility of occupation, a one-way MANOVA was conducted to determine if this resulted in significant variance explained across the major variables (occupational stress, overall job satisfaction and facet measure of job satisfaction). Occupation and the degree by occupation interaction failed to explain significant variance 
in overall or facet measures of job satisfaction and occupational stress. These findings suggest that it is not a specific occupation or specific degree type that results in reduced satisfaction or increased occupational stress. Instead it appears to be the overall graduate school and part-time working experience where the differences exist. This will be discussed further in the implications section when the stressors revealed by participants from the answers to the qualitative questions are discussed.

\section{Major findings: Qualitative}

The qualitative analysis, research question five, expanded on the results of the quantitative study. The qualitative portion of the study allowed for the creation of a matrix that delineated different stressors based on the students' open ended response to the question "What are the three main stressors in your life?" The utilization of an open ended question enabled the graduate student part-time worker to provide their own unique answers which were then compared to past empirical findings on graduate students. Qualitative analysis revealed that academics, balancing realms, and family relationships were the three biggest stressors reported in this population across occupations and degrees.

These findings echo prior research that the graduate student part-time worker experiences stress not just from the academic and graduate school experience, but from other realms (Golde, 1996; Lovitts, 2001; Smith et al., 2006). Though academic concerns were the primary stressors cited in this study, only two participants mentioned they may not have the academic fortitude to continue in their academic pursuits. Instead many participants reported the following stressors: being assigned too much work, the class load, the dissertation and/or thesis, and trying to find appropriate classes for the 
degree. This academic stressor is understandable as graduate school does require hard work to gain the expertise that is congruent with advanced degrees, such as a $\mathrm{PhD}$ or Masters. This may be startling to the graduate student part-time worker who has become accustomed to exceeding at academics and may mistakenly believe that the graduate school process will not require much more work than the undergraduate classes.

Not surprisingly, balancing realms and family relationships were the second and third cited stressors in the qualitative component. The majority of the sample were in the 20-29 age segment. Individuals in this age range are typically working in their first fulltime job, may be adjusting to married life, and some may even be in the process of becoming first time parents. These concerns may not have been present during an individual's undergraduate years. Several graduate students reported that the undergraduate experience was easier as they did not have the same responsibilities that they do now, including: a family, job, and bills. When these added stressors surface in combination with graduate school, the graduate students feel overwhelmed and unable to balance everything. These concerns are echoed in the money and personal stressor categories as many report concerns over bills and debt and mention they have little personal time or time to rest. This enhances feelings of stress from the academic realm and may result in attrition if the graduate student perceives the degree as too costly of an investment.

\section{Conclusion}

This dissertation was just a small step in understanding the graduate student parttime worker experience. Empirical evidence does exist in this study and in previous research that the graduate student part-time worker is valiantly trying to balance multiple 
responsibilities (e.g., Lovitts, 2001; Smith et al, 2006.). The attrition of doctoral students is a critical issue as $50 \%$ of the students fail to complete the graduate program (Cassuto, 2013; Golde, 2005). This is particularly problematic as economists are projecting a sharp increase in job openings over the next few years with the retirement of baby boomers (Dohm, 2000). If this increase in job openings is coupled with the lack of qualified applicants due to attrition of graduate students, this could potentially lead to significant gaps across multiple occupational spheres (Dohm, 2000). Such an effect has the potential to affect society as a whole and may result in delays in care or less qualified professionals in such positions. However, this graduate school attrition cannot be attributed solely to the dearth of academic skills as many in this study reported lesser concerns of their ability, but more towards the time investment and its impact on all areas of their lives.

The results of this study echo current research that the graduate student is a unique individual and a new type of student (e.g., Anderson et al., 2000; Smith et al., 2006). The current graduate student is not simply focused on the graduate school process, which may have been the case in the graduate students of years past. Instead the current graduate student valiantly tries to balance academic demands with the demands of a career and the demands of his or her personal life. These personal sacrifices may lead the graduate student part-time worker to become overwhelmed with stress and doubt their abilities to cope with such stress.

Graduate students may also enter the program with unrealistic expectations. Graduate students, who perform well at the undergraduate level, may believe that the higher caliber graduate school experience will be similar in level of difficulty or expect to maintain the same GPA as they achieved as an undergraduate. Academic advisers that 
address these issues and help graduate students manage expectations could hopefully reduce the stress students feel in graduate school. While this study found that sex and gender role did not predict job satisfaction and occupational stress, there are some promising findings in regards to gender role in the areas of job satisfaction. Androgynous graduate student part-time workers reported significantly higher job satisfaction than masculine, feminine, and undifferentiated graduate student part-time workers. Masculine individuals also reported significantly higher job satisfaction than their feminine counterparts. This phenomenon needs to be investigated in future research to determine the true effect gender role has on job satisfaction.

\section{Implications}

This dissertation is relevant in the current state of the economy and in light of new legislation on student loans. This legislation addresses both the student repayment process and the legislation affecting school funding. Though the legislation addresses unique aspects for the student or the school, this legislation has the potential to impact both the graduate application process and also graduation rates.

Though there were several significant quantitative findings, the qualitative findings may be the most telling in regards to the current graduate student part-time worker. In the past, many researchers have focused on the social support of the graduate student (Carroll et al., 2013) or the reasons for attrition (Golde, 2005). However, the results of this study indicate that it is less of the separation of the fields as much as it is the cumulative total of stressors from all areas of the graduate student part-time workers' life: academic, work, and family. Current graduate students, professors, and university 
administrators must work together to alleviate the stressors experienced by the graduate student in an effort to reduce attrition. Greater effort must be utilized to train the graduate student part-time worker in coping techniques and time management to remedy the imbalanced realms and to reduce the attrition of the graduate student part-time worker.

In an optimal world, both the academic sphere and occupational sector would work together to reduce the stress and imbalanced life the graduate student part-time worker experiences. As the financial impact is more geared toward the graduate school, it is crucial that training be enacted by the graduate school in order to reduce the attrition one experiences. Training sessions such as: balancing work, educating the social support, and dissertation workshops will bolster the graduate student part-time worker's resolve. These efforts will maintain the persistence of the current graduate student's dedication, and also provide a supportive environment for graduate student part-time workers for years to come.

Students in the past may have been saddled by student loan debt and delayed graduate school until they could reduce their student loan debt (Goodnight, Hingstman, \& Green, 2014). However, in light of current legislation in regards to the student loans, many individuals are able to reduce the student balance they owe, have a longer repayment plan, or in some cases have the debt eradicated. Many are beginning to feel the student loan debt burden ease and may begin to entertain the idea of an advanced degree (Goodnight et al., 2014). Indeed the two programs most represented in this study (education and psychology) require an advanced graduate degree in order to reach higher occupational levels in these fields. However, potential graduate students do not want to set themselves up to fail. When they begin to look at their schooling options, they want 
to attend a school with a history of high graduation rates, which increases their confidence that they will be able to attain this higher academic degree. Lower graduation rates are particularly problematic as this may dissuade the best candidates from applying to a program. This is a troubling aspect that may result in fewer candidates or candidates with lower qualifications applying to such graduate school programs.

Moreover, graduate schools and universities are increasingly being held accountable for the graduation rates of their students. This is starting to be linked to funding and lower graduation rates can potentially reduce the funding universities receive. Therefore, graduate schools and universities alike are motivated to increase graduation rates and determine factors that impede graduation. The results of this study suggest the fault for attrition may not be simply low admission standards, but rather the graduate student having to manage stress from multiple realms and siphoning off needed resources. If these resources are stretched too thin, the graduate student may withdraw from the university either permanently or temporarily.

This study suggests that steps must be taken to help the graduate student part-time worker once they are enrolled in the program. Several undergraduate programs have systems known as early alerts or early interventions, where they tabulate individuals who are struggling academically or are voicing lack of commitment to the university. By initiating such programs in graduate school and identifying when these students begin to flounder, steps can be taken to intervene. These steps can consist of: providing study tips, time management advice, and offers to reduce their class load for a semester. Reducing the class load may postpone the graduation date and increase time spent in the program, but in some instances it may prevent a qualified candidate from leaving the program 
when under increased stress.

Several universities have also offered the opportunities for graduate students to attend the program part-time or restrict the hours that the graduate student may work during their tenure in graduate school. Though this study consisted of part-time workers, many reported the demands of work conflicted with academic demands. One could speculate this would be magnified in full-time workers. Allowing and encouraging fulltime workers to enroll as part-time students would enable them the opportunity to obtain the advanced degree while minimizing the stress one experiences when trying to balance academic and work responsibilities. Several full-time workers may try to carry a fulltime class load on top of their full-time work schedule to graduate sooner, which will likely result in higher occupational stress and possible attrition. If part-time enrollment cannot be supported by the university, it may behoove the graduate school to restrict what work or the number of work hours a graduate student can work during their enrollment in graduate school. This will again allow the graduate student part-time worker to mitigate the effects of trying to balance multiple and conflicting demands.

The perception of the graduate school process as challenging, instead of daunting, will allow the graduate student part-time worker to persist in the degree when their resources are challenged by workload and time constraints. Steps must be taken to ensure that graduate school is viewed as a challenge stressor, which is a stressor that challenges the individual, but promotes growth and achievement (Podsakoff, LePine, \& LePine, 2007). This is a critical distinction when one is unsure of the graduate school process and exact graduation date. By ensuring that students know exactly what to expect and the steps needed to graduate, this will reduce ambiguity and increase one's 
satisfaction with the program. Satisfaction is a crucial aspect in the graduate school process, as attrition can result as a consequence of heightened stress and reduced job satisfaction. When a graduate student part-time worker leaves the university it is problematic, as they have had time invested in them by professors, cohort, and administrators. This time spent could have been better utilized in helping another student succeed in graduate school.

However, it is not just the university who is plagued by negative repercussions from the student leaving graduate school. The student also has suffered the negative consequence of not being able to attain the degree or career they sought for themselves. Those who leave the university report feeling depressed and suicidal (Hoskins \& Goldberg, 2005; Lovitts, 2001) and agonized over the decision (Golde, 2005). Therefore, it is crucial to prevent the qualified professional from leaving the university before they have the chance to achieve their goals. Possibly more important to graduate schools, the reduced numbers of those attending graduate school will result in lower funding and lower numbers of qualified candidates.

Many current and past graduate students report or may recall being told graduate school should remain your primary focus. However, this is problematic when one is pulled in many directions from work, school, family, and the need to survive in this economy. Many graduate students may have dropped out of the program when they realized they could not devote the time they needed to satisfy the program's requirements. As many in this study reported that they did not have time to relax, sleep, or exercise, it may be time to recognize that graduate students are juggling multiple realms and to adjust to the new generation of graduate students. This is crucial as high attrition rates and/or 
low graduation numbers may prevent qualified individuals from applying for higher education as they may feel that they are setting themselves up for failure.

Though the graduate school process is a challenging academic endeavor, successors of the program look back on it fondly. Steps taken to alleviate stress or increase coping skills for the graduate student part-time worker will allow more graduate students to successfully complete the program. This will increase satisfaction not only for the current graduate students, but also for graduate schools who can boast high graduation rates and the success of their alumni, encouraging other potential students to attend the program and become the newest success stories.

\section{Limitations and Future Research}

There were several limitations in this study that do limit the generalizability of the results. The first limitation is that the study was conducted in a narrowly defined geographical region with four schools represented. These four schools may have unique characteristics that are not representative of other graduate schools. The second limitation is that this study relied on self-report data from the graduate students. It is conceivable that this data was influenced by the timing the instruments were completed and they may have cited more stress as the semester demands were increasing. Lastly, several participants began the study, but failed to complete the instruments. They may have been more stressed out with the questions, which resulted in their termination from the study. They may have also judged the study to be too lengthy to complete. This could also explain the lower response rate, which severely limits the generalizability of the results. Future research with a smaller job satisfaction facet measure will be 
beneficial in determining the true representation of the graduate student part-time worker experience. As this is one of the few studies conducted on the graduate student part-time worker in the U.S., there are several directions that these research results can be expanded on.

As academics, balancing realms, and family are the most commonly reported stressors, it is crucial to address these issues and investigate this in future research. Although this study investigated the three main stressors inflicting the graduate student part-time worker, this study did not ask about their coping strategies or if this was affecting their commitment to the graduate school. It would be particularly telling in future studies to determine if any of these stressors are impacting their decision to remain enrolled in graduate school. By determining these stressors, this will enable graduate schools to determine trends to intervene with students to prevent the possible attrition from graduate school.

This study only investigated graduate students part-time workers and neglected to study other classifications of graduate students: full-time workers and full-time enrollment, full-time students without work, and part-time student and full-time workers. As this research gap is still present in today's society, greater investigation into the subgrouping of graduate students would bequeath greater understanding of the experience. It is feasible that the different categorizations of graduate school may experience differential stressors that need to be addressed appropriately. Moreover, it is believable that the attrition rates are different based on these previously mentioned classifications. It would be advantageous to determine these characteristics in future research as this will enable greater insight that can reduce the attrition. 
This study also did not address the potential change in the social support network for the graduate student. Perhaps the graduate student may experience changes in their social network, which may result in feelings of isolation. This is problematic as many graduate students may perceive the potential loss of the relationships as too costly for pursuit of the degree. Smith et al. (2006) even had several participants in his study report they would have graduated sooner had they neglected their family more. As far as this researcher can tell, such an investigation has not been undertaken, which could be due to the lower consideration of personal issues compared to academic concerns and graduate school attrition.

Similarly, future research may want to address the perceptions of the graduate student part-time worker by their loved ones. Though the impact of school on relationships has been examined in spouses, it does not appear friends or children of those enrolled in graduate school have been researched before. These loved ones may not fully understand the process the graduate student is undergoing. If this is the case, it may be beneficial to educate the support network of the graduate students to help them realize the rigorous demands placed on their loved ones to reduce the stress that their loved ones feel.

Moreover, the differences revealed by the gender role classification in this study suggest that the gender role needs to be investigated in the graduate student part-time worker environment in regards to job satisfaction to determine the true effects of gender role on the graduate school experience. Though it has not been previously investigated in U.S. graduate students as far as this researcher can tell, differences have been denoted in various populations across the gender role. Jacobs et al. (2010) found that men working 
in gender-incongruent roles reported significantly lower levels of stress than those in masculine jobs in regards to work-life balance and overload. Similarly, Conway (2000) found that workers with a higher degree of masculinity exhibited less stress and depression than workers with a higher degree of femininity (Wu \& Shih, 2010). Though these same differences in occupational stress were not found in the current study, it is a valuable gap for future research. It is possibly the case that feminine or androgynous individuals are more likely to apply and enroll in the graduate school program and remain engaged in the program. The classifications of individuals in this study suggest that this is plausible as the majority of participants were androgynous or feminine. Future research investigating the graduate students' gender role in relation to attrition will indicate if such a relationship exists.

Lastly, one area that was not asked about in this dissertation was whether the employer was paying for their tuition or if the student personally paid for their studies. If it was paid for by the organization, the graduate student may have perceived that the entity valued the advanced degree and would be more likely to help the employee balance work and attend school. During the tough economic times, it would have led to a difference in attrition if the employee had to pay it for themselves. On the other hand, the graduate student part-time worker may be less likely to persist in the program if they feel that it did not personally impact their finances. Future studies that examine tuition reimbursement may shed more light on whether this affects attrition or not. 


\section{REFERENCES}

Acker, J. (1992). Gendering organizational theory. In J. M. Shafritz , \& J. F. Ott (Eds.), Classics of organizational theory (pp. 480-489). Boston, MA: Wadsworth Cengage Learning.

Adamo, S. (2013). Attrition of women in the biological sciences: Workload, motherhood, and other explanations revisited. Bioscience, 63, 43-48.

http://dx.doi.org/10.1525/bio.2013.63.1.9

Adams, J. S. (1965). Inequity in social exchange. Advances in Experimental Social Psychology, 2, 267-299. http://dx.doi.org/10.1016/S0065-2601(08)60108-2

Alexander, S., \& Ruderman, M. (1987). The role of procedural and distributive justice in organizational behavior. Social Justice Research, 1, 117-198. http://dx.doi.org/10.1007/BF01048015

Alicke, M. D., Klotz, M. L., Breitenbecher, D. L., Yurak, T .J., \& Vredenburg, D .S. (1995). Personal contact, individuation, and the above average effect. Journal of Personality and Social Psychology, 68, 804-825.

http://dx.doi.org/10.1037/0022-3514.68.5.804 
Allen, R. S., Takeda, M., \& White, C. S. (2005). Cross-cultural equity sensitivity: A test of differences between the United States and Japan. Journal of Managerial Psychology, 20, 641-662. http://dx.doi.org/10.1108/02683940510631426

Allen, R. S., \& White, C. S. (2002). Equity sensitivity theory: A test of responses to two types of under-reward situations. Journal of Managerial Issues, 14, 435-451.

Anderson, G. L., Gumport, P. J., Rowan, B., \& Schneider, G. (2000, April). The organizational structure of the university: Its impact on epistemological diversity. Paper presented at the annual meeting of the American Educational Research Association, New Orleans, LA.

Avinash, K. S. (2006). Organizational climate as a dependent variable. Journal of Management Research,6, 125-136.

Baird, L. (1993). Studying graduate student retention and degree attainment: Resources for researchers. New Directions for Institutional Research, 80, 81-90. http://dx.doi.org/10.1002/ir.37019938009

Balzer, W. K., Kihm, J. A.,. . . Parra, L. F. (1997). User's manual for Job Descriptive Index (JDI; 1997 Version) and the Job in General scales. Bowling Green, Bowling Green State University.

Barhem, B. (2008). Are global managers able to deal with work stress. Journal of Accounting, Business \& Management, 15, 53-70.

Bashir, M., Jianqiao, L., Jun, Z., Ghazanfar, F., \& Khan, M. M. (2011). The role of demographic factors in the relationship between high performance work system and 
job satisfaction: A multidimensional approach. International Journal of Business and Social Science, 2, 207-218.

Bellman, S., Forester, N., Still, L., \& Cooper, C. L. (2003). Gender differences in the use of social support as a moderator of occupational stress. Stress and Health, 19, 45-48. http://dx.doi.org/10.1002/smi.954

Bem, S. L. (1974). The measure of psychological androgyny. Journal of Consulting and Clinical Psychology, 42, 155-162. http://dx.doi.org/10.1037/h0036215

Bem, S. L. (1975). Sex role adaptability: One consequence of psychological androgyny. Journal of Personality and Social Psychology, 31, 634-643. http://dx.doi.org/10.1037/h0077098

Bem, S. L. (1979). Theory and measurement of androgyny: A reply to the PedhazurTetenbaum and Locksley-Colten critiques. Journal of Personality, 37, 1047-1054. http://dx.doi.org/10.1037/0022-3514.37.6.1047

Bem, S. L. (1984). Androgyny and gender schema theory: A conceptual and empirical integration. Nebraska Symposium on Motivation, 32, 179-226.

Bem, S. L. (1993). The lenses of gender: Transforming the debate on sexual inequality. New Haven, CT: Yale University Press.

Berry, A. B. (2012). The relationship of perceived support to satisfaction and commitment for special education teachers in rural areas. Rural Special Education Quarterly, 31, 3-14. 
Blau, P. M. (1964). Exchange and power in social life. New York, NY: Wiley.

Bole, J. S., Wood, J. S., \& Johnson, J. (2003). Interrelationships of role conflict, role ambiguity, and work-family conflict with different facets of job satisfaction and the moderating effects of gender. Journal of Personal Selling and Sales Management, 23, 99-113.

Boles, J. S., \& Babin, B.J. (1994). Role stress revisited: One or two constructs? Journal of Marketing Theory and Practice, 2,57- 69.

Borna, S., \& White, G. (2003). "Sex' and "gender": Two confused and confusing concepts in the women in corporate management literature. Journal of Business Ethics, 47, 89-99. http://dx.doi.org/10.1023/A:1026082400801

Bosker, B. (2012, May 7). Fortune 500 list boasts more female CEOs than ever before. Huffington Post. Retrieved from http://www.huffingtonpost.com /2012/05/07 /fortune-500-female -ceos_n_1495734.html

Boswell, W. R., Olson- Buchanan, J. B., \& LePine, M. A. (2004). Relations between stress and work outcomes: The role of felt challenge, job control and psychological strain. Journal of Vocational Behavior, 64, 165-181. http://dx.doi.org/10.1016/S0001-8791(03)00049-6

Bowen, W. G., \& Rudenstine, N. L. (1992). In Pursuit of the Ph.D. Princeton, NJ: Princeton University Press.

Branch, D. (2011). Employee motivation, recognition, rewards, and retention: Kicking it up a notch! CPA Practice Management Forum, 7, 5-7. 
Brewer, E. W., \& McMahan-Landers, J. (2003). The relationship between job stress and job satisfaction among industrial and technical teacher educators. Journal of Career and Technical Education, 20, 37-57.

Brief, A. P. (1998). Attitudes in and around organizations. Thousand Oaks, CA: Sage.

Brief, A. P., \& Roberson, L. (1989). Job attitude organization: An exploratory study. Journal of Applied Social Psychology, 19, 717-727. http://dx.doi.org/10.1111/j.1559-1816.1989.tb01254.x

Brief, A. P., \& Weiss, H. M. (2002). Organizational behavior: Affect in the workplace. Annual Review of Psychology, 53, 279-307. http://dx.doi.org/10.1146/annurev.psych.53.100901.135156

Britton, D. (1997). Perceptions of the work environment among correctional officers: Do race and gender matter? Criminology, 35, 85-105. http://dx.doi.org/10.1111/j.17459125.1997.tb00871.x

Campbell, D. J., \& Campbell, K. M. (2003). Global versus facet predictors intention to quit: Differences in a sample of male and female Singaporean managers and nonmanagers. International Journal of Human Resource Management, 14, 11521177. http://dx.doi.org/10.1080/0958519032000114246

Campo, M. A., Weiser, S., \& Koenig, K. L. (2009). Job strain in physical therapy. Physical Therapy, 89, 946- 956. http://dx.doi.org/10.2522/ptj.20080322

Carlson, D. S., Ferguson, M., Perrewé, P. L., \& Whitten, D. (2011). The fallout from abusive supervision: An examination of subordinates and their partners. 
Personnel Psychology, 64, 937-961. http://dx.doi.org/10.1111/j.1744$6570.2011 .01232 . x$

Carlson, J. H., \& Mellor, S. (2004). Gender-related effects in the job-design-jobsatisfaction relationship: An interactional approach. Sex Roles, 51, 237-247. http://dx.doi.org/10.1023/B:SERS.0000037767.72299.bd

Carpenter, B. D. (2011). Examining teachers' perceptions of psychological gender and leadership behavior of principals in public elementary schools. (Unpublished doctoral dissertation). University of Louisville, Kentucky.

Carroll, D., Ng, E., \& Birch, D. (2009). Retention and progression of postgraduate business students: An Australian perspective. Open Learning, 24, 197-209. http://dx.doi.org/10.1080/02680510903201599

Cassuto, L. (2013, July 1). Ph.D. Attrition: How much is too much? The Chronicles of Higher Education. Retrieved from: http://chronicle.com/article/PhD-AttritionHow-Much-Is/140045/

Cavanaugh, M. A., Boswell, W. R., Roehling, M. V., \& Bourdreau, J.W. (2000). An empirical examination of self-reported work stress among U.S. managers. Journal of Applied Psychology, 85, 65-74. http://dx.doi.org/10.1037/0021-9010.85.1.65

Chan, D. W. (1991). Depressive symptoms and depressed mood among Chinese medical students in Hong Kong. Comp Psychiatry, 32, 170-180. http://dx.doi.org/10.1016/0010-440X(91)90010-A 
Chen, C. Y., Mao, H.Y., \& Hsieh, A. T. (2012). Role ambiguity, employee gender, and workplace friendship. Psychological Reports, 110, 719-730.

http://dx.doi.org/10.2466/01.07.21.PR0.110.3.719-730

Chesters, J., \& Baxter, J. (2011). Prisoners of love? Job satisfaction in care work. Australian Journal of Social Issues, 46, 49-67.

Chew-Graham, C. A., Rogers, A., \& Yassin, N. (2003). “I wouldn't want it on my CV or their records": Medical students' experiences of help-seeking for mental health problems. Medical Education, 37, 873-880. http://dx.doi.org/10.1046/j.13652923.2003.01627.x

Chisholm-Burns, M. A., Spivey, C. A., Billheimer, D., Schlesselman, L., Flowers, S. K., et al. (2012). Multi-institutional study of women and underrepresented minority faculty members in academic pharmacy. American Journal of Pharmaceutical Education, 76,7. http://dx.doi.org/10.5688/ajpe7617

Cho, J., Ramgolam, D. I., Schaefer, K. M., \& Sandlin, A. N. (2011). The rate and delay in overload: An investigation of communication overload and channel synchronicity on identification and job satisfaction. Journal of Applied Communication Research, 39, 38-54. http://dx.doi.org/10.1080/00909882.2010.536847

Choi, N., \& Fuqua, D. R. (2003). The structure of the Bem Sex Role Inventory: A summary report of 23 validation studies. Educational and Psychological Measurement, 68, 872-887. http://dx.doi.org/10.1177/0013164403258235 
Choi, N., Fuqua, D. R., \& Newman, J. L. (2008). The Bem Sex-Role Inventory: Continuing theoretical problems. Educational and Psychological Measurement, 68, 881-900. http://dx.doi.org/10.1177/0013164408315267

Choi, N., Fuqua, D. R., \& Newman, J. (2009). Exploratory and confirmatory studies of the structure of the Bem Sex-Role Inventory-short form with two divergent samples. Educational and Psychological Measurement, 69, 697-705.

Church, M. K. (2007). Emotional intelligence as the moderator between job satisfaction and occupational stress in mental health professionals (Unpublished Master's thesis). Xavier University, Ohio.

Clark, H.K., Murdock, N. L., \& Koetting, K. (2009). Predicting burnout and career choice satisfaction in counseling psychology graduate students. The Counseling Psychologists, 37, 580-606. http://dx.doi.org/10.1177/0011000008319985

CMA Management (2011, December/January). Poll: Canadians blame boss as reason for leaving the job, 8.

Cohen, J. (1992). A power primer. Psychological Bulletin, 112, 155-159.

Cohen, S., Kamarck, T., \& Mermelstein, R. (1983). A global measure of perceived stress. Journal of Health and Social Behavior, 24, 385-396. http://dx.doi.org/10.2307/2136404

Cohen, S., \& Williamson, G. M. (1988). Perceived stress in a probability in sample of the United States. In S. Spacapan \& S. Oskamp (Eds.), The social psychology of health (pp. 31-67). Newbury Park, CA: Sage. 
Conway, M. (2000). On sex roles and representations of emotional experiencemasculinity, femininity, and emotional awareness. Sex Roles, 43, 687-698. http://dx.doi.org/10.1023/A:1007156608823

Cooke, D. K., Sims, R. L., Peyrefitte, J. (1995). The relationship between graduate student attitudes and attrition. Journal of Psychology: Interdisciplinary and Applied, 129, 677-688. http://dx.doi.org/10.1080/00223980.1995.9914938

Cooper, D. A. (2000). Changing the faces of mathematics PhD's: What we are learning at the University of Maryland. In M. E. Strutchens, M. L. Johnson, and W. F. Tate (EDs.), Changing the faces of mathematics: Perspectives on African Americans (pp. 179-192). Reston, VA: National Council of Teachers of Mathematics.

Cotton, S. J., Dollard, M. F., \& de Jonge, J. (2002). Stress and student job design: Satisfaction, well being, and performance in university students. International Journal of Stress Management, 9, 147-162. http://dx.doi.org/10.1023/A:1015515714410

Cranston, S., \& Keller, S. (2013). Increasing the 'meaning quotient' of work. McKinsey Quarterly, 1, 48- 59.

Crosby, F. (1982). Relative deprivation and working women. New York, NY: Oxford University Press.

Cross, S., \& Bagilhole, B. (2002). Girls' jobs for the boys? Men, masculinity and nontraditional occupations. Gender, Work and Organization, 9, 204-226. http://dx.doi.org/10.1111/1468-0432.00156 
Deaux, K. (1976). The behavior of men and women. Monterey, CA: Brooks/Cole.

De Kock, U., Felce, D., Saxby, H., \& Thomas, M. (1987). Staff turnover in a small house service. Mental Handicap, 15, 97-101. http://dx.doi.org/10.1111/j.14683156.1987.tb00406.x

DeVellis, R. F. (2003). Scale development: Theory and applications $\left(2^{\text {nd }}\right.$ ed.). Thousand Oaks, CA: Sage Publications, Inc.

Devoe, S. E., Lee, B. Y., \& Pfeffer, J. (2010). Hourly versus salaried payment and decisions about trading time and money over time. Industrial and Labor Relations Review, 63, 627- 639 .

Dillman, D. A., Smyth, J. D., \& Christian, L. M. (2009). Internet, mail, and mixed-mode surveys: The tailored design method $\left(3^{\text {rd }}\right.$ ed.). Hoboken, NJ: John Wiley \& Sons, Inc.

Dinovitzer, R., \& Garth, B. (2010). Perspectives on association of attrition: Getting at the cause of dissatisfaction. Compensation \& Benefits for Law Offices, 10,7-10.

Disley, P., Hatton, C., \& Dagnan, D. (2009). Applying equity theory to staff working with individuals with intellectual disabilities. Journal of Intellectual \& Developmental Disability, 34, 55-66.

http://dx.doi.org/10.1080/13668250802684701

Dodson, T. A., \& Border, L. A. (2006). Men in traditional and nontraditional careers: Gender role attitudes, gender role conflict, and job satisfaction. Career 
Development Quarterly, 54, 283-296. http://dx.doi.org/10.1002/j.21610045.2006.tb00194.x

Dohm, A. (2000). Gauging the labor force effects of retiring baby-boomers. Monthly Lab. Rev., 123, 17.

Dunn, L. B., Iglewicz, A., \& Moutier, C. (2008). A conceptual model of medical student well-being: Promoting resilience and preventing burnout. Academic Psychiatry, 32, 44-53. http://dx.doi.org/10.1176/appi.ap.32.1.44

Duxbury, L., Higgins, C., \& Mills, S. (1992). After-hours telecommuting and work/family conflict: A comparative analysis. Information Systems Research, 3, 173-190. http://dx.doi.org/10.1287/isre.3.2.173

Eddleston, K. A., Powell, J. F., \& Powell, G. N. (2006). Explaining sex differences in managerial career satisfier preferences: The role of gender self- schema. Journal of Applied Psychology, 91, 437-445. http://dx.doi.org/10.1037/00219010.91.2.437

Eichinger, J. (2000). Job stress and satisfaction among special education teachers: Effects of gender and social role orientation. International Journal of Disability, Development and Education, 478, 497-512.

Eichinger, J., Heifetz, L. H., \& Ingraham, C. (1991). Situational shifts in social role orientation: Correlates of work satisfaction and burnout among women in special education. Sex Roles, 25, 427-442. http://dx.doi.org/10.1007/BF00292532 
Ely, R. J. (1995). The power in demography: Women's social constructions of gender identity at work. The Academy of Management Journal, 38, 589-634. http://dx.doi.org/10.2307/256740

Ferratt, T. W., Dunham, R. B., \& Pierce, J. K. (1981). Self-report measures of job characteristics and affective response: An examination of discriminant validity. Academy of Management Journal, 24, 780-794. http://dx.doi.org/10.2307/256176

Ferreira, M. M. (2003). Gender issues related to graduate student attrition in two science departments. International Journal of Science Education, 25, 969- 989. http://dx.doi.org/10.1080/09500690305026

Fickey, A., \& Pullen, E. (2011). Maintaining sanity in graduate school: A brief commentary on the significance of informal networks. Geographical Bulletin, 52, 64-66.

Firth-Cozens, J. (2003). Doctors, their wellbeing, and their stress. British Medical Journal, 326, 670-671. http://dx.doi.org/10.1136/bmj.326.7391.670

Fischer, R., \& Boer, D. (2011). What is more important for national well-being: Money or autonomy? A meta-analysis of well-being, burnout, and anxiety across 63 societies. Journal of Personality and Social Psychology, 101, 164-184. http://dx.doi.org/10.1037/a0023663

Fisher, C. D. (2000). Mood and emotions while working: Missing pieces of job satisfaction? [Special issue]. Journal of Organizational Behavior, 21, 185-202. 
http://dx.doi.org/10.1002/(SICI)1099-1379(200003)21:2\%3C185::AIDJOB34\%3E3.0.CO;2-M

Fisher, M. J. (2011). Sex differences in gender characteristics of Australian nurses and male engineers: A comparative cross-sectional study. Journal of Contemporary Nurse: A Journal for the Australian Nursing Profession, 39, 36-50. http://dx.doi.org/10.5172/conu.2011.39.1.36

Forgarty, T.J. (1996). Gender differences in the perception of the work environment within large international accounting firms. Managerial Auditing Journal, 11, 10-19. http://dx.doi.org/10.1108/02686909610107924

Ford, D. K., Truxillo, D. M., \& Bauer, T. N. (2009). Rejected, but still there: Shifting the focus in applicant reactions to the promotional context. International Journal of Selection and Assessment, 17, 402-416. http://dx.doi.org/10.1111/j.14682389.2009.00482.x

Fotinatos, R., \& Cooper, C. (2005). The role of gender and social class in work stress. Journal of Managerial Psychology, 20, 14-23. http://dx.doi.org/10.1108/02683940510571612

Fox, A. (2011). What you like about your job. HR Magazine, 22-27.

Frenkel, M. (2008). Reprogramming femininity? The construction of gender identities in the Israeli hi-tech industry between global and local gender orders. Gender, Work, and Organization, 15, 352-374. http://dx.doi.org/10.1111/j.14680432.2008.00398.x 
Gaensbauer, T. J., \& Mizner, G. (1980). Developmental stresses in medical education. Psychiatry, 43,60-70.

Galankaskis, M., Anastasios, S., Helen, K., Catherine, K., \& Christine, K. (2009). Gender differences in experiencing occupational stress: The role of age, education and marital status. Stress \& Health: Journal of the International Society for the Investigation of Stress, 25, 397-404. doi: 10.1002/smi.1248

Galletta, M., Portoghese, I., Penna, M. P., Battistelli,A., \& Saiani, L. (2011). Turnover intention among Italian nurses: The moderating roles of supervisor support and organizational support. Nursing and Health Sciences, 13, 184-191. http://dx.doi.org/10.1111/j.1442-2018.2011.00596.x

Garcia-Izquierdo, A. L., Moscoso, S., Ramos-Villagrasa, P. J. (2012). Reaction to the fairness of promotion methods: Procedural justice and job satisfaction. International Journal of Selection and Assessment, 20, 394- 403. http://dx.doi.org/10.1111/ijsa.12002

Gardner, S. (2009). Student and faculty attributions of attrition in high and low completing doctoral programs in the United States. Higher Education, 58, 97-122. http://dx.doi.org/10.1007/s10734-008-9184-7

Gasser, M., Flint, N., \& Tan, R. (2000). Reward expectation: The influence of race, gender, and type of job. Journal of Business and Psychology, 15, 321-329. http://dx.doi.org/10.1023/A:1007876103048

Gelso, C. J., \& Lent, R.W. (2000). Scientific training and productivity: The person, the training environment, and their interaction. In S. D. Brown \& R. W. Lent (Eds.), Handbook of counseling psychology ( $3^{\text {rd }}$ ed, pp. 109-139). New York, NY: Wiley. 
Ghazzawi, I. (2010). Gender role in job satisfaction: The case of the U.S. Information Technology Professionals. Journal of Organizational Culture, Communication, and Conflict, 14, 1-34.

Girves, J., \& Wemmerus, V. (1988). Developing models of graduate student progress. Journal of Higher Education, 59, 162-189. http://dx.doi.org/10.2307/1981691

Golde, C. M. (1996). How departmental contextual factors shape doctoral student attrition. (Unpublished doctoral dissertation). Stanford University, California.

Golde, C. M. (1998). Beginning graduate school: Explaining first-year doctoral attrition. New Directions for Higher Education, 101, 55-65. http://dx.doi.org/10.1002/he.10105

Golde, C. M. (2005). The role of the department and discipline in doctoral student attrition: Lessons from four departments. Journal of Higher Education, 76, 669731. http://dx.doi.org/10.1353/jhe.2005.0039

Goodnight, G. T., Hingstman, D., \& Green, S. (2014). The Student Debt Bubble: Neoliberalism, the university, and income inequality. Journal of Cultural Economy, (ahead-of-print), 1-26.

Goplerud, E. N. (1980). Social support and stress during the first year of graduate school. Professional Psychology, 11, 283-290. http://dx.doi.org/10.1037/07357028.11.2.283 
Grama, C., \& Sorin, G. (2011). Promotion of human resources in modern organizations. Revista Academiei Fortelor Terestre, 16,175-181.

Grebner, S., Elfering, A., Semmer, N., Kaiser-Probst, C., \& Schlapbach, M. L. (2004). Stressful situations at work and in private life among young workers: An event sampling approach. Social Indicators Research, 67, 11-49. http://dx.doi.org/10.1023/B:SOCI.0000007333.96382.3a

Greenberg, J. (1989). Cognitive re-evaluation of outcomes in response to underpayment in-equity. Academy of Management Journal, 32, 174-184. http://dx.doi.org/10.2307/256425

Greenberg, J. (1990). Employee theft as a reaction to underpayment inequity: The hidden cost of pay cuts. Journal of Applied Psychology, 75, 561-568. http://dx.doi.org/10.1037/0021-9010.75.5.561

Greenhaus, J. H., \& Parasuraman, S. (1987). A work-nonwork interactive perspective of stress and its consequences. In J. M. Ivancevich \& D. C. Ganster (Eds.), Job stress: From theory to suggestion (pp. 37-60). New York, NY: Haworth

Griffith, R. W., \& Gaertner, S. (2001). A role for equity theory in the turnover process: An empirical test. Journal of Applied Social Psychology, 31, 1017-1037. http://dx.doi.org/10.1111/j.1559-1816.2001.tb02660.x 
Grinnell, J. P. (2002). Effects of leaders' and evaluators on sex-role stereotyping of charismatic leaders. Psychological Reports, 91, 1247-1252. http://dx.doi.org/10.2466/pr0.2002.91.3f.1247

Haizlip, B. N. (2012). Addressing the underrepresentation of African-Americans in counseling and psychology program. College Student Journal, 46, 214-222.

Hall, D. S. (2007). The relationship between supervisor support and registered nurse outcomes in nursing care units. Nursing Administration Quarterly, 31, 68-80. http://dx.doi.org/10.1097/00006216-200701000-00015

Harris, M. B. (1998). Basic statistics for behavioral science research. Needham Heights, MA: Allyn \& Bacon.

Harris, K. J., Harvey, P., Harris, R. B., \& Cast, M. (2013). An investigation of abusive supervision, vicarious abusive supervision, and their joint impacts. Journal of Social Psychology, 153, 38- 50. http://dx.doi.org/10.1080/00224545.2012.703709

Harris, M. M., Anseel, F., \& Lievens, F. (2008). Keeping up with the Joneses: A field study of the relationships among upward, lateral, and downward comparisons and pay level satisfaction. Journal of Applied Psychology, 93, 665-673. http://dx.doi.org/10.1037/0021-9010.93.3.665

Hauge, L. J., Skogstad, A., \& Einarsen, S. (2007). Relationships between stressful work environments and bullying: Results of a large representative study. Work \& Stress, 21, 220-242. http://dx.doi.org/10.1080/02678370701705810 
Haydarov, R., Moxley, V., \& Anderson, D. (2012). Counting chickens before they are hatched: An examination of student retention, graduation, attrition, and dropout measurement validity in an online master's environment. Journal of College Student Retention, 14, 429-449. http://dx.doi.org/10.2190/CS.14.4.a

Henson, R.K. (2001). Understanding internal consistency reliability estimates: A conceptual primer on coefficient alpha. Measurement and Evaluation in Counseling and Development, 34, 177- 188.

Herzig, A. H. (2002). Where have all the students gone? Participation of doctoral students in authentic mathematical activity as a necessary condition for persistence toward the PH.D. Educational Studies in Mathematics, 50, 177-212. http://dx.doi.org/10.1023/A:1021126424414

Hewitt, P. L., Flett, G. L., \& Mosher, S. W. (1992). The perceived stress scale: factor structure and relation to depression symptoms in a psychiatric population. Journal of Psychopathology and Behavioral Assessment, 14, 247-257. http://dx.doi.org/10.1007/BF00962631

Higgins, C. A., \& Duxbury, L. E. (1992).Work-family conflict: A comparison of dualcareer and traditional-career men. Journal of Organizational Behavior, 13, 389411. http://dx.doi.org/10.1002/job.4030130407

Hochwarter,W. A., Ferris, G. R., Gavin, M., Perrewe, P. L., Hall, A. T., \& Frink, D. D. (2007). Political skill as a moderator of the felt accountability- job performance relationship: Longitudinal convergence of mediated moderation results. 
Organizational Behavior and Human Decision Processes, 102, 226-239. http://dx.doi.org/10.1016/j.obhdp.2006.09.003

Hoobler, J. M. (2007). On-site or out-of-sight? Family friendly childcare provisions and the status of working mothers. Journal of Management Inquiry, 16, 372-380. http://dx.doi.org/10.1177/1056492607305909

Hoobler, J. M., Wayne, S. J., \& Lemmon, G. (2009). Bosses' perceptions of family-work conflict and women's promotability. Glass ceiling effects, 52, 939-957.

Hoskins, C. M., \& Goldberg, A. D. (2005). Doctoral student persistence in counselor education programs: Student program match. Counselor Education and Supervision, 44, 175-187. http://dx.doi.org/10.1002/j.1556-6978.2005.tb01745.x

Howell, S., Laws, D., \& Lindsay, N. (2004). Reevaluating course completion in distance education. Avoiding the comparison between apples and oranges. The Quarterly Review of Distance Education, 5, 243-252.

Huseman, R. C., Hatfield, J. D., \& Miles, E. W. ( 1987). A new perspective on equity theory: The equity sensitivity construct. Academy of Management Review, 12, $222-234$.

Huseman, R. C., Hatfield, J. D., \& Miles, E. W. (1985). Test for individual perceptions of job equity: Some preliminary findings. Perceptual and Motor Skills, 61, 10551064. http://dx.doi.org/10.2466/pms.1985.61.3f.1055

Hyrkas, K. (2005). Clinical supervision, burnout, and job satisfaction among mental health and psychiatric nurses in Finland. Issues in Mental Health Nursing, 26, 531-556. http://dx.doi.org/10.1080/01612840590931975 
Idris, M. K., O’Driscoll, M. P., \& Anderson, M. H. (2011). Longitudinal mediation effects of strain on the relationships between role stressors and employees' withdrawal responses. Stress and Health, 27, 403-412. http://dx.doi.org/10.1002/smi.1392

Ironson, G. H., Smith, P. C., Brannick, M. T., Gibson, W. M., \& Paul, K. B. ( 1989). Construction of a job in general scale: A comparison of global, composite, and specific measures. Journal of Applied Psychology, 74, 193-200. http://dx.doi.org/10.1037/0021-9010.74.2.193

Isaac, P. (1993). Measuring graduate student retention. New Directions for Institutional Research, 80, 13-25. http://dx.doi.org/10.1002/ir.37019938004

Ivancevich, J. M., \& Matteson, M. T. (1980). Stress and Work. Glenview, IL, Scott, Forseman.

Iverson, K. (2000). The paradox of the contented female manager: An empirical investigation of gender differences in pay expectation in the hospitality industry. Hospitality Management, 19, 33-51. http://dx.doi.org/10.1016/S02784319(99)00032-8

Jacobs, P. A., Tytherleigh, M. Y., Webb, C., \& Cooper, C. L. (2010). Breaking the mold: The impact of working in gender-congruent versus gender-incongruent role on self-reported sources of stress, organizational commitment, and health in U.K. universities. International Journal of Stress Management, 17, 21-37. http://dx.doi.org/10.1037/a0018026 
Jamal, M. (2005). Short communication: Personal and organizational outcomes related to job stress and Type A behavior: A study of Canadian and Chinese employees. Stress and Health, 21, 129-137. http://dx.doi.org/10.1002/smi.1047

Jawahar, I. M., \& Stone, T. H. (2011). Fairness perceptions and satisfaction with components of pay satisfaction. Journal of Managerial Psychology, 26, 297-312. http://dx.doi.org/10.1108/02683941111124836

Johnson, H. D., McNair, R., Vojick, A., Congdon, D., Monacelli, J., \& Lamont, J. (2006). Categorical and continuous measurement of sex-role orientation: Differences in associations with young adults' reports of well-being. Social Behavior and Personality, 34, 59-75. http://dx.doi.org/10.2224/sbp.2006.34.1.59

Johnston, D. W., \& Lee, W. S. (2013). Extra status and extra stress: Are promotions good for us? Industrial and Labor Relations Review, 32-54.

Judge, T. A., Bono, J. E., \& Locke, E. A. (2000). Personality and job satisfaction: The mediating role of job characteristics. Journal of Applied Psychology, 85, 237-249. http://dx.doi.org/10.1037/0021-9010.85.2.237

Kahn, R. L., Wolfe, D. M., Quinn, R. P., Snoek, J. D., \& Rosenthal, R. A. (1964). Organizational stress: Studies in role conflict and role ambiguity. New York, NY: Wiley.

Kanai, A. (2006). Economic and employment conditions, karoshi (work to death) and the trend of studies on workaholism in Japan. In R. Burke (Ed.), Research companion 
to working time and work addiction (pp. 158-172). Cheltenham, UK: Edward Elgar. http://dx.doi.org/10.4337/9781847202833.00016

Kath, L. M., Stichler, J. F., Ehrhart, M. G., \& Schultze, T. A. (2012). Predictors and outcomes of nurse leader job stress experienced by AWHONN members. JOGNN, 2, $12-25$.

Kavitha, P. (2009). Organizational role stress among college faculties: An empirical study. Sona Global Management Review, 6, 36-50.

Kendall, E., \& Muenchberger, H. (2009). Stress at work: Using a process model to assist employers to understand the trajectory. Work: Journal of Prevention, Assessment \& Rehabilitation, 32, 19-25.

Kim, S. (2005). Gender differences in the job satisfaction of public employees: A study of Seoul metropolitan government, Korea. Sex Roles, 52, 667-681. http://dx.doi.org/10.1007/s11199-005-3734-6

Kim, S. K. (2012). The impact of human resource management on state government IT employee turnover intentions. Public Personnel Management, 41, 257-279. http://dx.doi.org/10.1177/009102601204100204

King, W. C., Jr., Miles, E. W., \& Day, D. D. (1993). A test and refinement of the equity sensitivity construct. Journal of Organizational Behavior, 14, 301-317. http://dx.doi.org/10.1002/job.4030140403 
King, W. C., Jr., \& Miles, E. W. (1994). The measurement of equity sensitivity. Journal of Occupational and Organizational Psychology, 67, 133-142. http://dx.doi.org/10.1111/j.2044-8325.1994.tb00556.x

Kinicki, A. J., McKee-Ryan, F. M., Schriesheim, C. A., \& Carson, K. P. (2002). Assessing the construct validity of the Job Descriptive Index: A review and metaanalysis. Journal of Applied Psychology, 87, 14-32. http://dx.doi.org/10.1037/0021-9010.87.1.14

Kinnunen, U., Feldt, T., Mauno, S., \& Rantanen, J. (2010). Interface between work and family: A longitudinal individual and crossover perspective. Journal of Occupational and Organizational Psychology, 83, 119-137. http://dx.doi.org/10.1348/096317908X399420

Klassen, R. M. (2010). Teacher stress: The mediating role of collective efficacy beliefs. The Journal of Educational Research, 103, 342-350.

Korabik, (1990). Androgyny and leadership style. Journal of Business Ethics, 9, 283-292. http://dx.doi.org/10.1007/BF00380328

Kosteas, V. D. (2011). Job satisfaction and promotions. Industrial Relations, 50, 1, 174194. http://dx.doi.org/10.1111/j.1468-232X.2010.00630.x

Koster, K. (2011). What's in it for me? (and me and me). Employee Benefits News, 25-26.

Kuchinke, K. P., Cornachione, E. B., Oh, S. Y., \& Kang, H. S. (2010). All work and no play? The meaning of work and work stress of mid-level managers in the United 
States, Brazil, and Korea. Human Resource Development International, 13, 393408. http://dx.doi.org/10.1080/13678868.2010.501961

Ladebo, O. (2008). Perceived supervisory support and organizational citizenship behaviors: Is job satisfaction a mediator. South African Journal of Psychology, 38, 479-488. http://dx.doi.org/10.1177/008124630803800303

Lam, S. K., \& Schaubroeck, J. (2000). The role of the locus of control in reactions to being promoted and to being passed over: A quasi experiment. Academy of Management Journal, 43, 66-78. http://dx.doi.org/10.2307/1556386

Lamb, D. H., Presser, N. R., Pfost, K. S., Baum, M. C., Jackson, V.R., \& Jarvis, P. A. (1987). Confronting professional impairment during the internship: Identification, due process, and remediation. Professional Psychology: Research and Practice,18, 597-603. http://dx.doi.org/10.1037/0735-7028.18.6.597

Lambert, L. S. (2011). Promised and delivered inducements and contributions: An integrated view of psychological contract appraisal. Journal of Applied Psychology, 96, 695-712. http://dx.doi.org/10.1037/a0021692

Lazarus, R. S., \& Folkman, S. (1984). Stress, appraisal, and coping. New York, NY: Springer.

Leary, T. G., Green, R. Denson, K., Schoenfeld, G., Henley, T., \& Langford, H. (2013). The relationship among dysfunctional leadership dispositions, employee engagement, job satisfaction, and burnout. The Psychologist-Manager Journal, 16, 112-130. http://dx.doi.org/10.1037/h0094961 
Ledet, L., \& Henley, T. B. (2000). Perceptions of women's power as a function of position within an organization. Journal of Psychology: Interdisciplinary and Applied, 134, 515-526. http://dx.doi.org/10.1080/00223980009598233

LePine, J., LePine, M., \& Jackson, C. (2004). Challenge and hindrance stress: Relationship with exhaustion, motivation to learn, and learning performance. The Journal of Applied Psychology, 89, 883-891. http://dx.doi.org/10.1037/00219010.89 .5 .883

Leung, S. A. (1988). An examination of circumscription and compromise in career decision-making among college students. (Unpublished doctoral dissertation). University of Illinois, Urbana-Champaign.

Levya, V. L. (2011). First-generation Latina graduate students: Balancing professional identity development with traditional family roles. New Directions for Teaching \& Learning, 127, 21-31. http://dx.doi.org/10.1002/t1.454

Linz, S. J., \& Semykina, A. (2012). What makes workers happy? Anticipated rewards and job satisfaction. Industrial Relations, 51, 811-844. http://dx.doi.org/10.1111/j.1468-232X.2012.00702.x

Livini, D., Crowe, T. P., \& Gonsalvez, C. J. (2012). Effects of supervision modality and intensity on alliance and outcomes for the supervisee. Rehabilitation Psychology, 57, 178-186. http://dx.doi.org/10.1037/a0027452

Locke, E. A. (1969). Job satisfaction and job performance: A theoretical analysis. Organizational Behavior and Human Performance, 4, 309-336. http://dx.doi.org/10.1016/0030-5073(69)90013-0 
Long, C. P., \& Bendersky, C., \& Morrill, C. (2011). Fairness monitoring: Liking managerial controls and fairness judgments in organization. Academy of Management Journal, 54, 1045-1068. http://dx.doi.org/10.5465/amj.2011.0008

Longo, D. (2/8/2010). U.S. Workers Stumble in Pursuit of Happiness. Convenience Store News, 46(2), 3 .

Lovett, S. \& Galy, E. (2003). Gender differences and organizational adaptation/withdrawal in a Mexican assembly plant. Journal of Applied Management and Entrepreneurship, 8, 3-20.

Lovitts, B. E. (2001). Leaving the ivory tower: The causes and consequences of departure from doctoral student. New York, NY: Rowman \& Littlefield Publishers, Inc.

Lu, L., Shiau, C., \& Cooper, C. L. (1997). Occupational stress in clinical nurses. Counseling Psychology Quarterly, 10, 39-50.

http://dx.doi.org/10.1080/09515079708251410

Lue, B. H., Chen, H. J., Wang, C. W., Cheng, Y., \& Chen, M. C. (2010). Stress, personal characteristics and burnout among first post graduate year residents: A nationwide study in Taiwan. Medical Teacher, 32, 400-407. http://dx.doi.org/10.3109/01421590903437188 
Lynch, K. D. (2008). Gender roles and the American academe: A case study of graduate student mothers. Gender \& Education, 20, 585-605. http://dx.doi.org/10.1080/09540250802213099

Madlock, P. E. (2008). The link between leadership style, communicator competence, and employee satisfaction. Journal of Business Communication, 45, 61-78. http://dx.doi.org/10.1177/0021943607309351

Magoon, T. M., \& Hollan, J. L. (1984). Research training and supervision. In S. D. Brown \& R. W. Lent (Eds.), Handbook of counseling psychology (pp.687 -715). New York, NY: Wiley

Maki, N., Moore, S., Grunberg, L., \& Greenberg, E. (2005). The responses of male and female managers to workplace stress and downsizing. North American Journal of Psychology, 7, 295-312.

Malaney, G. D. (1987). Why students pursue graduate education, how do they find out about a program and why they apply to a specific school. College and University, 62, 247-258.

Mark, G., \& Smith, A. P. (2012). Effects of occupational stress, job characteristics, coping, and attributional style on the mental health and job satisfaction of university employees. Anxiety, Stress \& Coping, 25, 63-78. DOI: 10.1080/10615806.2010.548088. 
Mars, G. (1973). Chance, punters, and the fiddle: Institutionalized pilferage in a hotel dining room. In M.Warner (Ed.), The sociology of the workplace (pp. 200-210). New York, NY: Halsted Press.

Martin, R. A., Kazarian, S. S., \& Breiter, H. J. (1995). Perceived stress, life events, dysfunctional attitudes, and depression in adolescent psychiatric inpatients. Journal of Psychopathology and Behavioral Assessment, 17, 81-95. http://dx.doi.org/10.1007/BF02229205

Martocchio, J. J., \& O’ Leary, A. M. (1989). Sex differences in occupational stress: A meta-analytic review. Journal of Applied Psychology, 74, 495-501. http://dx.doi.org/10.1037/0021-9010.74.3.495

Mazzola, J. J., Schonfeld, S. S., \& Spector, P. E. (2011). What qualitative research has taught us about occupational stress. Stress and Health, 27, 93-110. http://dx.doi.org/10.1002/smi.1386

McAuliffe, E., Daly, M., Kamwendo, F. Masanja, H., Sidat, M., \& de Pinho, H. (2013). The critical role of supervision in retaining staff in obstetric services: A three country study. PLoS ONE, 8(3), 1-7. http://dx.doi.org/10.1371/journal.pone.0058415

Mednick, M. S., \& Tangri, S. S. (1972). New social psychological perspectives on women. Journal of Social Issues, 28, 1-16. http://dx.doi.org/10.1111/j.15404560.1972.tb00014.x 
Mehta, C. M., Kenner, E., \& Shrier, L. (2013). Perceived advantages and disadvantages of being a female graduate student in the U.S. and the UK. Gender and Education, 25, 37-55. http://dx.doi.org/10.1080/09540253.2012.752794

Meier, K. J. (1991). Representative bureaucracy: What we know. Paper presented at the meeting of American Society of Public Administration, Washington, D.C.

Menzies, H. (2005). No time: Stress and the crisis of modern life. Vancouver, British Columbia, Canada: Douglas and McIntrye.

Michael, G., Anastasios, S., Helen, K., Catherine, K., \& Christine, K. (2009). Gender differences in experiencing occupational stress: The role of age, education and marital status. Stress \& Health: Journal of the International Society for the Investigation of Stress, 25, 397-404. doi: 10.1002/smi.1248

Middleton, E. J., Mason, E. J., Stilwell, W. E., \& Parker, W. C. (1988). A model for recruitment and retention of minority students in teacher preparation programs. Journal of Teacher Education, 39, 14-18.

http://dx.doi.org/10.1177/002248718803900104

Miles, M. B., \& Huberman, A. M. (1994). An expanded sourcebook: Qualitative data analysis. Thousand Oaks, CA: Sage Publishing.

Milkovich, G.T, \& Anderson, P.H. (1973). Management compensation and secrecy policies. Personnel Psychology, 25, 293-302. http://dx.doi.org/10.1111/j.17446570.1972.tb01105.x 
Miller, B. K. (2009). Confirmatory factor analysis of the equity preference questionnaire. Journal of Managerial Psychology, 24, 328-347. http://dx.doi.org/10.1108/02683940910952714

Miller, N. B., Falk, F., \& Huang, Y. (2009). Gender identity and the overexcitability profiles of gifted college students. Roeper Review, 31, 161-169. http://dx.doi.org/10.1108/02683940910952714

Mohr, L. A., \& Henson, S. W. (1996). Impact of employee gender and job congruency on customer satisfaction. Journal of Consumer Psychology, 5, 161-187. http://dx.doi.org/10.1207/s15327663jcp0502_04

Moore, D. (2009). Job concessions, role conflict and work satisfaction in gender-typical and -atypical occupation: The case of Israel. Gender Issues, 26, 42-64. http://dx.doi.org/10.1007/s12147-009-9070-3

Moorman, R. H. (1993). The influence of cognitive and affective based job satisfaction measures on the relationship between satisfaction and organizational citizenship behavior. Human Relations, 6, 759-776. http://dx.doi.org/10.1177/001872679304600604

Mori, M., Nakashima, Y., Yamazaki, Y, \& Kurita, H. (2002). Sex-role orientation, marital status, and mental health in working women. Archives of Women's Mental Health, 5, 161-176. http://dx.doi.org/10.1007/s00737-002-0148-0

Mowday, R. T. (1991). Equity theory predictions of behavior in organizations. In R. M. Steers, \& L. W. Porter (Eds.), Motivation and Work Behavior (5 ${ }^{\text {th }}$ ed, pp. 111 131). New York, NY: McGraw-Hill. 
Moyer, A., Salovey, P., \& Cannon- Cash, S. (1999). Challenges facing female doctoral students and recent graduates. Psychology of Women Quarterly, 23, 607-631. http://dx.doi.org/10.1111/j.1471-6402.1999.tb00384.x

McIntyre, S., McIntyre, E., \& Mendonca, T. (2010). Measuring job satisfaction in Portuguese health professionals: Correlates and validation of the job descriptive index and job in general scale. International Journal of Selection and Assessment, 18, 425-431. http://dx.doi.org/10.1111/j.1468-2389.2010.00524.x

Nagy, M. S. (2002). Using a single-item approach to measure facet job satisfaction. Journal of Occupational \& Organizational Psychology, 75, 77-86. http://dx.doi.org/10.1348/096317902167658

Nelson, C., \& Lovitts, B. E. (2001, June 29). 10 ways to keep graduate students from quitting. The Chronicle of Higher Education, p. b20.

Ngo, H. Y., Foley, S., Ji, M. S.,\& Loi, R. (2014). Linking gender role orientation to subjective career success: The meditating role of psychological capital. Journal of Career Assessment, 22, 290- 303. http://dx.doi.org/10.1177/1069072713493984

Nicholson, L. (1994). Interpreting Gender. Signs, 20, 79-105. http://dx.doi.org/10.1086/494955

Noblet, A. J., \& Gifford, S. M. (2002). The sources of stress experienced by Australian footballers. Journal of Applied Sport Psychology, 14, 1-13. http://dx.doi.org/10.1080/10413200209339007 
Nolan, S. A., \& Heinzen, T. E. (2012). Statistics for the behavioral sciences. New York, NY: Worth Publishers.

Norvilitis, J. M., \& Reid, H. M. (2002). Evidence for an association between gender role identity and a measure of executive function. Psychological Reports, 90, 35-45. http://dx.doi.org/10.2466/pr0.2002.90.1.35

Nurmi, N. (2011). Coping with coping strategies: how distributed teams and their members deal with the stress of distance, time zones and culture. Stress \& Health: Journal of the International Society for the Investigation of Stress, 27, 123-143 http://dx.doi.org/10.1002/smi.1327

Okpara, J. O., Squillace, M., \& Erondu, E. A. (2005). Gender differences and job satisfaction: a study of university teachers in the United States. Women in Management Review, 3, 177-190. http://dx.doi.org/10.1108/09649420510591852

Okasha, A., Lotaif, F., Sadek, A. (1981). Prevalence of suicidal feelings in a sample of non-consulting medical students. Actual Psychiatry Scan, 62, 409-415. http://dx.doi.org/10.1111/j.1600-0447.1981.tb00690.x

Olsen, K. M., \& Dahl, S. A. (2010). Working time: Implications for sickness absence and the work-family balance. International Journal of Social Welfare, 19, 45-53. http://dx.doi.org/10.1111/j.1468-2397.2008.00619.x

O'Neill, B. S., \& Mone, M. A. (1998). Investigating equity sensitivity as a moderator of relations between self-efficacy and workplace attitudes. Journal of Applied Psychology, 83,805-816. http://dx.doi.org/10.1037/0021-9010.83.5.805 
Onyemah, V. (2011). Role ambiguity, role conflict, and performance: Empirical evidence of an inverted U-relationship. Journal of Personal Selling \& Sales Management, 28, 299-313. http://dx.doi.org/10.2753/PSS0885-3134280306

Örücü, M. C., \& Demir, A. (2008). Psychometric evaluation of perceived stress scale for Turkish university students. Stress and Health, 25, 103-109. http://dx.doi.org/10.1002/smi.1218

Ozturk, A. B., \& Hancer, M. (2011). The effect of demographics on job satisfaction: A study of hotel managers in Turkey. International Journal of Hospitality \& Tourism Administration, 12, 189-201. http://dx.doi.org/10.1080/15256480.2011.590735

Park, C. L., Perry, B., \& Edwards, M. (2011). Minimizing attrition: Strategies for assisting students who are at risk of withdrawal. Invocations in Education \& Teaching International, 48, 37-37. http://dx.doi.org/10.1080/14703297.2010.543769

Parker, S., \& Griffin, M. (2002). What is so bad about a little name calling? Negative consequences of gender harassment for over performance demands and distress. Journal of Occupational Health Psychology, 7, 195-210. http://dx.doi.org/10.1037/1076-8998.7.3.195

Pedhazur, E. J., \& Tetenbaum, T. J. (1979). Bem Sex Role inventory: A theoretical and methodological critique: Journal of Personality and Social Psychology, 37, 9961016. http://dx.doi.org/10.1037/0022-3514.37.6.996

Perie, M, \& Baker, D. P. (1997). Job satisfaction among America's teachers: Effects of workplace conditions, background characteristics, and teacher compensation. 
Statistical Analysis Report, U.S. Department of Education, Office of Educational Research and Improvement, NCES 97- xxx.

Perry, L. S. (1993). Effects of inequity on job satisfaction and self-evaluation in a national sample of African-American workers. Journal of Social Psychology, 133, 565-573. http://dx.doi.org/10.1080/00224545.1993.9712182

Perrewe, P. L., Zellars, K. L., Rossi, A. M., Ferris, G. R., Kacmar, C. J., Liu, Y., et al. (2005). Political skill: An antidote in the role overload - strain relationship. Journal of Occupational Health Psychology, 10, 239-250. doi: 10.1037/10768998.10.3.239

Pestonjee, D. M. (1973). Organizational Structure and Job Attitude, Minerva, Calcutta. Pestonjee, D. M. (1999). Stress and Coping: The Indian Experience. New Delhi: Sage Publication.

Pettersson, L. (2006). Masculinities in an occupational setting: A gender perspective on resistance toward formal control. Journal of Scandinavian Studies in Criminology and Crime Prevention, 7, 107-125.

http://dx.doi.org/10.1080/14043850601010422

Piccolo, R., \& Judge, T. A. (2011, September 8). Will a raise make you like your job better? Maybe not. Forbes.com. 47.

Platsidou, M., \& Agaliotis, I. (2008). Burnout, job satisfaction, and instructional assignment-related sources of stress in Greek special education teachers. Development and Education, 55, 61-76.

Podsakoff, N. P., LePine, J. A., \& LePine, M. A. (2007). Differential challenge stressorhindrance stressor relationships with job attitudes, turnover intentions, turnover, 
and withdrawal behavior: A meta-analysis. Journal of Applied Psychology, 92, 438-454. http://dx.doi.org/10.1037/0021-9010.92.2.438

Presser, H. B. (2005). Embracing complexity: Work schedule and family life in 24/7 economy. In S. Bianchi, L. Casper, \& R. King (Eds.), Work, Family, Health, and Well-being (pp 43-48). Mahwah, New Jersey: Lawrence Erlbaum Associates.

Price, C. J., \& Wulff, S. S. (2005). Does sex make a difference? Job satisfaction of television network news correspondents. Women's Studies in Communication, 28, 207-234. http://dx.doi.org/10.1080/07491409.2005.10162492

Rain, J. S., Lane, I. M., \& Steinger, D. D. (1991). A current look at the job satisfaction/life satisfaction relationship: Review and future considerations. Human Relations, 44, 287-307. http://dx.doi.org/10.1177/001872679104400305

Rajapaksa, S. \& Rothstein, W. (2009). Factors that influence the decisions of men and women nurses to leave nursing. Nurse Forum, 44, 195-206. http://dx.doi.org/10.1111/j.1744-6198.2009.00143.x

Rast, S., \& Tourani, A. (2012). Evaluation of employees' job satisfaction and role of gender difference: An empirical study at airline industry in Iran. International Journal of Business \& Social Science, 3, 91-100.

Rice, M. (2011). Compensation and talent strategies that minimize turnover. Chief Learning Officer, 10, 32-33. 
Robert, J. W., Harrington, L. N., \& Storch, E. A. (2006). Further psychometric support for the 10-items version for the Perceived Stress Scale. Journal of College Counseling, 9, 135-147. http://dx.doi.org/10.1002/j.2161-1882.2006.tb00100.x

Rochlen, A. B., Good, G.E., \& Carver, T. A. (2009). Predictors of gender related barriers, work, and life satisfaction among men in nursing. Psychology of Men \& Masculinity, 10, 44-56. http://dx.doi.org/10.1037/a0013291

Rodwell, J., Brunetto, Y, Demir, D., Shacklock, K., \& Farr- Wharton, R. (2014). Abusive supervision and links to nurse intentions to quit. Journal of Nursing Scholarship, 46, 357-365. http://dx.doi.org/10.1111/jnu.12089

Rodwell, J., Noblet, A., Demir, D., \& Steane, P. (2009). Supervisors are central to work characteristics affecting nurse outcomes. Journal of Nursing Scholarship, 41, 310319. http://dx.doi.org/10.1111/j.1547-5069.2009.01285.x

Rollins, A. L., Bond, G. R., Jones, A. M., Kukla, M., \& Collins, L. A. (2011). Workplace social networks and their relationship with job outcomes and other employment characteristics for people with severe mental illness. Journal of Vocational Rehabilitation, 35, 243-252.

Rolston, J. (2010). Talk about technology: Negotiating gender differences in Wyoming coal mines. Signs, 35, 893-918. http://dx.doi.org/10.1086/651039 
Rosal, M. C., Ockene, I. S., Ockene, J.K., Barrett, S. V., Ma, Y., \& Herbert, J.R. (1997). A longitudinal study of students' depression at one medical school. Academy Medical, 72, 542-546. http://dx.doi.org/10.1097/00001888-199706000-00022

Rovai, A. (2002). Development of an instrument to measure classroom community. The Internet and Higher Education, 5, 197-211. http://dx.doi.org/10.1016/S10967516(02)00102-1

Rubino, C., Perry,S. J., Milam, A. C., Spitmueller, C., \& Zapf, D. (2012). Demandcontrol-person: Integrating the demand-control and conservation f resources to test an expanded stressor-strain model. Journal of Occupational Health Psychology, 17, 456- 472. http://dx.doi.org/10.1037/a0029718

Ryan, J. R. (9/1/2010). Keeping employees happy in a post-recession world. BusinessWeek.com

Saldana, J. (2009). The coding manual for qualitative researchers. Thousand Oaks, CA: Sage Publishing.

Sallee, M. W. (2011). Performing masculinity: Considering gender in doctoral student socialization. Journal of Higher Education, 82, 187-216. http://dx.doi.org/10.1353/jhe.2011.0007

Saygi, H., Tolon, T., \& Tekogul, H. (2011). Job satisfaction among academic staff in fisheries faculties at Turkish universities. Social Behavior and Personality, 39, 1395-1402. http://dx.doi.org/10.2224/sbp.2011.39.10.1395 
Scarpello, V., \& Campbell, J. P. (1983). Job satisfaction: Are all the parts there? Personnel Psychology, 36, 577-600. http://dx.doi.org/10.1111/j.17446570.1983.tb02236.x

Schaufeli, W. B., Van Dierendonck, D., \& Van Gorp, K. (1996). Burnout and reciprocity: Towards a dual-level social exchange model. Work \& Stress, 10, 224-237. http://dx.doi.org/10.1080/02678379608256802

Schexneider, K. (2010). Stethoscopes and headscarves: Female medical students in present day Afghanistan. Military Medicine, 175, 21- 24. http://dx.doi.org/10.7205/MILMED-D-09-00046

Schonfeld, I. S., \& Farrell, E. (2010). Qualitative methods can enrich quantitative research on occupational stress: An example from one occupational group. In D. C. Ganster, \& P. L. Perrewe (Eds.), Research in occupational stress and wellbeing series. New developments in theoretical and conceptual approaches to job stress (pp. 137- 197). Bingley, UK: Emerald. http://dx.doi.org/10.1108/S1479-3555(2010)0000008007

Schuttenberg, E. M., O’Dell, F., \& Kaczala, C.M.(1990). Vocational personality types and sex-role perceptions of teachers, counselors, and educational administrators. The Career Development Quarterly, 39, 60-71. http://dx.doi.org/10.1002/j.21610045.1990.tb00236.x

Selden, M. P., \& Downey, R. G. (2012). Workplace hostility: defining and measuring the occurrence of hostility in the workplace. Journal of Prevention, Assessment, and Rehabilitation, 42, 93- 105. 
Sharma, R. D., \& Jyoti, K. (2006). Job satisfaction among school teachers. IIMB Management Review, 18, 349-363.

Shore, T. H. (2004). Equity sensitivity theory: Do we all want more than we deserve?; Journal of Managerial Psychology, 19, 722-728. http://dx.doi.org/10.1108/02683940410559400

SHRM (2007). 2007 Job Satisfaction Report. Society for Human Resource Management, Alexander, VA.

Sinden, K., MacDermid, J., Buckman, S., Davis, B., Matthews, T., \& Viola, C.(2013). A qualitative study on the experience of female firefighters. Work: Journal of Prevention, Assessment \& Rehabilitation, 45, 97-105.

Singer, A. R., Cassin, S. E., \& Dobson, K. S. (2005). The role of gender in the career aspirations of professional psychology graduates: Are there more similarities than differences? Canadian Psychology, 46, 215-222. http://dx.doi.org/10.1037/h0087029

Sloan, M. M. (2012). Unfair treatment in the workplace and worker well-being: The role of coworker in a service work environment. Work and Occupations, 39, 3- 34. http://dx.doi.org/10.1177/0730888411406555

Smith, M. (2009). Gender, pay, and work satisfaction at UK University. Gender, Work, and Organization, 16, 621-641. http://dx.doi.org/10.1111/j.14680432.2008.00403.x 
Smith, P. C., Balzer, Josephson, H. I. . . Whalen, M. A. (1989). Users' manual for the Job Descriptive Index (JDI) and the Job in General (JIG) scales. Bowling Green, OH: Bowling Green Scale University.

Smith, P. C., Kendall, L., \& Hulin, C. L. (1969). The measurement of satisfaction in work and retirement: A strategy for the study of attitudes. Chicago, IL: Rand McNally

Smith, P., Kendall, L. M., Hulin, C. L., . . . Parra, Luis F. (2009). Job Descriptive Index (2009 Revision) and The Job in General Scales (2009 Revision). Mental Measurement Yearbook, 15.

Smith, R. L., Maroney, K., Nelson, K. W., Abel, A. L., \& Abel, H. S. (2006). Doctoral Programs: Changing high rates of attrition. Journal of Humanistic Counseling, Education, and Development, 45, 17-31. http://dx.doi.org/10.1002/j.21611939.2006.tb00002.x

Soares, M. M., Jacobs, L., Yu, N, Shen, L. M., \& Lewark, S. (2012). Gender differences on the job satisfaction in the phase of implementing advanced manufacturing technology in the Chinese manufacturing firms. Work, 41, 4320-4322.

Spector, P. E. (1997). Job satisfaction: Application, assessment, causes, and consequences. Thousand Oaks, CA: Sage.

Spence, J. T. (1982). Comments on Baumrind's “Are androgynous individuals more effective persons and parents?' Child Development, 53, 76-80. http://dx.doi.org/10.2307/1129638 
Spence, J. T. (1983). Comment on Lubinski, Tellegen, and Butcher's “Masculinity, Femininity, and Androgyny viewed and assessed. Journal of Personality and Social Psychology, 44, 440-446. http://dx.doi.org/10.1037/0022-3514.44.2.440

Spence, J. T., \& Buckner, C. E. (2000). Instrumental and expressive traits, trait stereotypes, and sexist attitudes: What do they signify? Psychology of Women Quarterly, 24, 44-62. http://dx.doi.org/10.1111/j.1471-6402.2000.tb01021.x

Spence, J. T., \& Helmreich, R. L. (1981). Theoretical notes. Androgyny versus gender schema: A comment on Bem's gender schema theory. Psychological Review, 88, 365-368. http://dx.doi.org/10.1037/0033-295X.88.4.365

Steel, R. P., \& Orvalle, N. K., II (1984). A review and meta-analysis of research on the relationship between behavioral intentions and employee turnover. Journal of Applied Psychology, 69, 673-686. http://dx.doi.org/10.1037/0021-9010.69.4.673

Steinhardt, M. A., Dolbier, C. L., Gottlieb, N. H., \& McCalister, K. T. (2003). The relationship between hardiness, supervisor support, group cohesion, and job stress as predictors of job satisfaction. American Journal of Health Promotion, 17, 382389. http://dx.doi.org/10.4278/0890-1171-17.6.382

Sterner, W. R. (2009). Influence of the supervisory working alliance on supervisee work satisfaction and work-related stress. Journal of Mental Health Counseling, 31, 249- 263. 
Stevens, L. P. (2002). Applied multivariate statistics for the social sciences. (4th ed.) Mahwah, NJ: Lawrence Erlbaum Associates.

Stewart, S. M., Lam, T. H., Beston, C. L., Wong, C. M., \& Wong, A. M. (1999). A prospective analysis of stress and academic performance in the first two years of medical school. Medical Education, 33, 243-250. http://dx.doi.org/10.1046/j.1365-2923.1999.00294.x

Stewart, S. M., Beston, C., Lam, T. H., Marshall, I. B., Lee, P. W., \& Wong, C. M. (1977). Predicting stress in first year medical students: A longitudinal study. Medical Education, 31, 163-168. http://dx.doi.org/10.1111/j.13652923.1997.tb02560.x

Sundin, L., Hochwalder, J., Bildt, C., \& Lisspers, J. (2007). The relationship between different work-related sources of social support and burnout among registered and assistant nurses in Sweden: A questionnaire survey. International Journal of Nursing Studies, 44, 758-769. http://dx.doi.org/10.1016/j.jnurstu.2006.01.004

Taris, T. W., Peeters, M. C. W., Le Blanc, P. M., Schaufeli, W. B., \& Schreurs, P. J.G. (2001). From inequity to burnout: The role of job stress. Journal of Occupational Health Psychology, 6, 303-323. http://dx.doi.org/10.1037/1076-8998.6.4.303

Tata, J. (2000). Influence of role and gender on the use of distributive versus procedural justice principles. Journal of Psychology, 134, 261-269.

http://dx.doi.org/10.1080/00223980009600866 
Tepper, B. J. (2000). Consequences of abusive supervision. Academy of Management Journal, 43, 178-190. http://dx.doi.org/10.2307/1556375

Tepper, B. J., Moss, S. E., \& Duffy, M. K. (2011). Predictors of abusive supervision: Supervisor perceptions of deep-level dissimilarity, relationship conflict, and subordinate performance. Academy of Management Journal, 54, 279-294. http://dx.doi.org/10.5465/AMJ.2011.60263085

Terrell, S. (2005). A longitudinal investigation of the effect of information perception and focus on attrition in online learning environments. The Internet and Higher Education, 8, 213-219.

Terrell, S. R., Snyder, M. M., Dringus, L. P., \& Maddrey, E. (2012). A grounded theory of connectivity and persistence in a limited residency doctoral program. The Qualitative Report, 17, 1-214.

Thompson, E. R., \& Phua, F. T. T. (2012). A brief index of affective job satisfaction. Group and Organization Management, 37, 275-307. http://dx.doi.org/10.1177/1059601111434201

Ting, Y. (1996). Analysis of job satisfaction of the federal white-collar work force: Findings from the survey of federal employees. American Review of Public Administration, 26, 439-456. http://dx.doi.org/10.1177/027507409602600404

Torkelson, D., \& Seed, M. S. (2011). Gender differences in the roles and functions of inpatient psychiatric nurses. Journal of Psychosocial Nursing \& Mental Health Services, 49, 34-41. 
Toutkoushian, R. K., Bellas, M. L., \& Moore, J. V. (2007). The interaction effects of gender, race, and marital status on faculty salaries. Journal of Higher Education, 78, 572-601. http://dx.doi.org/10.1353/jhe.2007.0031

Tyssen, R. Vaglum, P., Gronvold, N.T., \& Ekeberg, O. (2001). Factors in medical school that predict postgraduate mental problems in the need of treatment: A nationwide and longitudinal study. Medical Education, 35, 110-120.

http://dx.doi.org/10.1046/j.1365-2923.2001.00770.x

U. S. Department of Commerce, United States Census (2012). Educational attainment table. Table 1. Educational Attainment of the Population 18 Years and Over, by Age, Sex, Race, and Hispanic Origin. Retrieved from U.S. Census Website: http://www.census.gov/hhes/socdemo/education/data/cps/2012/tables.html

Van Beek, Taris, T. W., \& Schafeli, W. B. (2011). Workaholic and work engaged employees: Dead ringers or worlds apart. Journal of Occupational Health Psychology, 16, 468-482. http://dx.doi.org/10.1037/a0024392

Vadenberghe, C., Bentein, K., \& Stinglhamber, F. (2004). Affective commitment to the organization, supervisor, and work group: Antecedents and outcomes. Journal of Vocational Behavior, 64,47- 71.

Van der Hulst, M. (2003). Long work hours and health. Scandinavian Journal of Work, Environment, and Health, 29, 171-188. http://dx.doi.org/10.5271/sjweh.720 
Van der Hulst, M., \& Geurts, S. (2001). Associations between overtime and psychological health in high and low reward jobs. Work \& Stress, 15, 227-240. http://dx.doi.org/10.1080/026783701110.1080/02678370110066580

Van Dierendonck, D., Schaufeli, W. B., \& Bunk, B. P. (2001). Burnout and inequity amongst human services professionals: A longitudinal study. Journal of Occupational and Health, 6, 43-52. http://dx.doi.org/10.1037/1076-8998.6.1.43

Van Yperen, N. W. (1995). Communal orientation and the burnout syndrome among nurses: A replication and extension. Journal of Applied Social Psychology, 26, 338-354. http://dx.doi.org/10.1111/j.1559-1816.1996.tb01853.x

Van Yperen, N.W., Hagedoorn, M. \& Geurts, S. A. E. (1996). Intent to leave and absenteeism as reactions to perceived inequity: The role of psychological and social constraints. Journal of Occupational and Organizational Psychology, 69, 367- 372. http://dx.doi.org/10.1111/j.2044-8325.1996.tb00622.x

Wallace, S. L., Lee, J., \& Lee, S. M. (2010). Job stress, coping strategies and burnout among abuse-specific counselors. Journal of Employment Counseling, 47, 111122. http://dx.doi.org/10.1002/j.2161-1920.2010.tb00096.x

Wallen, A. S., Mor, S., \& Devine, B. A. (2014). It's about respect: Gender-professional identity integration affects male nurses' job attitudes. Psychology of Men and Masculinity, 15, 305- 312. http://dx.doi.org/10.1037/a0033714

Walsh, B. M., Matthews, R. A., Tuller, M. D., Parks, K. M., \& McDonald, D. P. (2010). A multilevel model of the effects of equal opportunity climate on job satisfaction 
in the military. Journal of Occupational Health Psychology, 15, 191- 207. http://dx.doi.org/10.1037/a0018756

Wan, H. L., Sulaiman, M., \& Omar, A. (2012). Procedural justice in promotion decisions of managerial staff in Malaysia. Asia Pacific Business Review, 18, 99-121. http://dx.doi.org/10.1080/13602380903424167

Wang, Z., Chen, J., Boyd, J. E., Zhang, H., Jia, X., Qui, J., \& Xiao, A. (2011). Psychometric properties of the Chinese version of the perceived stress scale in policewomen. PLOS ONE, 6, 1-4.

Warde, B. (2009). Male social workers in child welfare: A qualitative analysis. Child Welfare, 88, 113-133.

Wasburn-Moses, L. (2008). Satisfaction among current doctoral students in special education. Remedial \& Special Education, 29, 259-268. http://dx.doi.org/10.1177/0741932507312014

Watson, R., Storey, D., Wynarczyk, P., Keasey, K., \& Short, H. (1996). The relationship between job satisfaction and managerial remuneration in small and medium-sized enterprises: An empirical test of 'comparison income' and 'equity theory' hypotheses. Applied Economics, 28, 567-576. http://dx.doi.org/10.1080/00036849600000036

Weaver, C. N. (1974). Sex differences in job satisfaction. Business Horizons, 17,43-50 . http://dx.doi.org/10.1016/0007-6813(74)90073-1 
Whitley, B. E. (2001). Principles of research in behavior science ( $2^{\text {nd }}$ Ed.). Boston, MA: McGraw- Hill.

Widmer, P. S., Semmer, N. K., Kalin, W., Jacobshagen, N., \& Meier, L. L. (2012). The ambivalence of challenge stressors: time pressure associated with both negative and positive well being. Journal of Vocational Behavior, 80, 422-433. http://dx.doi.org/10.1016/j.jvb.2011.09.006

Williams, M. L., McDaniel, M. A., \& Nguyen, N. T. (2006). A meta-analysis of the antecedents and consequences of pay level satisfaction. Journal of Applied Psychology, 91, 392-413. http://dx.doi.org/10.1037/0021-9010.91.2.392

Wongpakaran, N., \& Wongpakaran, T. (2010). The Thai version of the PSS-10: An investigation of its psychometric properties. BioPsychoSocial Medicine, 4

Wu, Y. C., \& Shih, K. Y. (2010). The effects of gender role on perceived job stress. The Journal of Human Resources and Adult Learning, 6, 74-79.

Wyss, V. L., \& Tai, R. H. (2010). Conflicts between graduate study in science and family life. College Student Journal, 44, 475-491.

Yu, M. C., Lee, Y. D., \& Tasi, B. C. (2010). Relationships among stressors, work-family conflict, and emotional exhaustion: A study of electronics industry employees in China. Social Behavior and Personality, 38, 829-844. http://dx.doi.org/10.2224/sbp.2010.38.6.829

Zangaro, G. A. (2009). Registered nurses' job satisfaction in navy hospitals. Military Medicine, 174, 76-81. http://dx.doi.org/10.7205/MILMED-D-04-1307 
Zangaro, G. A., \& Johantgen, M. (2009). Registered nurses' job satisfaction in navy hospitals. Military Medicine, 174, 76-81. http://dx.doi.org/10.7205/MILMED-D04-1307

Zapf, D., \& Einarsen, S. (2003). Individual antecedents of bullying: Victims and perpetrators. In S. Einarsen, H. Hoel, D. Zapf, \& C. L. Cooper (Eds.), Bullying and emotional abuse in the workplace. International perspectives in research and practice (pp. 165-184). London: Taylor \& Francis.

Zellars, K. L., Hochwarter, W. A., Lanivich, S. E., Perrewé, P. L., \& Ferris, G. R. (2011) .Accountability for others, perceived resources, and well being: Convergent restricted non-linear results in two samples. Journal of Occupational \& Organizational Psychology, 84, 97-115. http://dx.doi.org/10.1348/20448325.002004

Zhu, Y. (2013). A review of job satisfaction. Asian Social Science, 9, 293-298.

Zontek, T. L., DuVernois, C. C., \& Ogle, B. R. (2009). Job satisfaction and issues related to the retention of environmental health professionals in North Carolina. Journal of Environmental Health, 72, 10-15. 
Appendix A.

IRB Approval

Human Subjects Protection Program Office

MedCenter One - Suite 200

501 E. Broadway

Louisville, KY 40202-1798

Office: 502.852.5188 Fax: 502.852.2164 February 05, 2014

DATE:

TO:

FROM:

Namok Choi

The University of Louisville Institutional

Review Board

IRB NUMBER:

STUDY TITLE:

14.0038

Graduate students who are part time workers: How does occupational stress and gender role affect job satisfaction?

REFERENCE \#: 330950

IRB STAFF CONTACT:

Name: Jacqueline S. Powell

Phone: 852-4101

Email: jspowe01@Louisville.edu

This study now has final IRB approval from 02/05/2014 through 02/04/2015. You should submit the Continuing Review Form EIGHT weeks prior to $02 / 04 / 2015$ in order to ensure that no lapse in approval occurs.

This study was also approved through 45 CFR 46.117(c), which means that an IRB may waive the requirement for the investigator to obtain a signed informed consent form for some or all subjects if it finds either:

- That the only record linking the subject and the research would be the consent document and the principal risk would be potential harm resulting from a breach of confidentiality. Each subject will be asked whether the subject wants documentation linking the subject with the research, and the subject's wishes will govern; or

- That the research presents no more than minimal risk of harm to subjects and involves no procedures for which written consent is normally required outside of the research context.

The following items have been approved: 
Full Accreditation since June 2005 by the Association for the Accreditation of Human Research Protection Programs, Inc.

\begin{tabular}{|c|c|c|c|c|}
\hline \multicolumn{5}{|c|}{ Submission Components } \\
\hline \multicolumn{5}{|l|}{ Submission Form } \\
\hline \multicolumn{3}{|l|}{ Form Name } & \multicolumn{2}{|l|}{ Outcome } \\
\hline \multicolumn{3}{|c|}{ Initial Review Submission Packet } & \multicolumn{2}{|c|}{ Approved as Submitted } \\
\hline \multicolumn{3}{|c|}{$\begin{array}{l}\text { Review Response Submission } \\
\text { Form }\end{array}$} & \multicolumn{2}{|c|}{ Approved as Submitted } \\
\hline \multicolumn{5}{|c|}{ Study Application } \\
\hline \multicolumn{3}{|l|}{ Form Name } & \multicolumn{2}{|l|}{ Outcome } \\
\hline \multicolumn{3}{|c|}{ IRB Study Application } & \multicolumn{2}{|c|}{ Approved as Submitted } \\
\hline \multicolumn{5}{|l|}{ Study Document } \\
\hline Title & \multicolumn{2}{|c|}{$\begin{array}{l}\text { Version } \\
\text { Number }\end{array}$} & Version Date & Outcome \\
\hline \multicolumn{2}{|l|}{ IRB Protocol } & \multicolumn{2}{|l|}{ Version 1.0} & $01 / 13 / 2014$ \\
\hline \multicolumn{2}{|c|}{$\begin{array}{l}\text { Demographics and } \\
\text { Overall Satisfaction }\end{array}$} & \multicolumn{2}{|l|}{ Version 1.0} & $01 / 13 / 2014$ \\
\hline \multicolumn{2}{|c|}{ Qualitative stressors } & \multicolumn{2}{|l|}{ Version 1.0} & $01 / 13 / 2014$ \\
\hline \multicolumn{2}{|l|}{$\begin{array}{l}\text { Bem Sex Role } \\
\text { inventory }\end{array}$} & \multicolumn{2}{|l|}{ Version 1.0} & $01 / 13 / 2014$ \\
\hline \multicolumn{2}{|c|}{$\begin{array}{l}\text { Percieved Stress Scale- } \\
10\end{array}$} & \multicolumn{2}{|l|}{ Version 1.0} & $01 / 13 / 2014$ \\
\hline \multirow{2}{*}{\multicolumn{5}{|c|}{$\begin{array}{l}\text { Job Descriptive Index } \\
\text { Study Consent Form }\end{array}$}} \\
\hline & & & & \\
\hline Title & \multirow{2}{*}{\multicolumn{2}{|c|}{$\begin{array}{l}\text { Version Number } \\
\text { Version } 1.2\end{array}$}} & \multirow{2}{*}{\begin{tabular}{|l|} 
Version Date \\
$01 / 13 / 2014$
\end{tabular}} & Outcome \\
\hline $\begin{array}{l}\text { Church Nally } \\
\text { Preamble } \\
\text { revised }\end{array}$ & & & & Approved \\
\hline
\end{tabular}

\section{Privacy \& Encryption Statement}

The University of Louisville's Privacy and Encryption Policy requires such information as identifiable medical and health records: credit card, bank account and other personal financial information; social security numbers; proprietary research data; dates of birth (when combined with name, address and/or phone numbers) to be encrypted. For additional information: http://security.louisville.edu/PolStds/ISO/PS018.htm.

\section{Implementation of Changes to Previously Approved Research}

Prior to the implementation of any changes in the approved research, the investigator will submit any modifications to the IRB and await approval before implementing the changes, unless the change is being made to ensure the safety and welfare of the subjects enrolled in the research. If such occurs, a Protocol Deviation/Violation should be submitted within five days of the occurrence indicating what safety measures were taken, along with an amendment to revise the protocol. 


\section{Unanticipated Changes Involving Risks to Subjects or Others (UPIRTSOs)}

In general, these may include any incident, experience, or outcome, which has been associated with an unexpected event(s), related or possibly related to participation in the research, and suggests that the research places subjects or others at a greater risk of harm than was previously known or suspected. UPIRTSOs may or may not require suspension of the research. Each incident is evaluated on a case by case basis to make this determination. The IRB may require remedial action or education as deemed necessary for the investigator or any other key personnel. The investigator is responsible for reporting UPIRTSOs to the IRB within 5 working days. Use the UPIRTSO form located within the iRIS system to report any UPIRTSOs. Full Accreditation since June 2005 by the Association for the Accreditation of Human Research Protection Programs, Inc.

\section{Continuation Review Requirements}

You are responsible for submitting a continuation review 45 days prior to the expiration date of your research study. Investigators who allow their study approval to expire have committed significant non-compliance with federal regulations. Such lapses may require reporting to federal agencies, a program audit by compliance auditors to ensure that subjects were not enrolled during the expired period, and may lead to findings of serious and continuing non-compliance if expiration were to occur a second time.

The committee will be advised of this action at a regularly scheduled meeting.

If you have any questions, please contact the HSPPO at (502) 852-5188 or

hsppofc@louisville.edu

Thank you for your submission.

Sincerely, Peter M. Quesada, Ph.D., Chair

Social/Behavioral/Educational Institutional Review Board $\mathrm{PMQ} / \mathrm{jsp}$ 
Appendix B.

Recruitment letter

Investigation into the Academic and Occupational Perceptions of Graduate Student

Dear Graduate Student:

You are being invited to participate in a research study by answering the attached survey about your experience as a graduate student and your perceptions of the academic and occupational settings. There are no known risks for your participation in this research study. The information collected may not benefit you directly. The information learned in this study may be helpful to others. The information you provide may be helpful for future generations of the graduate students who are part time workers. Your completed survey will be stored electronically with no identifiers. The survey will take approximately 15-20 minutes to complete. You will also be given the opportunity to enter a raffle at the end of the survey for a chance to win one of two $\$ 50$ gift cards. If you are selected to receive a gift card, these gift cards will be personally purchased by Megan Church Nally as an incentive to participate in this study. If you decide to participate, please click on this unique surveymonkey link at the end of the email. (https://www.surveymonkey.com/s/DXLWC92)

Individuals from the Department of Educational Leadership, Foundation, and Human Resource Education, the Institutional Review Board (IRB), the Human Subjects Protection Program Office (HSPPO), and other regulatory agencies may inspect these records. In all other respects, however, the data will be held in confidence to the extent permitted by law. Should the data be published, your identity will not be disclosed.

Taking part in this study is voluntary. By completing this survey you agree to take part in this research study. You do not have to answer any questions that make you uncomfortable. You may choose not to take part at all. If you decide to be in this study you may stop taking part at any time. If you decide not to be in this study or if you stop taking part at any time, you will not lose any benefits for which you may qualify. 
If you have any questions, concerns, or complaints about the research study, please contact Dr. Namok Choi at namok.choi@louisville.edu or (502) 852-4014.

If you have any questions about your rights as a research subject, you may call the Human Subjects Protection Program Office at (502) 852-5188. You can discuss any questions about your rights as a research subject, in private, with a member of the Institutional Review Board (IRB). You may also call this number if you have other questions about the research, and you cannot reach the research staff, or want to talk to someone else. The IRB is an independent committee made up of people from the University community, staff of the institutions, as well as people from the community not connected with these institutions. The IRBhas reviewed this research study.

If you have concerns or complaints about the research or research staff and you do not wish to give your name, you may call 1-877-852-1167. This is a 24 hour hot line answered by people who do not work at the University of Louisville.

https://www.surveymonkey.com/s/DXLWC92

Sincerely,

Dr. Namok Choi

Megan Church Nally 


\section{Appendix C.}

Evidence of assumptions for research question 1
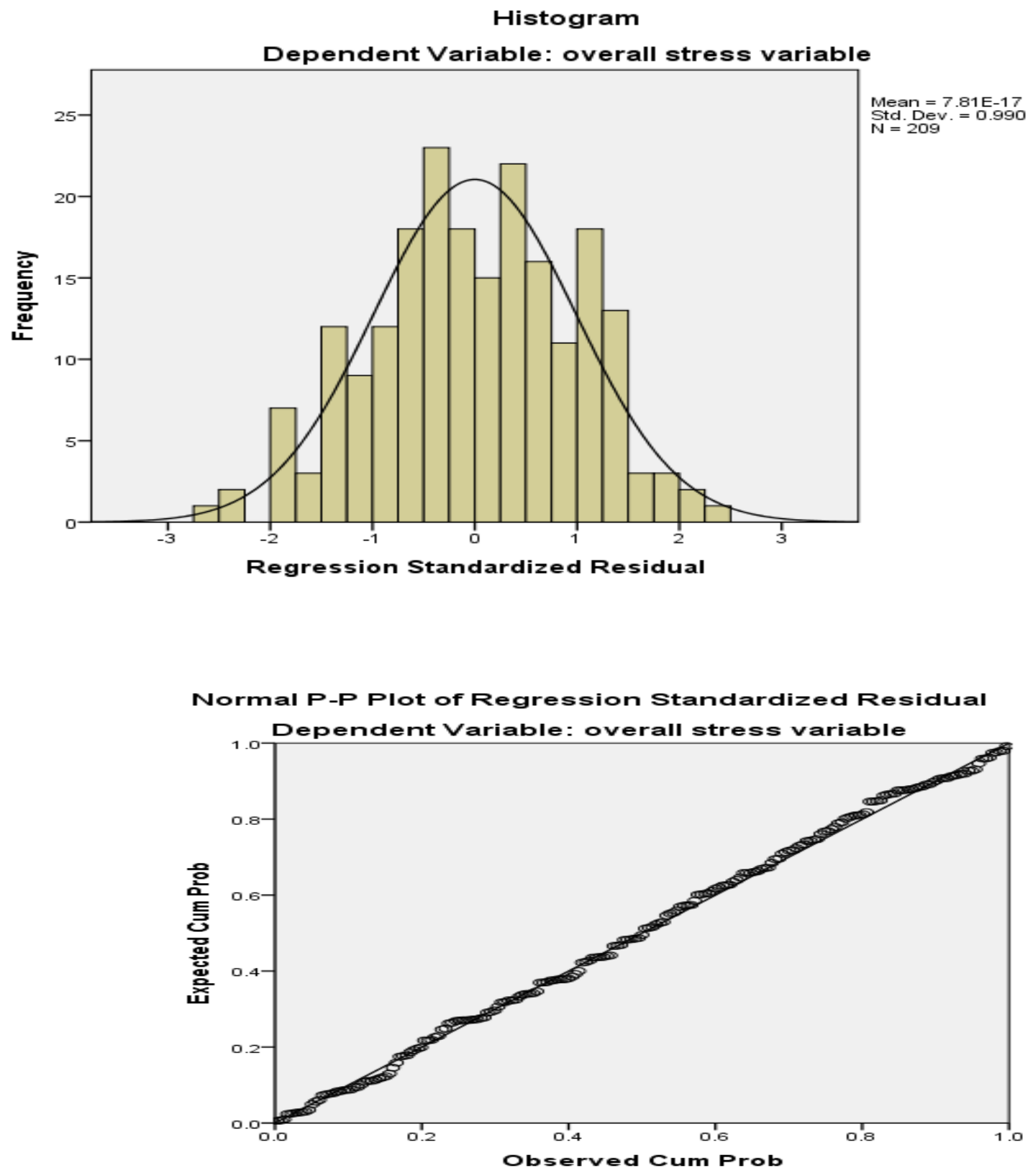
Scatterplot

Dependent Variable: overall stress variable

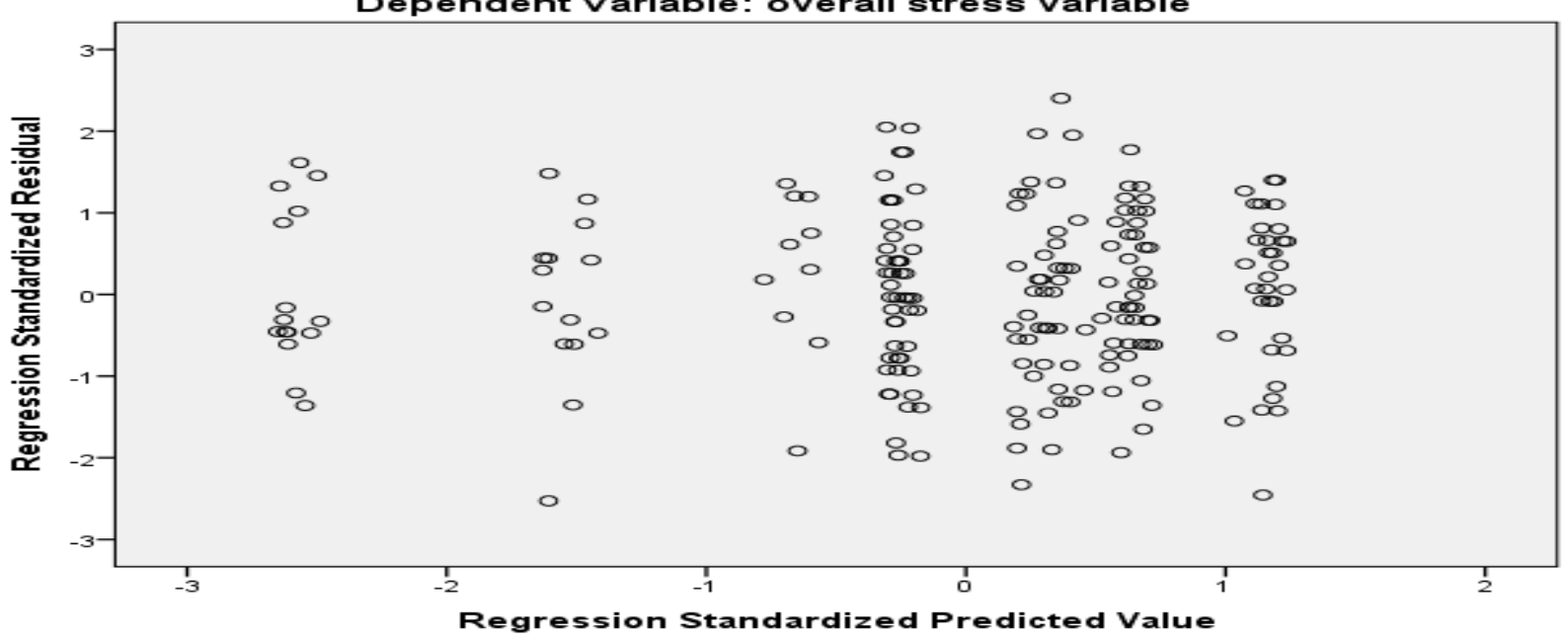

Partial Regression Plot

Dependent Variable: overall stress variable

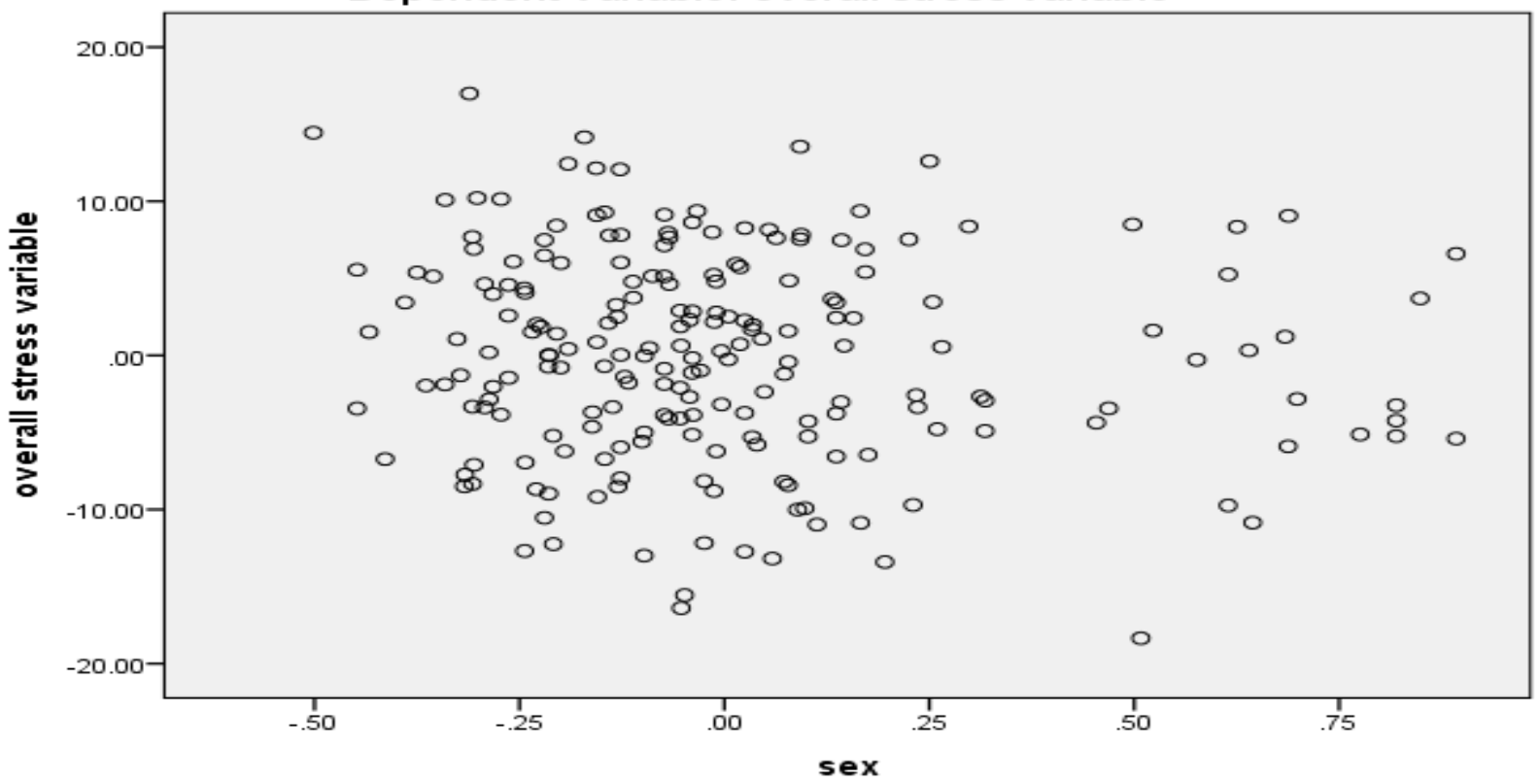



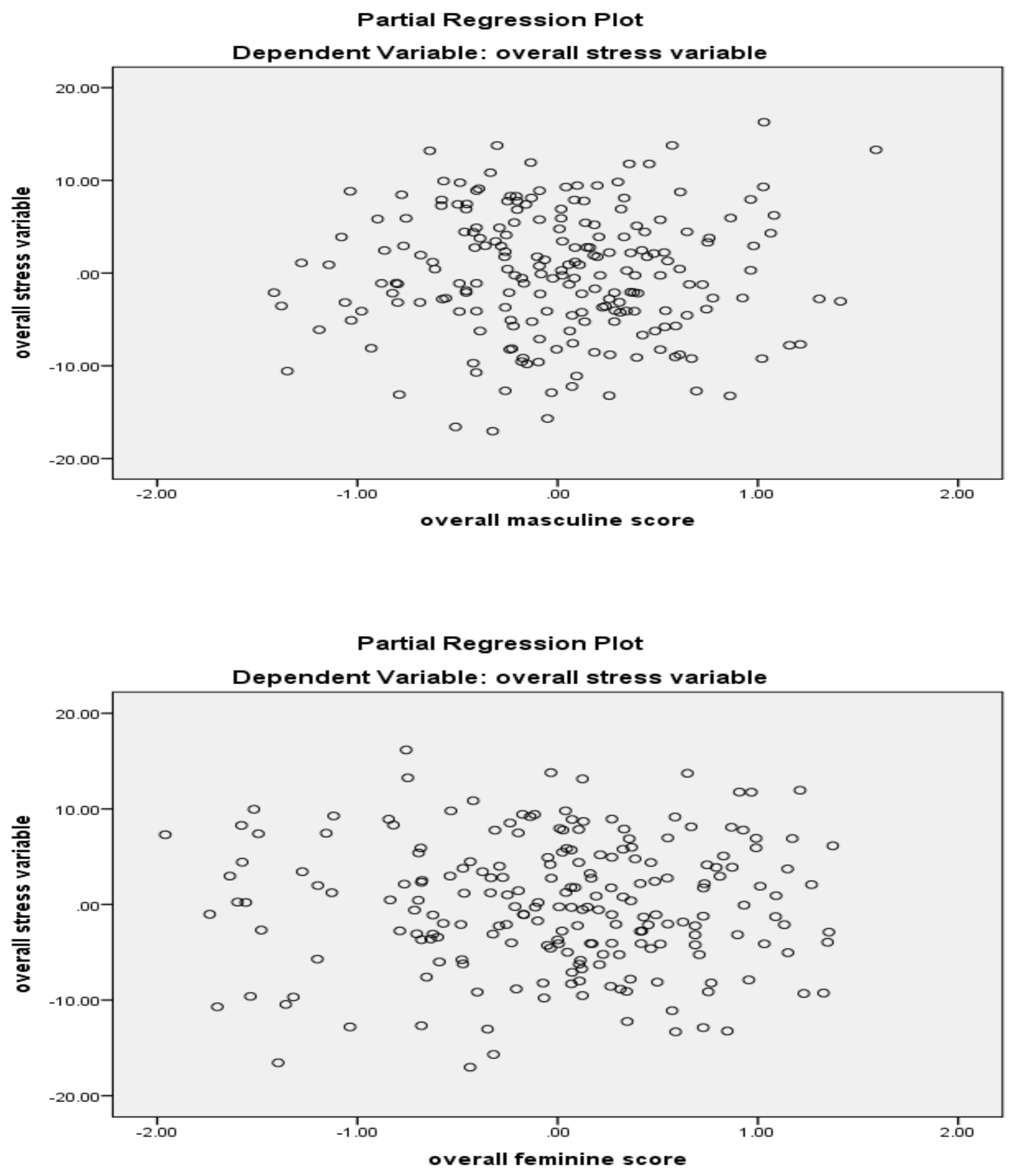


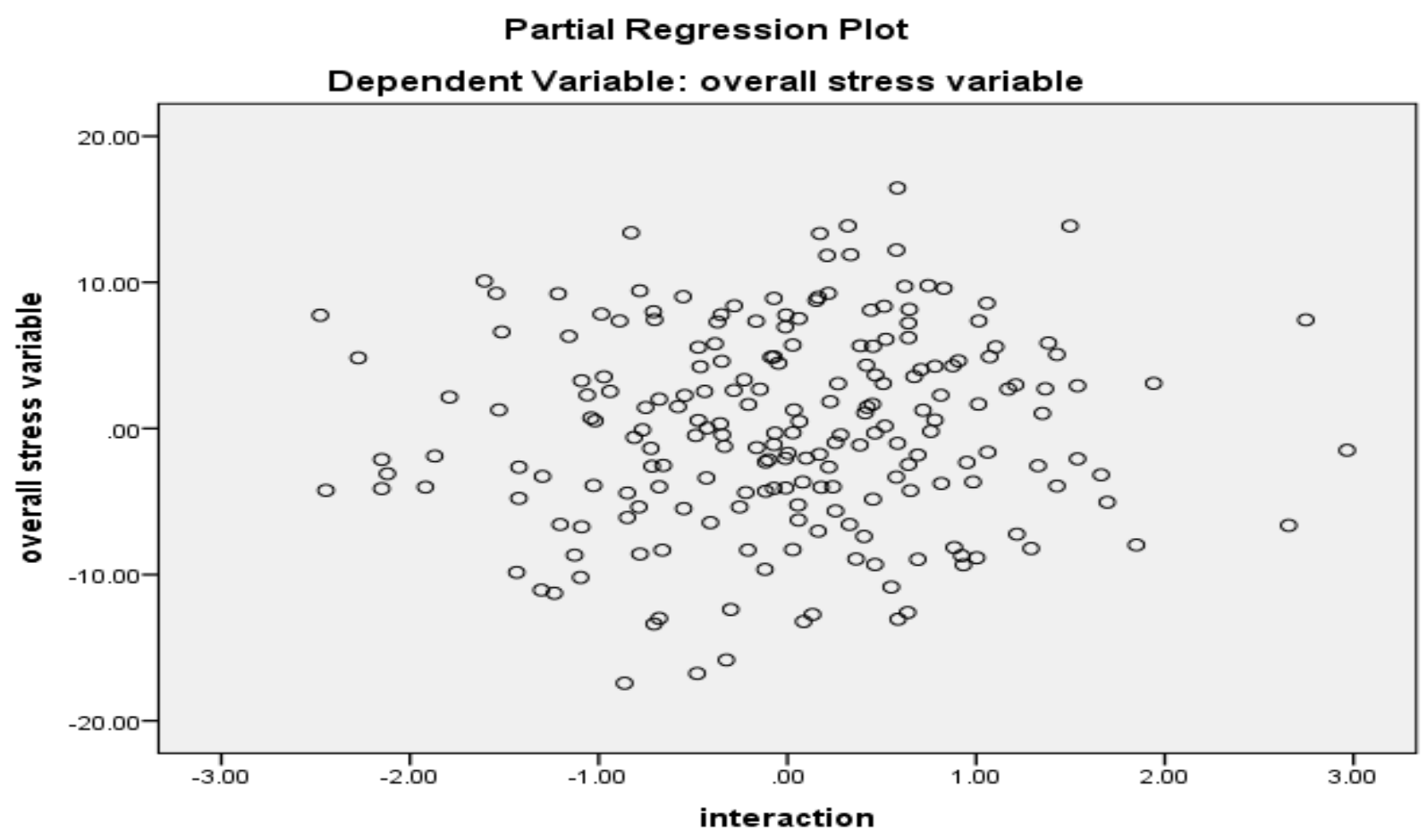

Collinearity Diagnosis

\begin{tabular}{ccc}
\hline Variable & Tolerance & VIF \\
\hline 1. Sex & 1.00 & 1.00 \\
2. Sex & .98 & 1.02 \\
M & 1.00 & 1.01 \\
F & .98 & 1.03 \\
3. Sex & .43 & 2.35 \\
M & .44 & 2.27 \\
F & .63 & 1.58 \\
Sex x MF & .24 & 4.18 \\
\hline
\end{tabular}


Appendix D.

Evidence of assumptions for research question 2

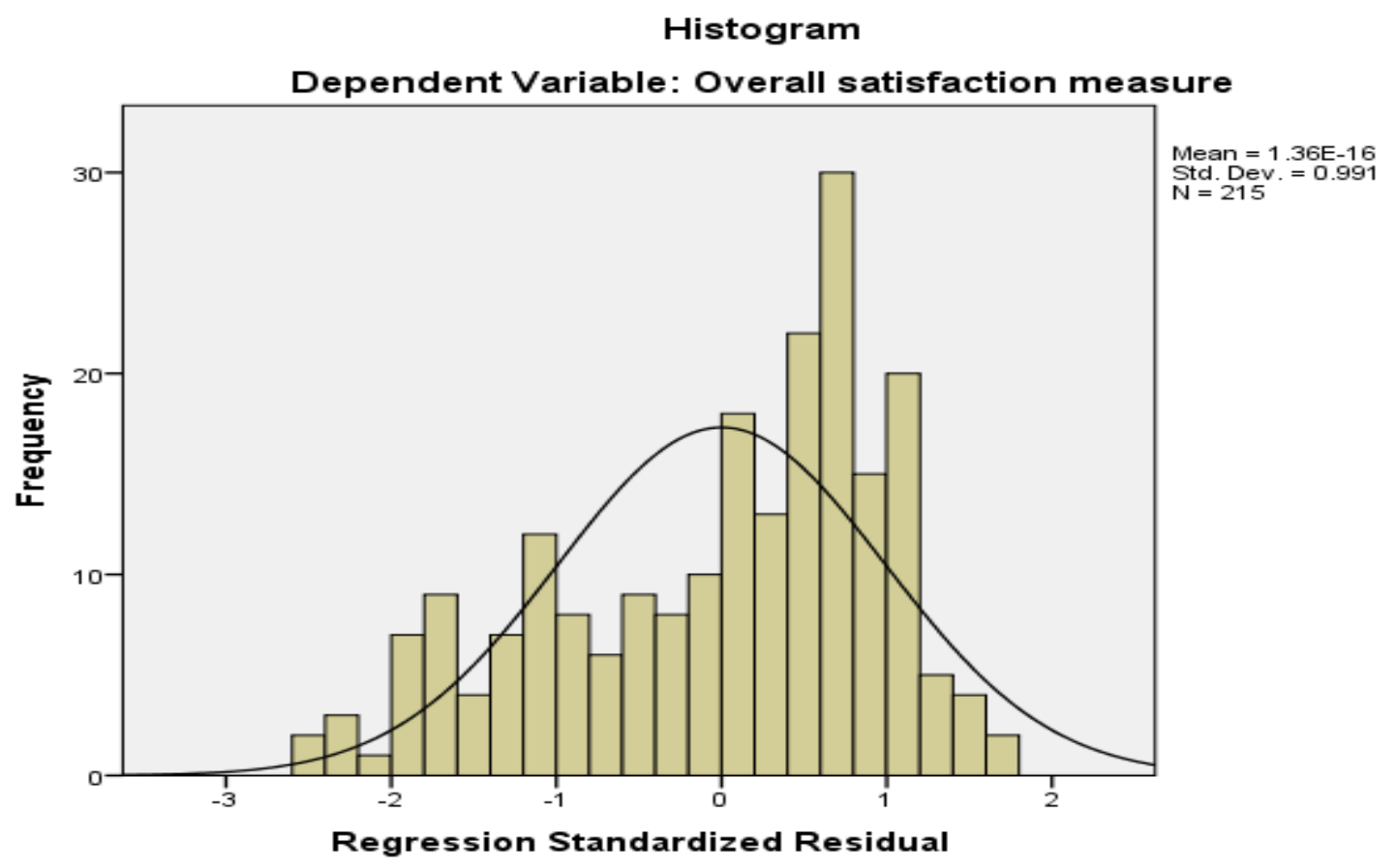

Normal P-P Plot of Regression Standardized Residual

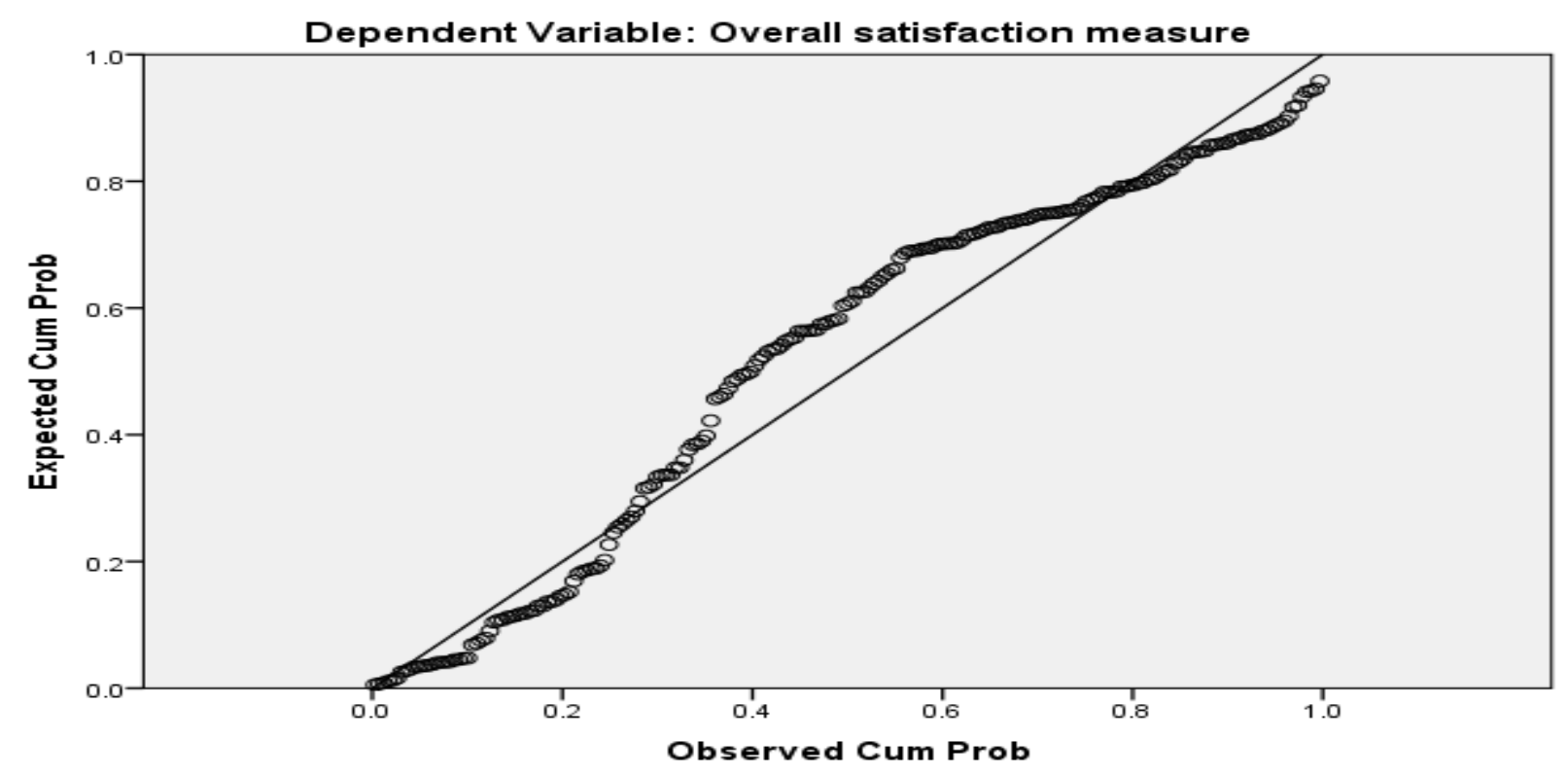



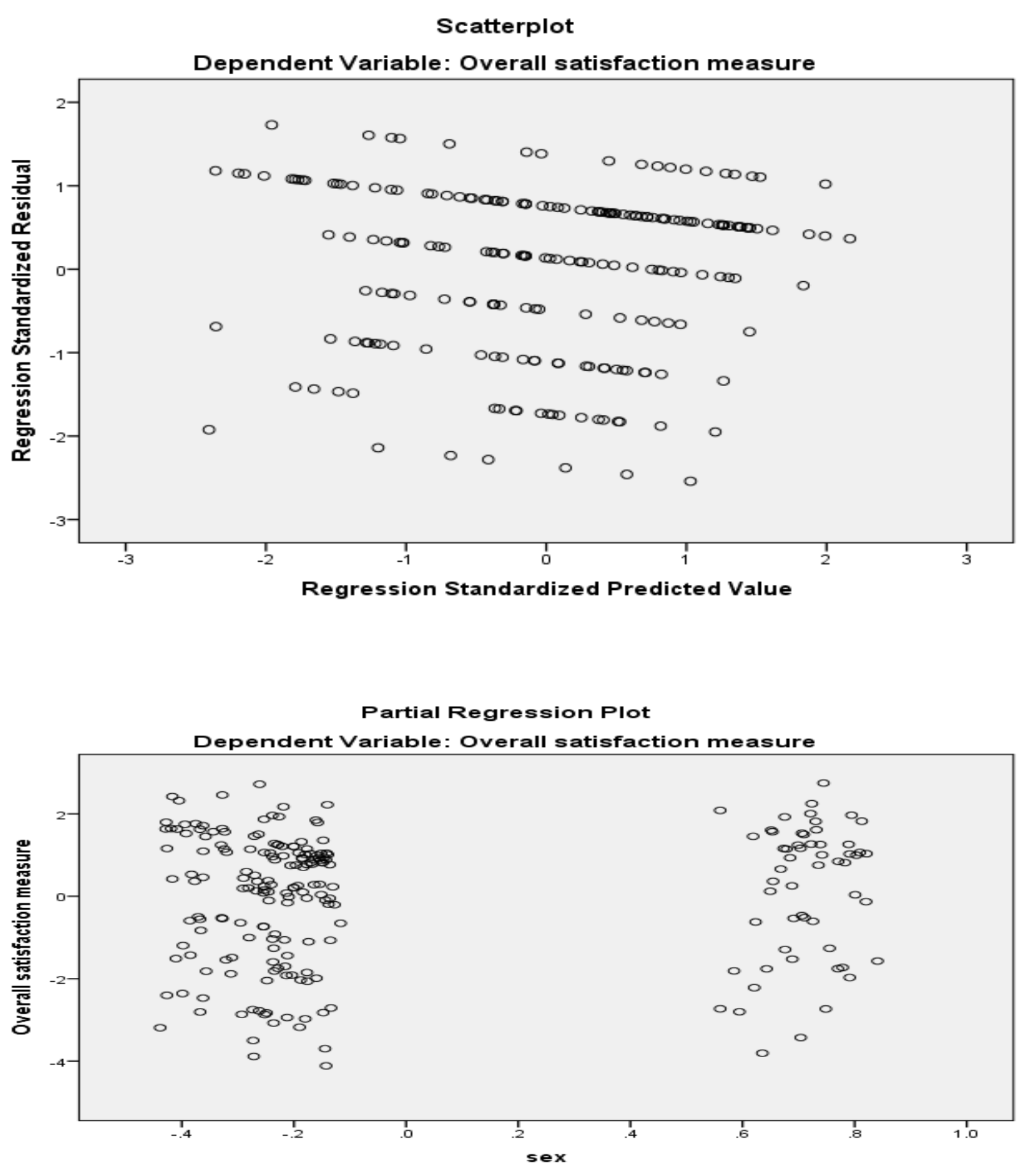
Partial Regression Plot

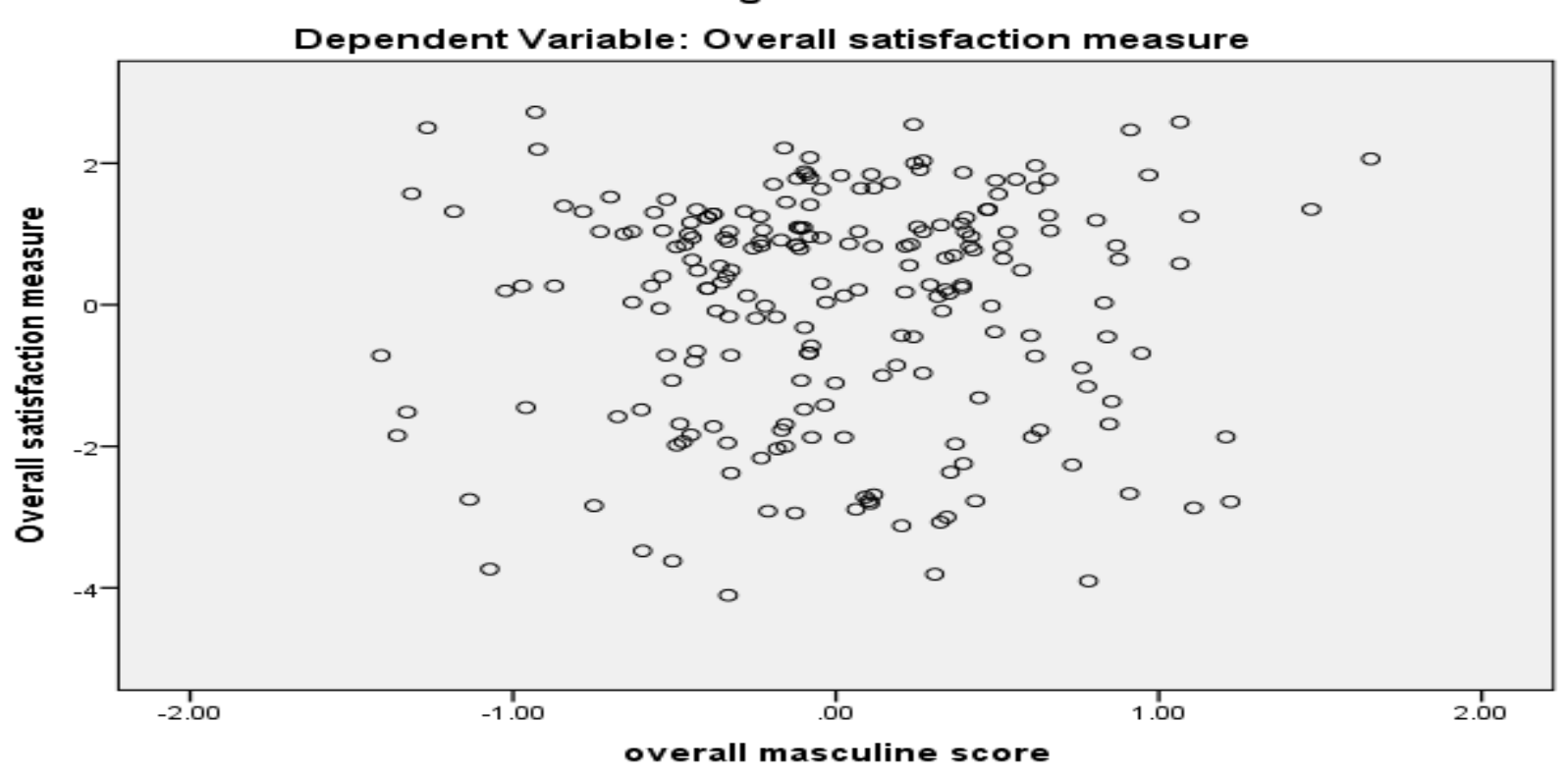

Partial Regression Plot

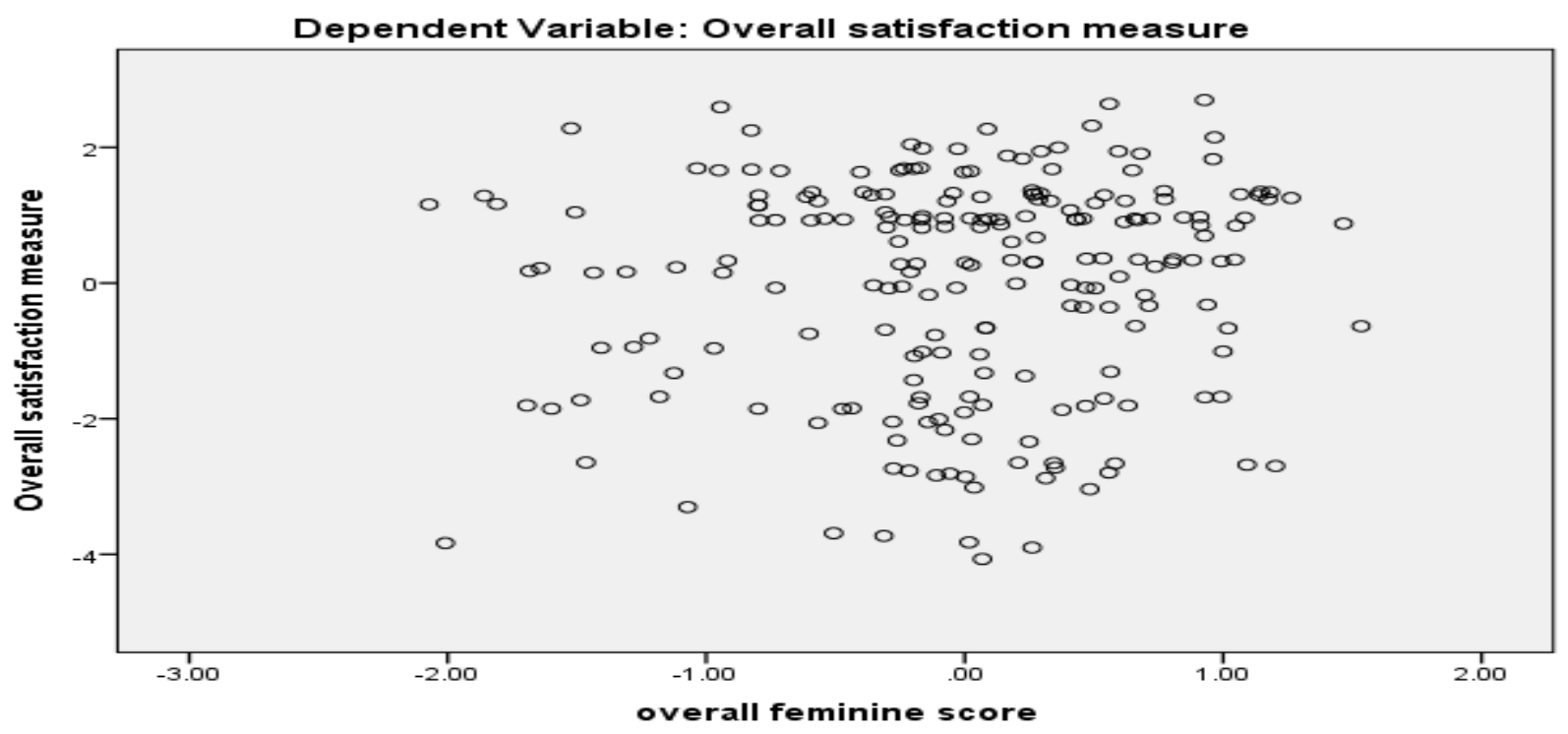




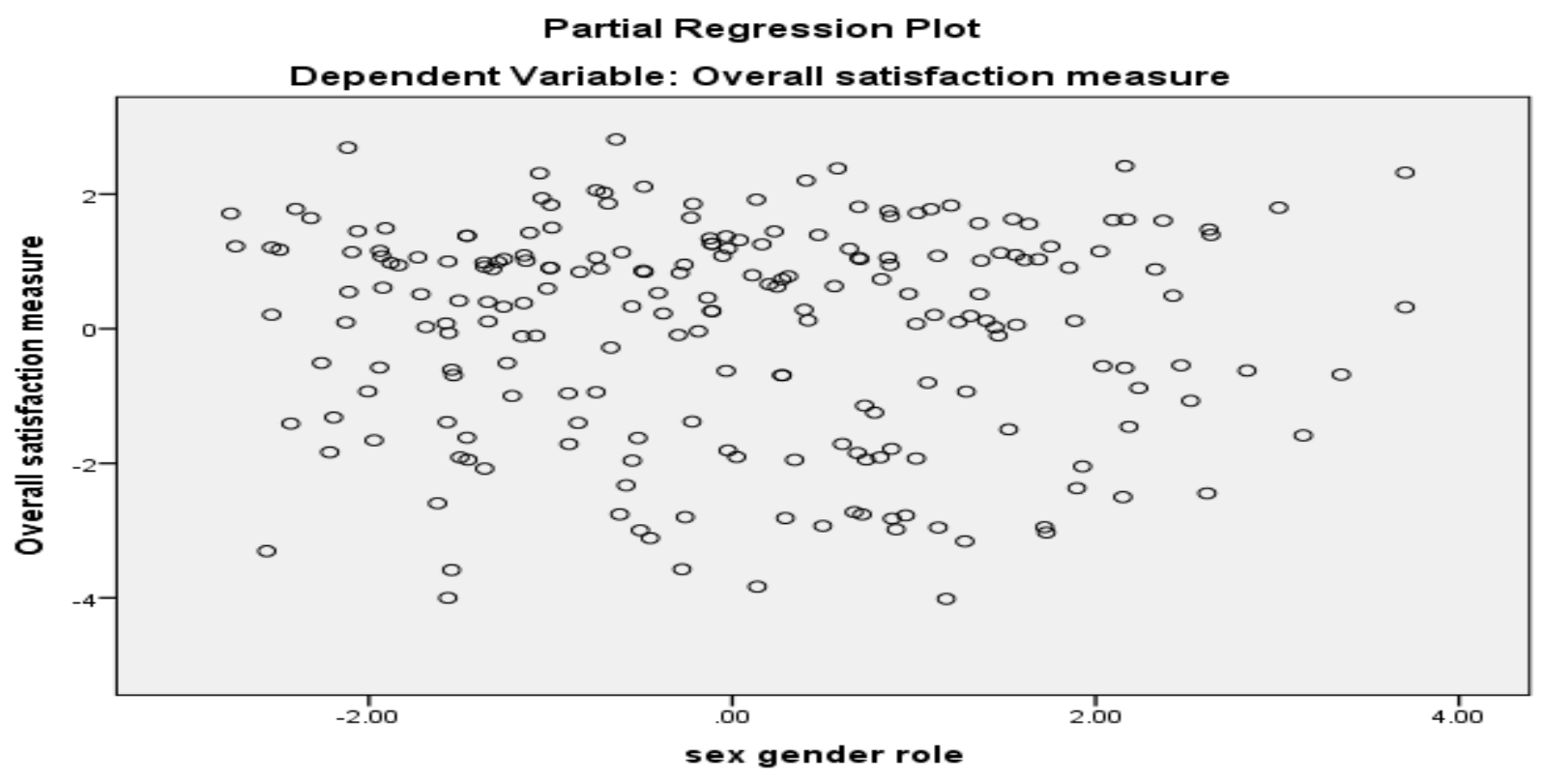

Collinearity Diagnosis

\begin{tabular}{ccc}
\hline Variable & Tolerance & VIF \\
\hline 1. Sex & 1.00 & 1.00 \\
2. Sex & .98 & 1.02 \\
& & \\
M & 1.00 & 1.01 \\
F & .98 & 1.02 \\
3. Sex & .96 & 1.04 \\
M & .43 & 2.33 \\
F & .63 & 1.60 \\
Sex x MF & .35 & 2.83 \\
\hline
\end{tabular}




\section{Appendix E.}

Evidence of assumptions for research question 3
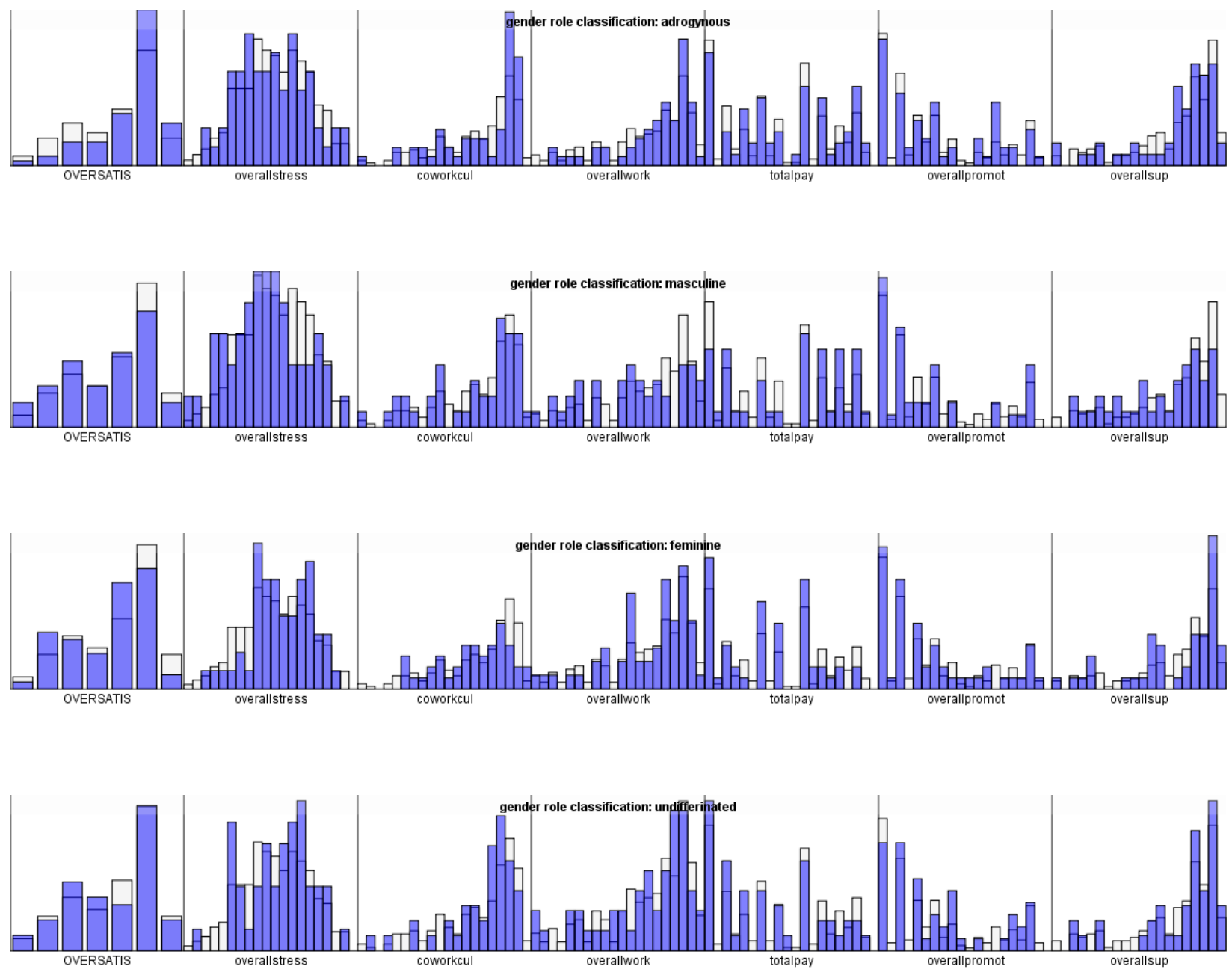
Appendix F.

Evidence of assumptions for research question 4
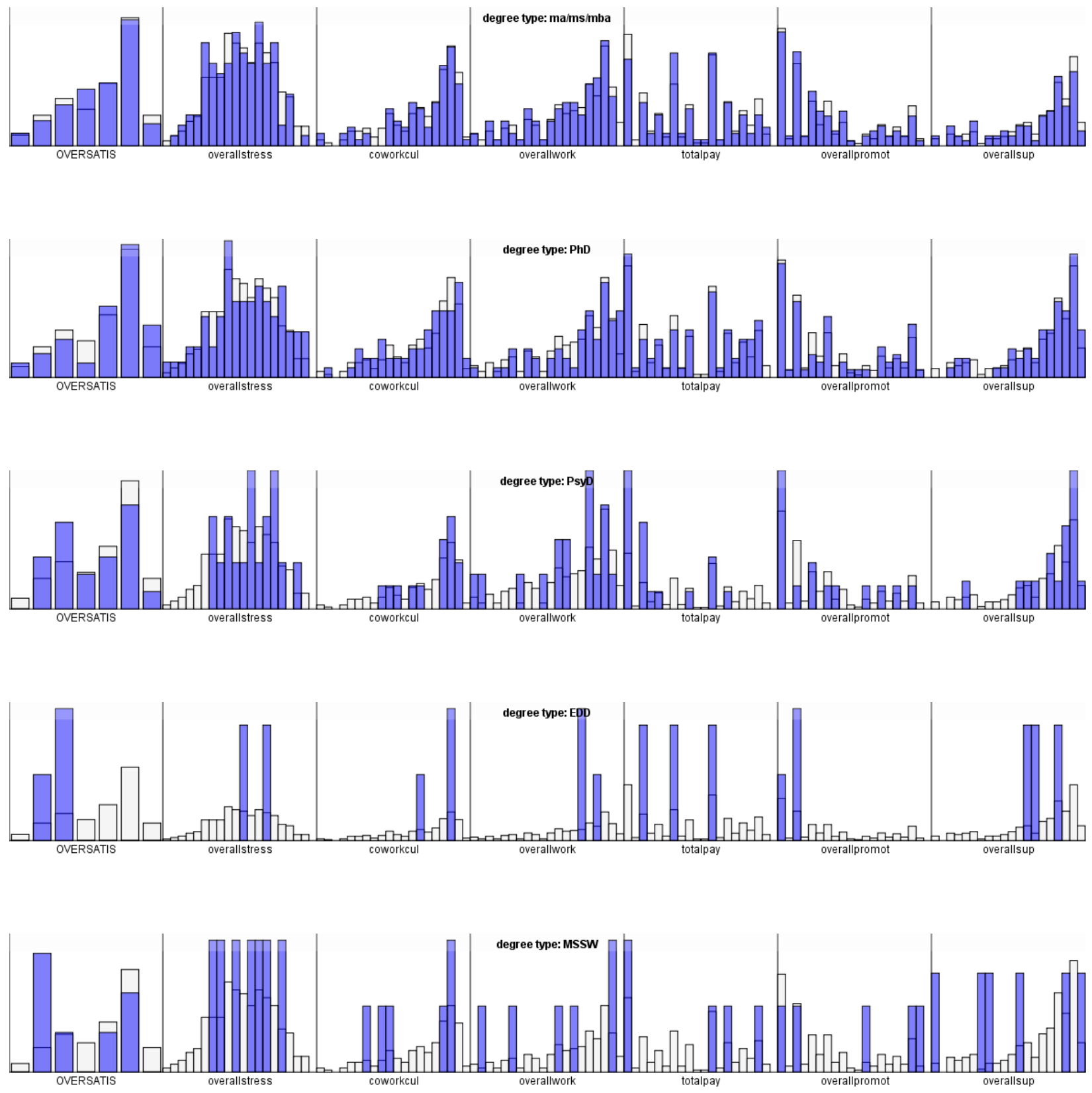

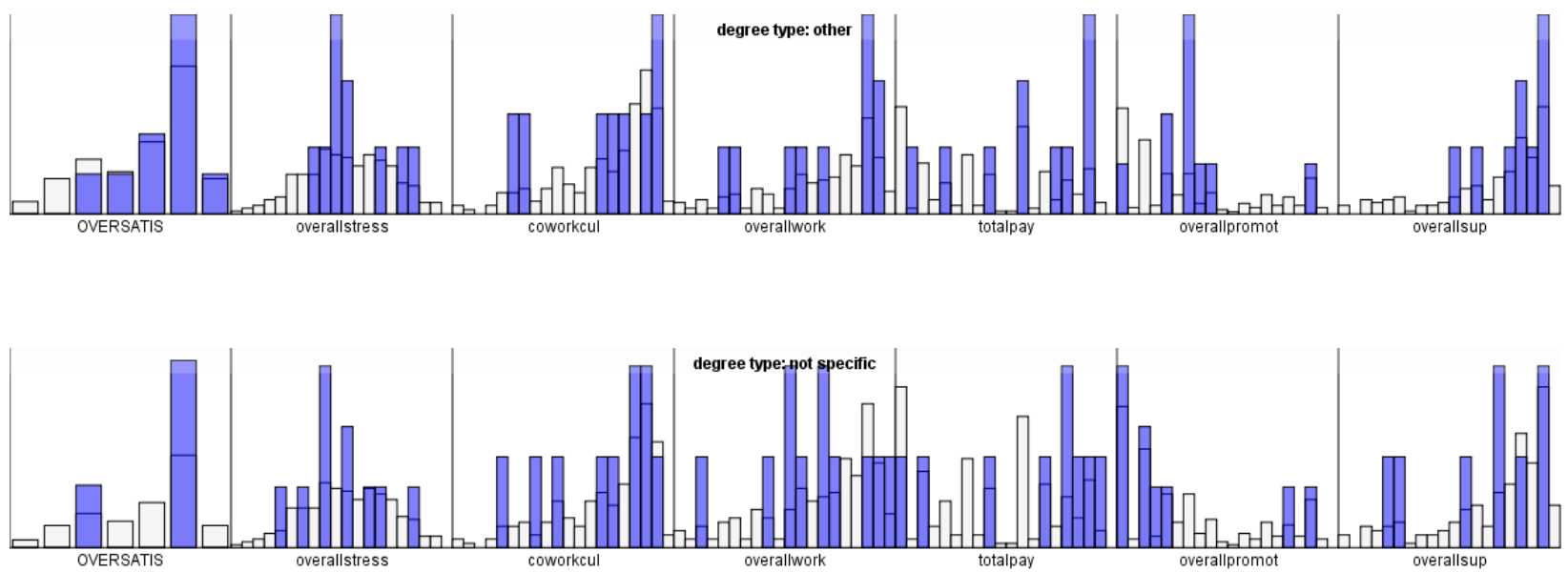


\section{Appendix G.}

PSS-10 Scree test and Parallel Analysis

Scree test of PSS-10

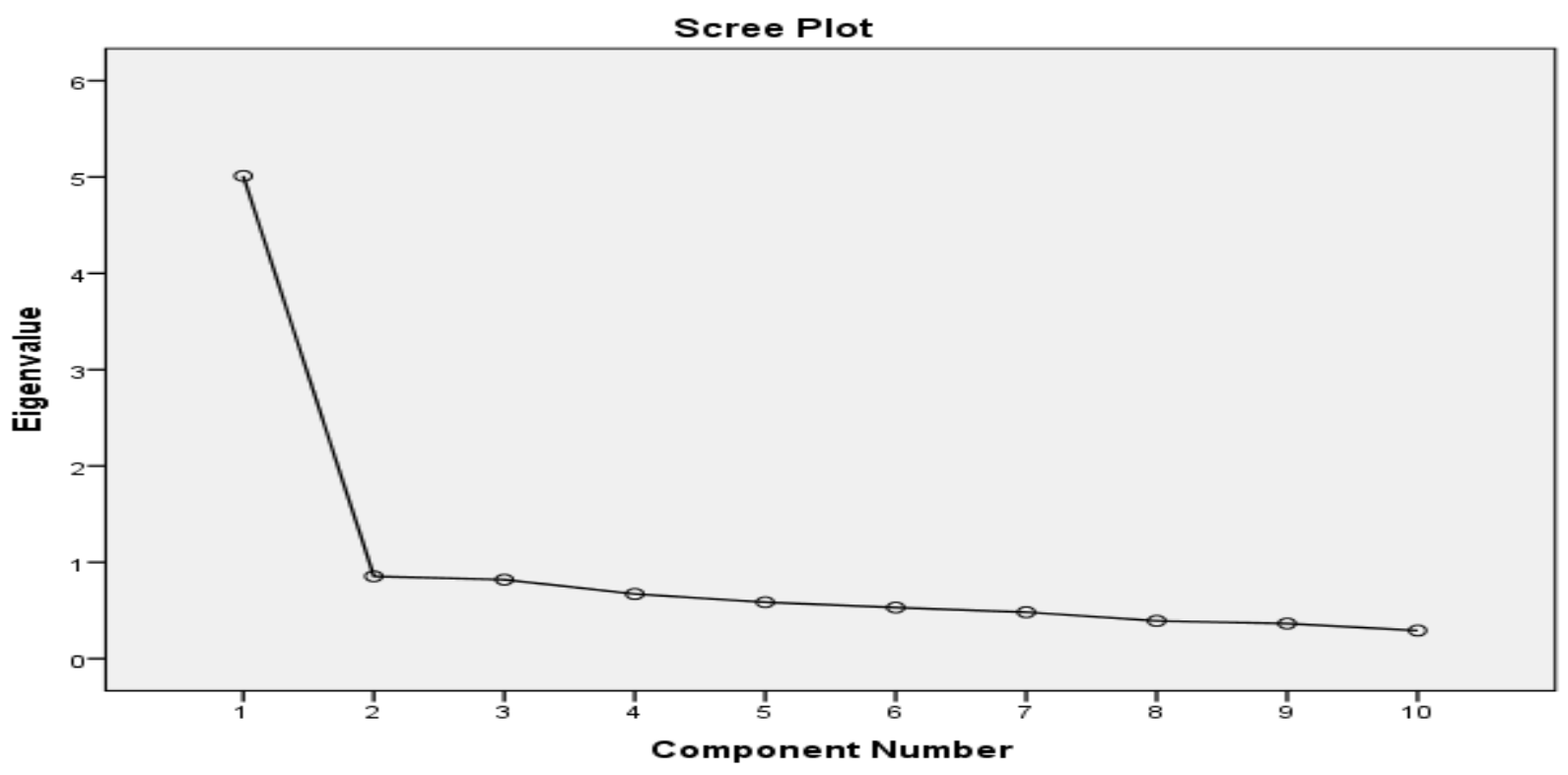

Parallel analysis of PSS-10

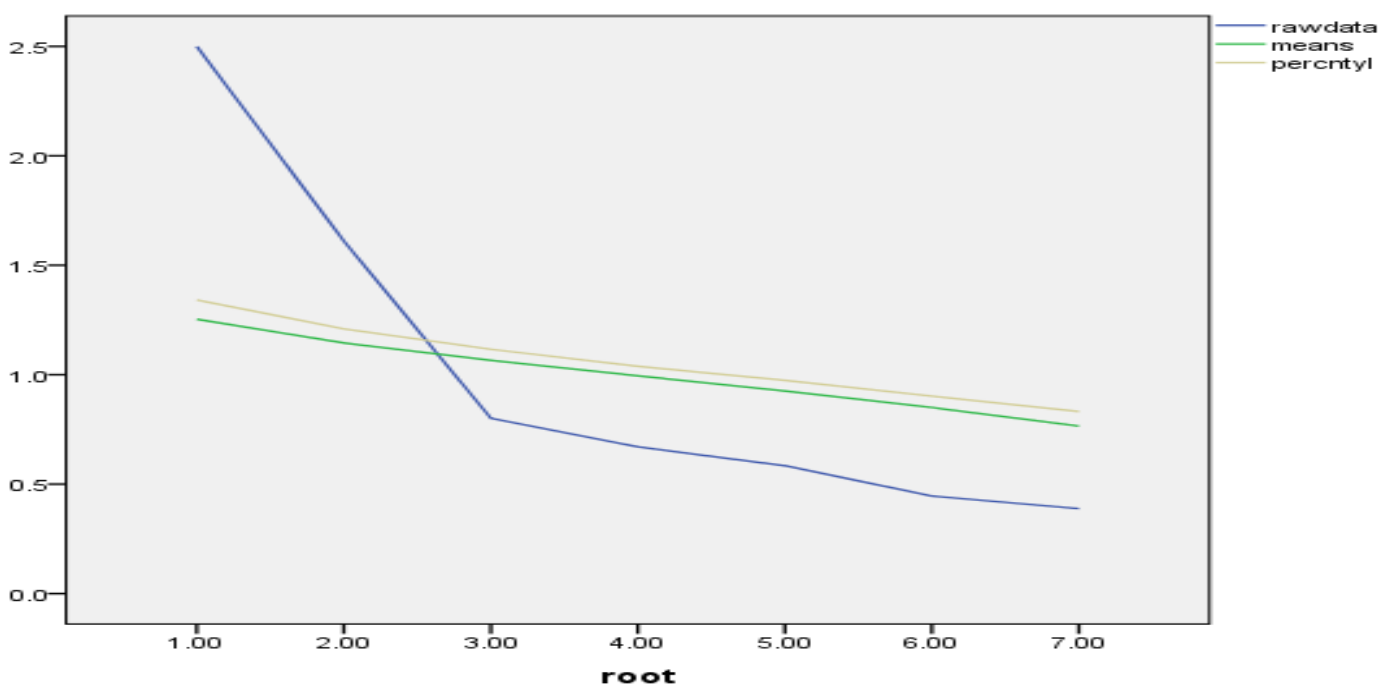


Appendix $\mathrm{H}$

BSRI Scree test and parallel analysis

Scree test

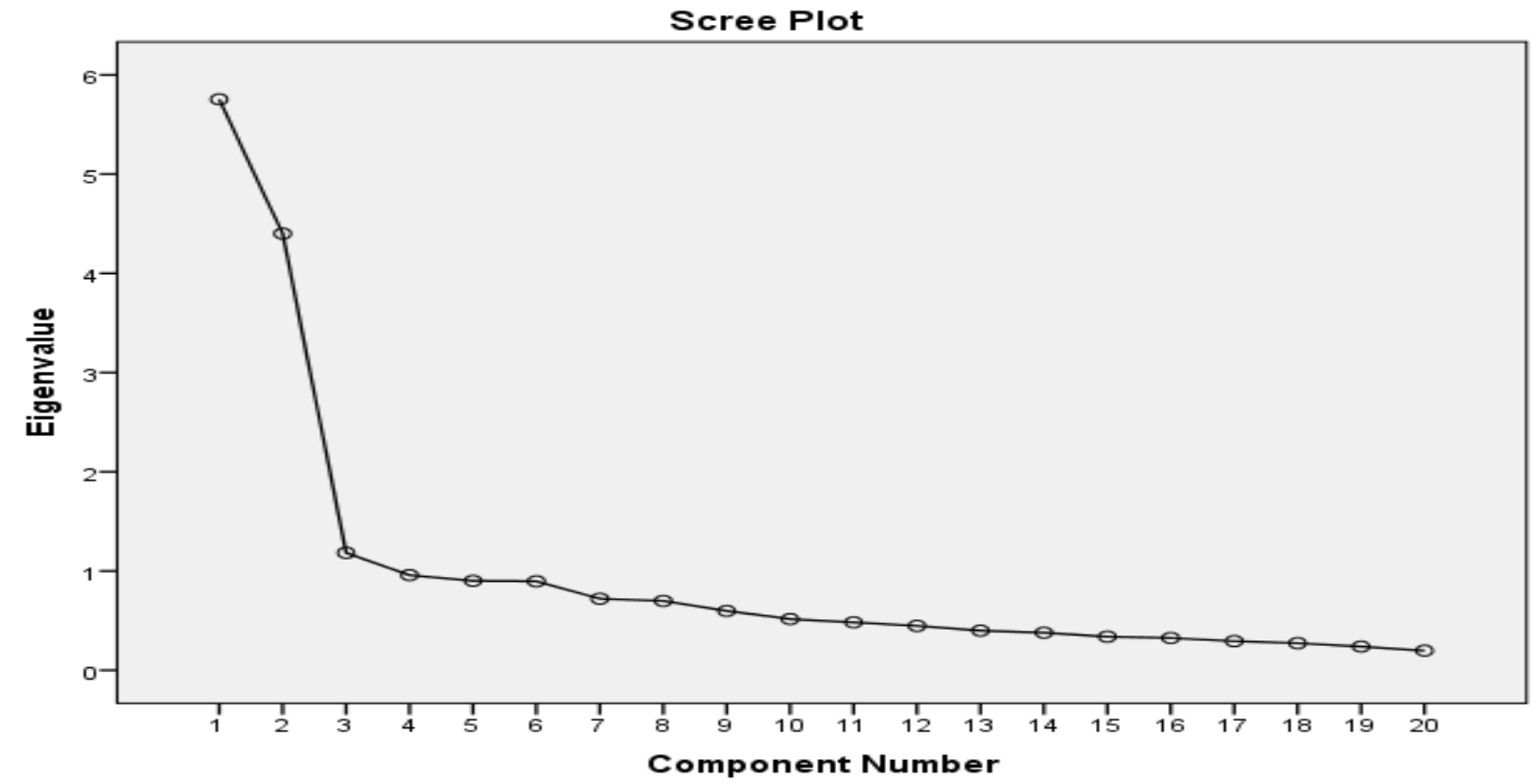

Parallel analysis of BSRI

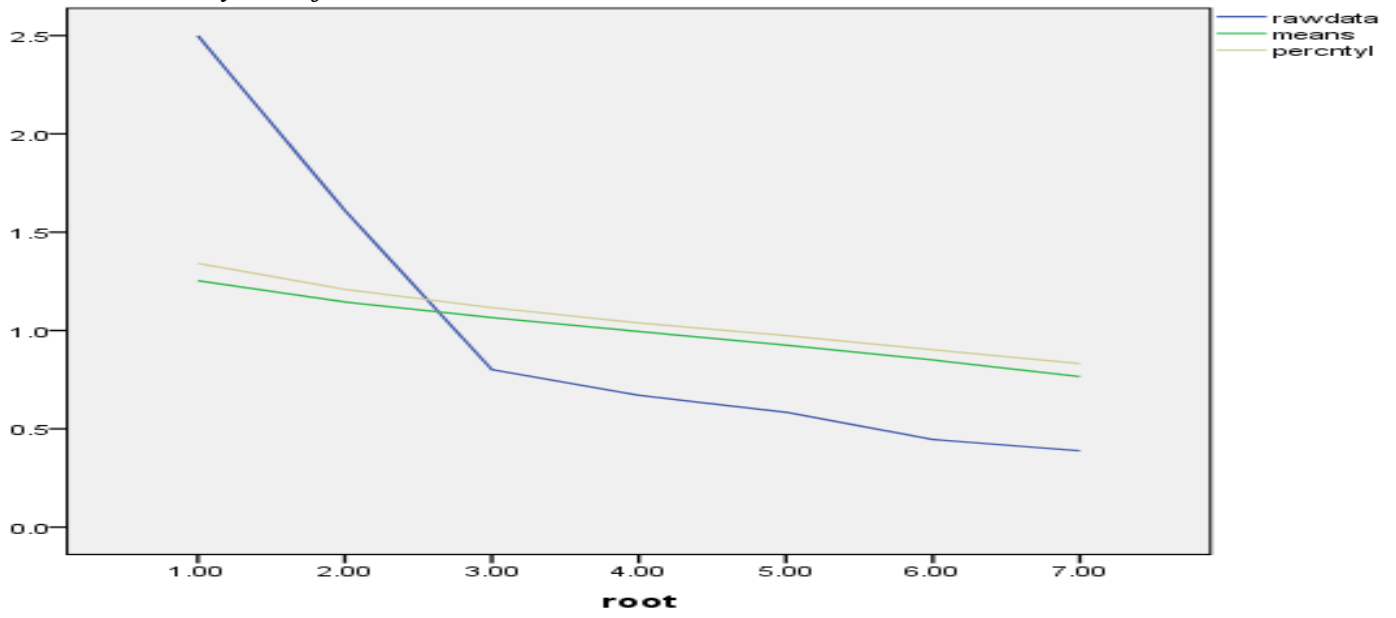


Appendix I.

\section{JDI Scree test and Parallel analysis}

Scree test

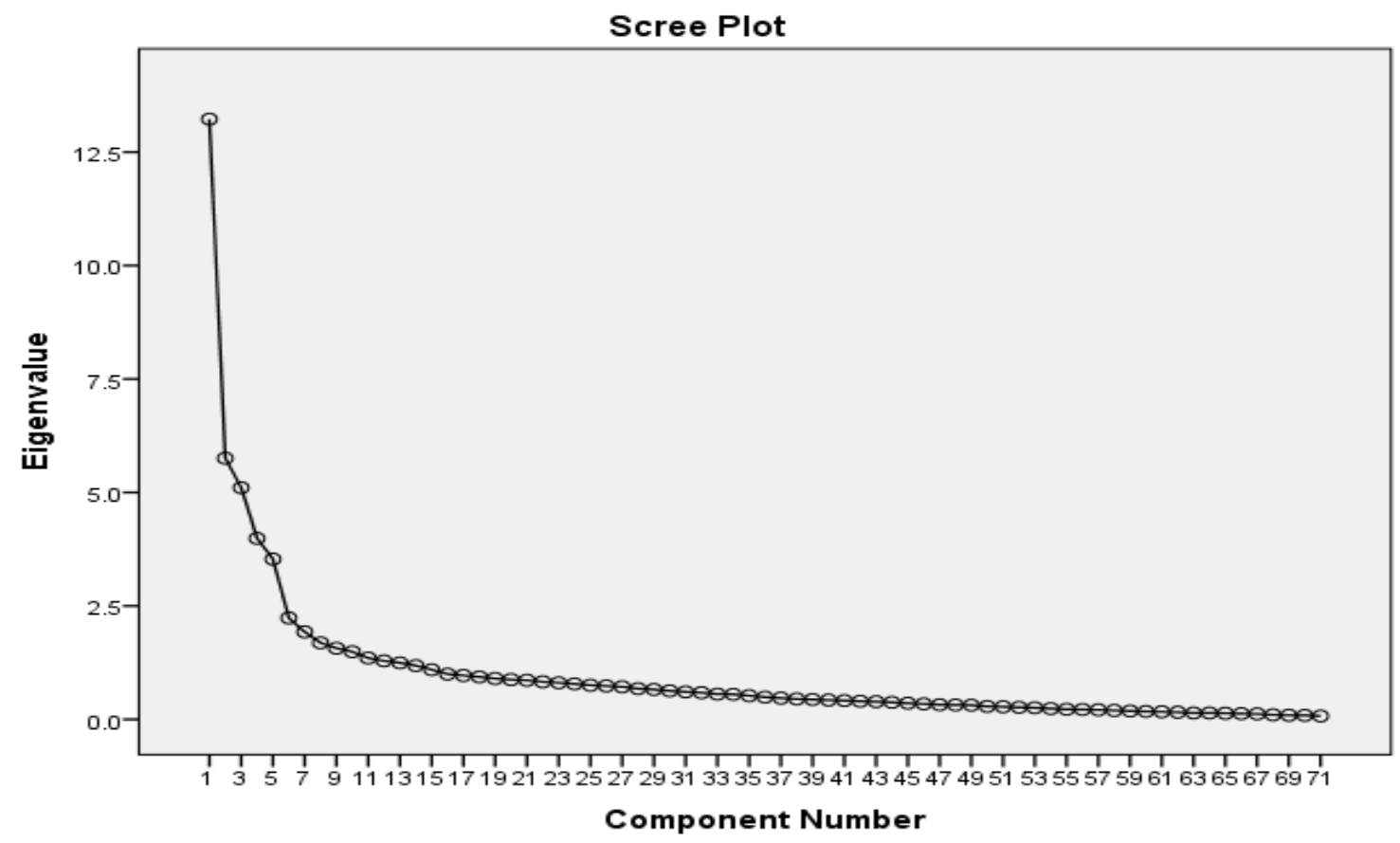

Parallel analysis of the JDI

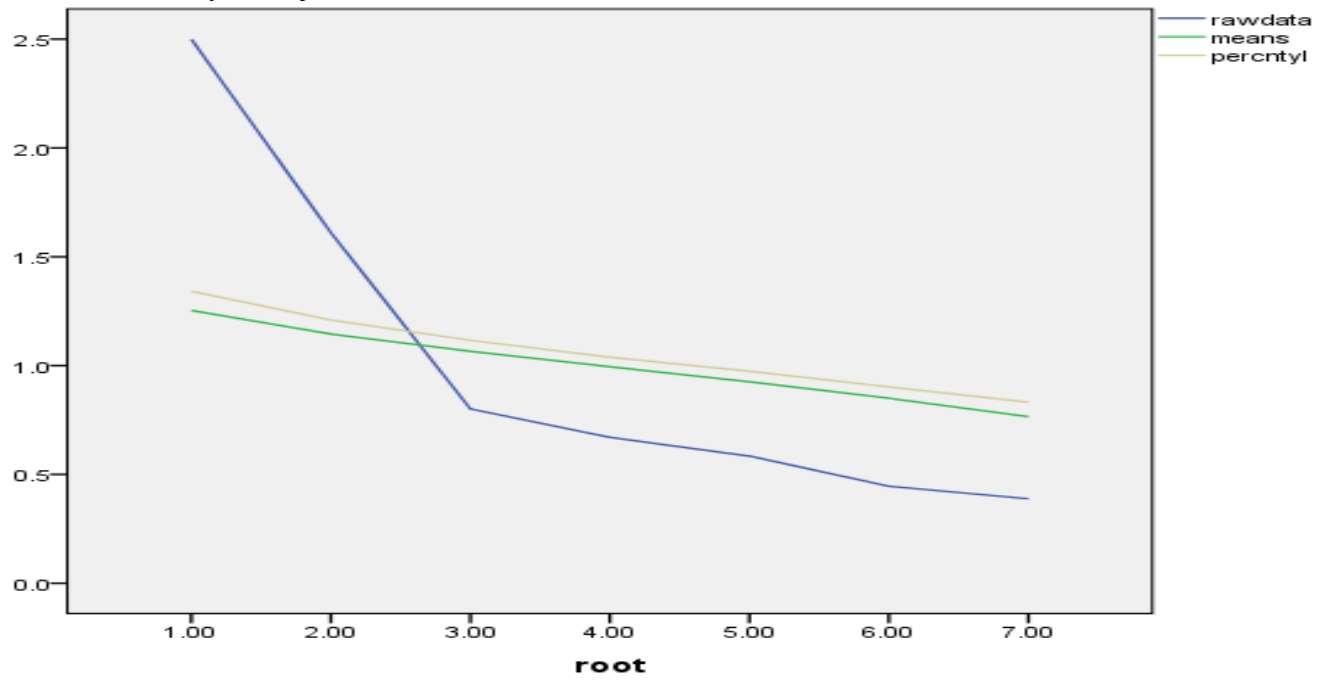




\section{CURRICULUM VITAE}

\section{Megan Church-Nally}

PhD Educational Leadership and Organizational Development with Human Resource Concentration University of Louisville

Dissertation: Graduate students who are part time workers: How does occupational stress and gender role affect job satisfaction?

M.S. Industrial-Organizational Psychology, GPA 4.0

Xavier University, May 2007

Thesis: Emotional intelligence as the moderator between job satisfaction and occupational Stress in Mental Health Professionals

B.A. Psychology and Sociology

Bellarmine University, May 2005

Salutatorian, GPA 3.98, graduated Summa cum laude

\section{Academic Experience}

Bellarmine University

2014- Present

Psychology Department, Instructor of Psychology

- Classes Taught: Introductory Psychology, Introductions to Professional Psychology, Psychology of Learning, and Organizational Behavior and Leadership

- Developed lectures, exams, and application assignments

- Mentored students and worked on a manuscript for publication

- Advised students on appropriate classes to take and professionals to shadow to help determine career goals 


\section{Academic Experience(continued)}

\section{Spalding University}

2013- Present

Psychology Department, Adjunct Faculty

- Classes taught: Abnormal Psychology, Developmental Psychology, and Introductory Psychology

- Lectured on major schools of psychology, psychological disorders, disorder classification, and treatment

- Developed lectures, exams, and application assignments

\section{Bellarmine University}

2008- Present

Psychology Department, Adjunct Faculty

- Classes Taught: Organizational Behavior and Leadership; Introductory Psychology; Psychology of Learning; Lifespan Development; and Social Psychology

- Lectured on topics of selection, stress, performance appraisal, training, and ethics

- Developed lectures, exams, and application assignments

- Served on two students' thesis committees

- Mentored students and worked on a manuscript for publication

- Advised students on appropriate classes to take and professionals to shadow to help determine career goals

\section{St. Catharine University}

2012- 2014

Psychology Department, Adjunct Faculty

- Classes Taught: Introductory Psychology; Introduction to IndustrialOrganizational Psychology; Organizational Behavior and Leadership, Social Psychology; and Social Statistics

- Lectured on major schools of psychology, personality, and social psychology

- Lectured students on statistical techniques and statistical tests

- Taught students how to do statistical tests and graphs in both excel and SPSS

- Developed lectures, exams, and application assignments

\section{University of Louisville}

Teaching Assistant

- Lectured on classical Human Resources theory in modern corporate America

- Guest lecture as needed 


\section{$\underline{\text { Academic Experience (continued) }}$}

Statistics Teaching Assistant at Xavier University

- Assisted students with statistical homework and graded papers

- Lead study sessions for tests

- Assisted student's learning and utilization of SPSS

Graduate Assistant at Xavier University

2005- 2006

- Researched mail and electronic surveys

- Researched ethics and safety data

- Coded and analyzed dataset on 360 degree Feedback

- Prepared 360 degree data for study publication

Teaching Assistant at Bellarmine University

Fall 2004

- Assisted students with statistical homework for Research Methods

- Lead study sessions for tests

- Held office hours

- Graded papers

- Lectured on "Recording Observational Data"

\section{Professional Experience}

Mercer

2007- 2012

\section{Mercer Benchmark Database Team, Project Management}

- Process data for Mercer Benchmark Survey, Insurance Survey, Consumer Goods, Total Remuneration, Information Technology Compensation and Policies and Practices Survey, and Financial Operations Survey

- Performed Regression Analysis on Total Remuneration Surveys

- Adhere to established standards and procedures in conducting compensation/benefits surveys

- Manipulate data and perform statistical analysis

- Process data, ensure proper population of survey data files and accuracy of the data

- Trained Summer interns on processes

- Served as a peer guide to new employees and conducted on-the-job training 


\section{Professional Experience (continued)}

\section{Appriss Human Resource (Intern)}

Fall 2006

- Created Regional College Contact Information Database

- Participated in recruitment strategy session and brainstormed creative recruitment ideas

- Created succession planning charts

\section{VHA National Center for Organization Development}

Summer 2006

- Compiled and aggregated a complete participant list for All Employee Survey (AES) research project

- Combined quantitative data to facilitate comparison of 2004 and 2006 AES survey results

- Created and ran the syntax to compare AES survey results by facilities and VISNs

- Combined various 360-degree feedback project data for research study

- Verified three AES presentations for accuracy before presentations at facilities

- Created AES graphs for 8 presentations for various VISNs

- Created the entire PowerPoint and graphs for LEAD presentation

- Manipulated Proclarity (in-house data server) to create and modify AES graphs

- Attended face-to-face meeting to record verbatim notes

- Researched ethics, safety data, succession planning, 360-degree feedback, and female executives for various presentations

- Compiled a comprehensive list of NCOD interventions as a quick reference to determine what interventions have been conducted at various facilities

- Compiled data and graphs for a current study on female executives within the VHA

- Created graphs for CREW presentations

- Conducted 21 360-degree feedback orientation conference calls

- Conducted 5 360-degree feedback individual orientation calls

- Project manager for 180-degree feedback assessment for Columbus VHA

- Project manager for 360-degree feedback assessment for Office of the General Counsel

- Cleaned the preliminary and final 360-degree feedback data before final reports sent

- Compiled, bound, and sent three 360-degree feedback projects 


\section{Professional Experience (continued)}

Right Management Consultants in Louisville, KY

Fall 2004

- Overview of typical consultant duties

- Assisted with project proposals

- Conducted literature reviews

- Learned to define core competencies

- Interpreted tests results with supervisor's assistance

- Attended client meetings and presentations

- Listened in on conference calls

Kentucky Psychological Association (KPA)

- Assisted with mailings to members

- Updated member's information online

- Answered phones

- Assisted in annual convention preparation

- Worked the annual convention

- Helped revise the member directory

\section{Applied Projects}

Spring 2004 Prescription Privileges for Psychologists survey

Supervisor: Dr. Pam Cartor, Testing and Measurement class

Fall 2005 Validity Study of Harrison InnerView Suitability Profile

Supervisor: Dr. Morrie Mullins, Assessment Techniques class

Fall 2005 Implemented and designed new Psychology Departmental Evaluation Supervisor: Dr. Morrie Mullins, Assessment Techniques Class

Spring 2006 Job Analysis Project on Global Lead Interns

Supervisor: Dr. Morrie Mullins, Personnel Psychology Class

Fall 2006 Statistical Consultant on William Boyce’s Dissertation

\section{Published Manuscripts}

Kerrick, S., Cumberland, D., Church-Nally, M., \& Kemelgor, B. (2014). Military veterans marching towards entrepreneurship: An exploratory mixed methods study. The International Journal of Management Education. In press 


\section{Manuscripts in Process}

Church-Nally, M. (2014). Use of educational memes in the me, me generations. In process.

Church-Nally, M., \& Cumberland, D. (2014). Impact of texting in professor-student relationships. In process.

Cumberland, D., \& Church-Nally, M. (2013). Word phobia: Differential responses to feedback across sexes. In process.

Church-Nally, M. (2013). PAR in cross cultural communication research. In process.

\section{$\underline{\text { Research Projects }}$}

Church, M. K. (2012). Structural equation model of occupational stress and job satisfaction in mental health professionals. Unpublished manuscript, University of Louisville at Louisville, KY.

Church, M. K., \& Nagy, M.S. (2011). Emotional Intelligence as the Moderator Between Job Satisfaction and Occupational Stress in Mental Health Professionals. Unpublished manuscript, Xavier University at Cincinnati, $\mathrm{OH}$.

Church, M. K (2004). Avoidance conditioning of everyday harmless things by verbal material. Unpublished manuscript, Bellarmine University at Louisville, KY.

Church, M. K., Willet, A.M., \& Church, E. S. (2003).The influence of rejection-thenretreat on charitable behavior of college students. Unpublished manuscript, Bellarmine University at Louisville, KY.

\section{Conference Presentations}

Kerrick, S., Cumberland, D., Kemelgor, B., \& Church-Nally, M. (2014). Military veterans marching toward entrepreneurship: An exploratory mixed methods study. Presentation at Small Business Institute. Las Vegas

Church, M. K. and Cumberland, D. (2012). Occupational Stress and Job Satisfaction in part time students-full time professionals. Presentation at the University of Louisville Research conference, University of Louisville.

Church, M. K., \& Nagy, M.S. (2011). Emotional Intelligence as the Moderator Between Job Satisfaction and Occupational Stress in Mental Health Professionals. Poster session presented at the annual meeting of Kentucky Psychological Association, Louisville, KY 


\section{Conference Presentations (continued)}

Church, M.K. \&Wilson, T.L (2005, May).The correlation between impulsivity and occupational stress coping skills. Poster session presented at the annual meeting of American Psychological Sciences, Los Angeles.

Church, M.K. (2004, April).Avoidance conditioning of everyday harmless items by verbal material. Paper presented at the Mid-America Undergraduate Psychology Research Conference, University of Southern Indiana.

Church, M. K. (2004, April).Avoidance conditioning of everyday harmless items by verbal material. Poster presented at the Kentucky Psychological Association annual Spring Convention, Science Saturday, Louisville, KY.

\section{Professional Leadership}

Kentucky Psychological Association

$2008-2014$

PsychBowl Coordinator

2014

Internal Audit Committee

2013

Psychbowl Judge

$2008-2014$

Developed Psychbowl questions

2011,2014

Undergraduate Research Poster Judge

$2012-2013$

Reviewer for Sage Publications

2014

Reviewer for Spring Research Conference, University of Louisville

Spring 2010

Planning Committee for Second Annual River City IO Convention

Fall 2007

Reviewer for I-O and Organizational Behavior Conference

Fall 2007

\section{Professional Development}

Bellarmine University

- Adjunct Faculty Development

- Initiated Adjunct Learning Community with Dr. Ann Bucalos

St. Catherine College

- Attended Student Government Committee

- Attended Curriculum Meetings 


\section{$\underline{\text { Invited Lectures }}$}

Stats Madness: The newest version of March Madness, for Dr. Denise Cumberland's Research Methods class, Spalding University, March 12th, 2012.

Lecture on Statistics: Putting the treat back into Trick-or Treat, for Dr. Denise

Cumberland's Research Methods class, Spalding University, October $31^{\text {st }}, 2012$.

Panel on Graduate School and the Graduate School experience, sponsored by River City Industrial Organizational Psychology Conference, Northern Kentucky University, November 2006.

Lecture on Graduate School and the Graduate School experience, sponsored by Bellarmine University Psychology Department, Bellarmine University, October 2005

Lecture on "Recording Observational Data," for Dr. Tom Wilson's Psychology Research Methods class, Bellarmine University, October 2004

\section{Professional Organizations}

Kentucky Academy of Science

Kentucky Psychological Association

American Psychological Association Graduate Students

\section{Honor Societies}

Kappa Gamma Pi

Golden Key

Psi Chi

Omicron Delta Kappa

\section{$\underline{\text { Awards and Honors }}$}

- Nomination for Phi Mu Favorite Professor (2012, 2014)

- Bieliauskas Award for Academic Achievement in Psychology

- Quatman Award for Excellence in Statistics

- Nomination for Best thesis of the year

- Salutatorian Bellarmine University

- Archbishop's Medal for Scholastic Excellence

- Robert F. Munson Award for Outstanding Senior Psychology Student

- St. Robert Bellarmine College of Arts and Sciences- Faculty Merit Award Social Sciences 


\section{Awards and Honors (continued)}

- In Veritatis Amore Award for Outstanding Female Graduate as voted by the faculty, Bellarmine University

- Mr. \& Mrs. Kenneth A. Barker Distinguished Service Award

- Dean's List all semesters

- Meyer Award Undergraduate Research Poster Competition, Kentucky Psychological Association Convention

- $\quad$ Psychbowl State Champions (2005) 